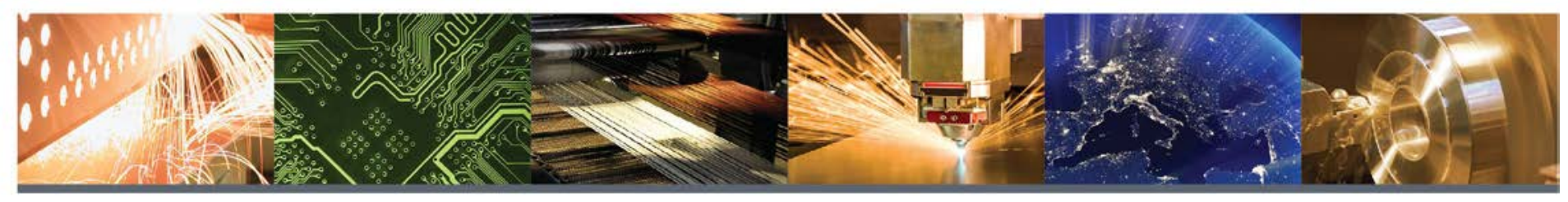

\title{
Carbon Fiber Manufacturing Facility Siting and Policy Considerations: International Comparison
}

Jeffrey J. Cook and Samuel Booth National Renewable Energy Laboratory

Technical Report

NREL/TP-6A20-66875

June 2017

Contract No. DE-AC36-08G028308 


\section{Carbon Fiber Manufacturing Facility Siting and Policy Considerations: International Comparison}

Jeffrey J. Cook and Samuel Booth

National Renewable Energy Laboratory

Prepared under Task No. AM05.5820

CEMAC is operated by the Joint Institute for Strategic Energy Analysis for the U.S. Department of Energy's Clean Energy Manufacturing Initiative.

Clean Energy Manufacturing Analysis Center 15013 Denver West Parkway Golden, CO 80401

303-275-3000

www.manufacturingcleanenergy.org
Technical Report

NREL/TP-6A20-66875

June 2017

Contract No. DE-AC36-08GO28308 


\section{NOTICE}

This report was prepared as an account of work sponsored by an agency of the United States government. Neither the United States government nor any agency thereof, nor any of their employees, makes any warranty, express or implied, or assumes any legal liability or responsibility for the accuracy, completeness, or usefulness of any information, apparatus, product, or process disclosed, or represents that its use would not infringe privately owned rights. Reference herein to any specific commercial product, process, or service by trade name, trademark, manufacturer, or otherwise does not necessarily constitute or imply its endorsement, recommendation, or favoring by the United States government or any agency thereof. The views and opinions of authors expressed herein do not necessarily state or reflect those of the United States government or any agency thereof.

Available electronically at SciTech Connect: http:/www.osti.gov/scitech

Available for a processing fee to U.S. Department of Energy and its contractors, in paper, from:

U.S. Department of Energy

Office of Scientific and Technical Information

P.O. Box 62

Oak Ridge, TN 37831-0062

OSTI http://www.osti.gov

Phone: 865.576 .8401

Fax: 865.576.5728

Email: reports@osti.gov

Available for sale to the public, in paper, from:

U.S. Department of Commerce

National Technical Information Service

5301 Shawnee Road

Alexandria, VA 22312

NTIS http://www.ntis.gov

Phone: 800.553 .6847 or 703.605 .6000

Fax: 703.605.6900

Email: orders@ntis.gov

Cover Photos: (left to right) iStock 2225189; iStock 16687273; Oak Ridge National Laboratory; iStock 24304597; iStock 26005993; iStock 2069560

NREL prints on paper that contains recycled content. 


\section{Acknowledgments}

We would like to thank Joe Cresko and Brian Walker from the U.S. Department of Energy's Advanced Manufacturing Office, and Margaret Mann and Jill Engel-Cox from the Clean Energy Manufacturing Analysis Center at the National Renewable Energy Laboratory for their support and guidance throughout this project. We would also like to thank Joseph Chavez and Ted James for their initial work on an internal memorandum that served as the foundation for this more comprehensive technical report. Finally, we sincerely appreciate Sujit Das from Oak Ridge National Laboratory, John Larkin from Larkin Trade International, and Doug Arent, Francisco Floreis-Espino, Jeff Logan, Mike Meshek, Paul Schwabe, and Tian Tian of the National Renewable Energy Laboratory for their technical reviews and helpful suggestions. 


\section{Preface}

Founded in 2015 with support from U.S. Department of Energy's Clean Energy Manufacturing Initiative, the Clean Energy Manufacturing Analysis Center (CEMAC) draws from open-source and industry data to deliver insights of supply chains and manufacturing for clean energy technologies through uniquely detailed, bottom-up cost analysis. CEMAC provides objective analysis and up-to-date information on global clean energy manufacturing to inform choices for economic growth and the transition to a clean energy economy.

This report focuses on national polices to support carbon fiber manufacturing, how these policies and other factors influence manufacturing location decisions, and opportunities to further support carbon fiber manufacturing and deployment. The report is a follow-on report to CEMAC's initial report on an analysis of the competitiveness of the global carbon fiber composites supply chain. That report (Das et al. 2016) provided an analysis of carbon fiber and carbon fiber polymer composites supply, demand, markets, and the geographic distribution of these in four major market growth areas: aerospace, automotive, wind energy, and pressure vessels. 


\section{Executive Summary}

Carbon fiber is a high strength-to-weight ratio material manufactured principally from acrylonitrile, which is increasingly being used in a variety of applications, including recreational products, automobiles, aircraft, wind turbines, and gas pressure vessels. Manufacturing costs can vary between $\$ 10$ and $\$ 25$ per kilogram for industrial grades of carbon fiber, and they largely depend on the type and quality of fiber produced (Das et al. 2016). Cumulative demand for carbon fiber has been projected to grow 10\% per year between 2015 and 2024 (Sloan 2015a; see Figure ES-1).

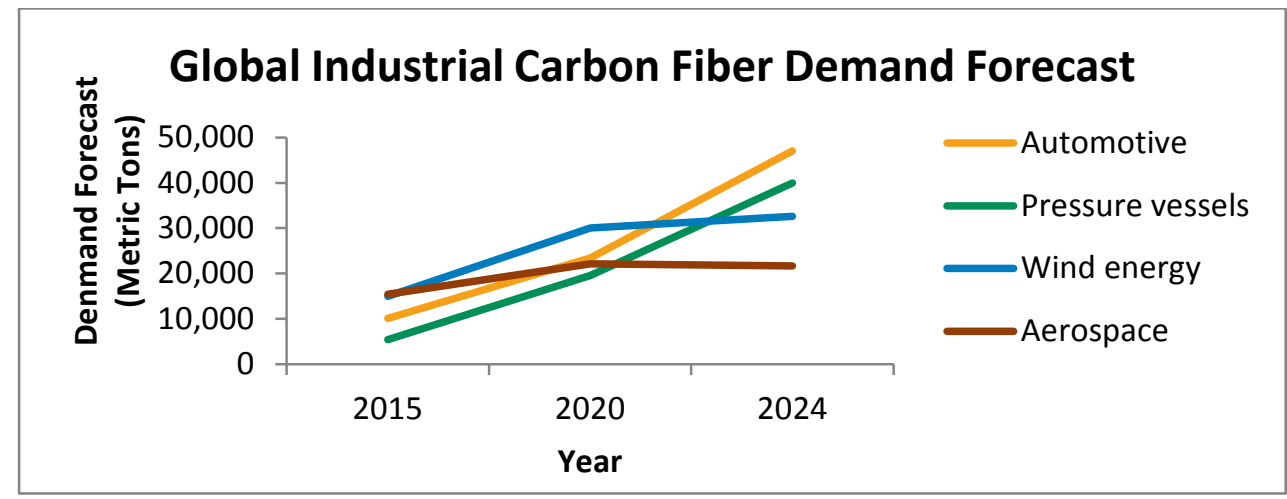

Figure ES-1. Projected demand for carbon fiber, by selected industrial application (metric tons) Data are from Sloan 2015a.

This report is a follow-on report to CEMAC's initial analysis of the competitiveness of the global carbon fiber composites supply chain. That report (Das et al. 2016) provided an analysis of carbon fiber and carbon fiber polymer composites supply, demand, markets, and manufacturing costs. This report focuses on carbon fiber manufacturing siting and policy considerations. The current global carbon fiber manufacturing industry is predominately located in the United States, Japan, Europe, and China (Figure ES-2).
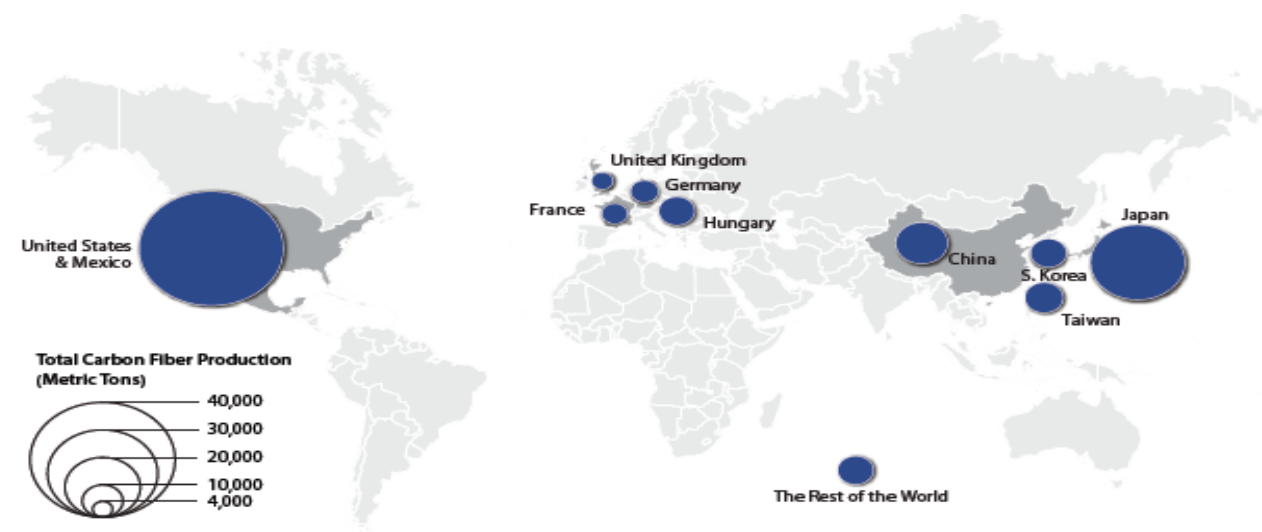

Figure ES-2. Location of carbon fiber manufacturing capacity worldwide Source: Das 2016

Manufacturing facilities for carbon fiber and associated products can offer significant economic development and employment opportunities. For example, Toray has committed to a \$1 billion 
investment and 500 jobs at a new plant in Moore, South Carolina (Sloan 2015b), and two other carbon fiber manufacturing facilities in Decatur, Alabama employ 500 people (Alabama Department of Commerce 2015).

Though the market is expected to expand, it is not clear where new manufacturing facilities will locate to meet demand. This report examines aspects related to carbon fiber manufacturing in the top producing countries, including China, France, Germany, Hungary, Japan, Mexico, South Korea, Taiwan, the United Kingdom, and the United States. And, the report reviews various metrics of manufacturing location decisions such as costs of labor and energy, as well as policy directed at supporting carbon fiber development, domestic deployment, and exports. The report concludes with a discussion of various policy options that may (1) encourage new carbon fiber manufacturers to locate in certain jurisdictions and (2) foster broader end-use markets for deployment.

\section{Manufacturing Siting Considerations}

The cost of production is a significant factor in facility siting decisions. Locations with lower costs of production may have an advantage in attracting new manufacturing. A recent CEMAC report (Das et al. 2016) illustrates the influence of varying carbon fiber and product manufacturing costs for a variety of supply chain scenarios. That report illustrates that equipment and material costs are relatively constant across economies, while labor and energy costs vary significantly. Section 2 of this report provides an international comparison of these two key manufacturing cost drivers. These are not the only production cost-related considerations that influence manufacturer siting decisions in the carbon fiber sector. Currency, environmental and safety, intellectual property, and quality considerations can also impact siting decisions. These factors cannot be easily converted into a cost/kilogram metric for comparison with the aforementioned energy and labor costs. Thus, Section 2 also qualitatively discusses how each location differs across these factors and how they can impact manufacturers' siting decisions.

\section{Labor}

Labor costs currently represent $12 \%$ of overall production expenses (Das et al. 2016) and can influence carbon fiber manufacturers' decisions to locate in certain locations. In this context, hourly labor rates, labor productivity, and automation are most relevant. Ultimately, manufacturers must weigh the benefits of lower hourly labor rates available in countries such as China and Mexico against countries with higher labor productivity such as the United States and Germany that also have higher hourly labor costs (Figures ES-3 and ES-4). At the same time, automation could displace up to $60 \%$ of manufacturing labor (Manyika et al. 2017), which may reduce overall labor costs. This development could also decrease the importance of this factor in manufacturers' siting decisions overall, while incentivizing greater attention to labor productivity rates for the processes that cannot be automated. 


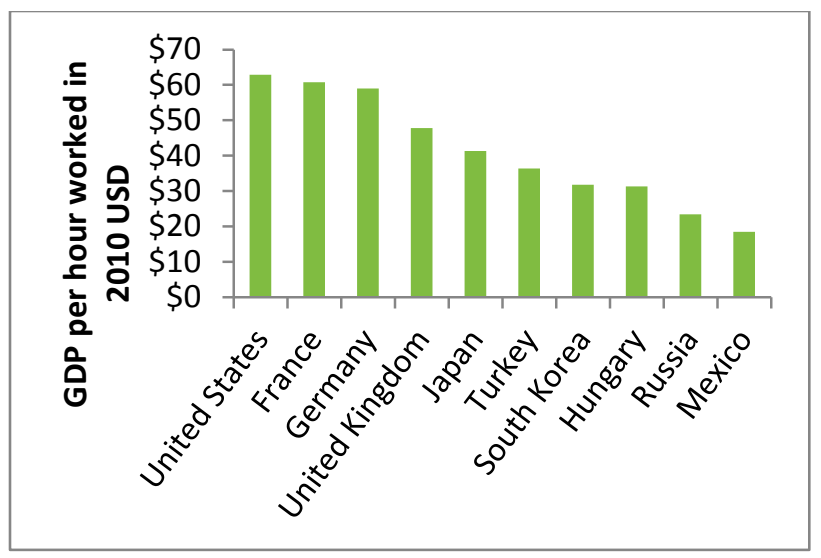

Figure ES-3. Comparison of labor productivity in GDP per hour worked in 2015 (2010 USD)

Source: Organisation for Economic Co-operation and Development 2017

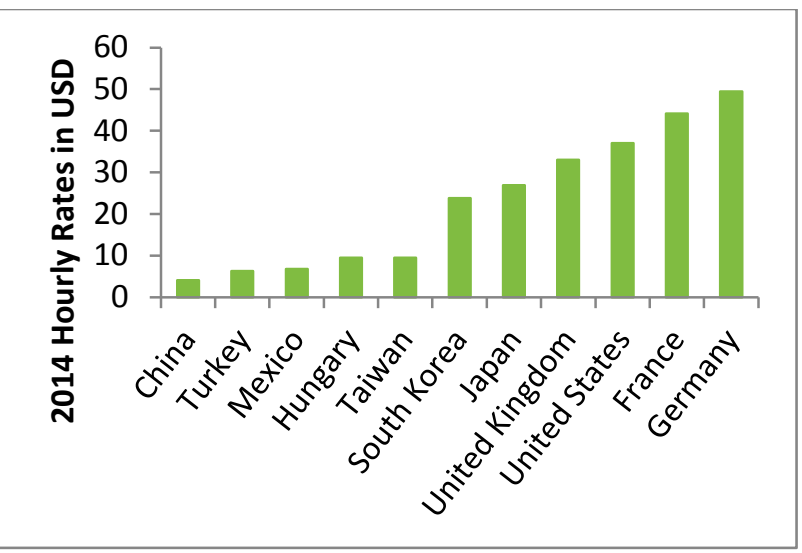

Figure ES-4. Comparison of hourly compensation costs in manufacturing, by economy in USD in 2014

Sources: The Conference Board 2016a, 2016b

\section{Energy}

Energy costs are an important consideration for the carbon fiber industry, and this is likely to continue to be true because of the energy-intensive nature of the carbon fiber manufacturing process. Several countries, including the United States, offer comparatively low energy costs that are reflected by low industrial electricity and natural gas costs (Figures ES-5 and ES-6), and these countries may thus be attractive for future carbon fiber manufacturing facilities.

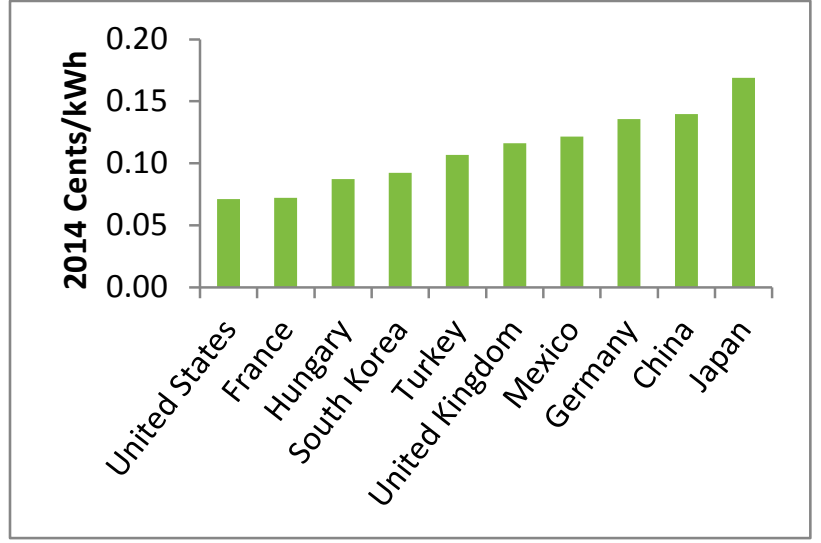

Figure ES-5. Comparison of 2014 average industrial electricity costs, by country (kWh)

Sources: EIA 2016, BNEF 2015, DECC 2016

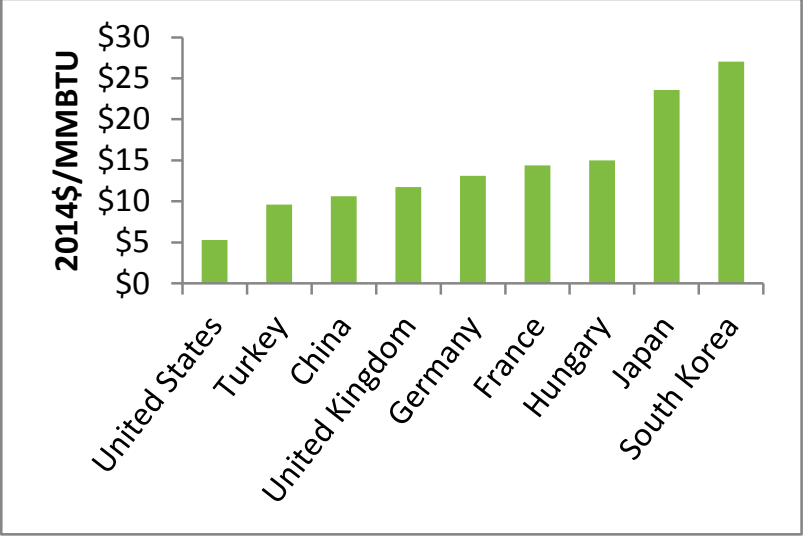

Figure ES-6. Comparison of 2014 industrial natural gas prices, by country (\$/MMBTU)

Sources: Enerdata 2014, IEA 2016, Russell 2014 


\section{Currency}

The strength and stability of the local currency can impact manufacturers' decisions to build and expand facilities in certain countries. First, manufacturers located in countries with higher valued currency such as the United States, can be at a production cost disadvantage compared to facilities operating in countries with lower value currency. This issue has been cited as one factor behind the stagnation of the United States steel manufacturing industry (Elmquist 2015). In addition, unexpected volatility in currency values can be problematic for those carbon fiber manufacturers that export or import to the effect markets. For example, the Euro lost $20 \%$ of its value in comparison to the USD from 2014 - 2015 (IRS 2016). Depending on the currency used to trade products, carbon fiber manufacturers' products could be priced out of the European market as a result. These volatility issues can be mitigated by employing certain hedging strategies. Though effectively minimizing these risks is possible, properly hedging against currency volatility can be challenging, particularly when unexpected exchange rate moves occur, as exemplified by recent volatility in the Euro. As a result, locations with more stable currencies and large end-use markets, which result in less international trade along the supply chain, may be preferred, given the lower risk of unpredictable exchange rate volatility.

\section{Environment and Health}

Carbon fiber manufacturing is subject to environmental and safety regulations that impact production processes and costs. For example, each economy has adopted air pollution standards that carbon fiber manufacturers and all industrial applications must meet (see Section 2.4). These emission standards are generally similar across locations, which potentially mitigates the impact of these policies on production costs (see Table 3). However, emerging policies that address greenhouse gas emissions could have an impact on carbon fiber facilities because carbon fiber manufacturing emits 24-31 kilograms of carbon dioxide per kilogram of product (Das 2011). Policies that limit these emissions may affect manufacturers' decisions to locate in certain jurisdictions, though decisions relating to energy procurement could mitigate the potential impact of compliance.

\section{Intellectual Property}

The production of carbon fiber is a highly specialized and technical process, and economies with strong policies for intellectual property rights may offer carbon fiber manufacturers the assurance that their technology and research and development findings will be protected. The U.S. Chamber of Commerce ranks locations based on the stringency of their policy in the International Intellectual Property Index (U.S. Chamber of Commerce 2016). The United States ranks highest on the index and is followed by many of the European economies, Japan, and South Korea. Taiwan, Mexico, Russia, China, and Turkey rank significantly lower than the United States (U.S. Chamber of Commerce 2016).

\section{Quality of Production}

Given the specialty nature of carbon fiber manufacturing, existing manufacturers may have an advantage in terms of product and brand quality considerations when capturing any anticipated increased demand. These advantages may encourage carbon fiber manufacturers to expand operations at existing facilities and particularly those in areas with strong intellectual property 
right protections. In fact, co-locating carbon fiber manufacturing near customers that manufacture end-use products may offer other significant benefits in terms of logistics and quality control cost reductions that could also influence prospective manufacturers' siting decisions (Delgado, Porter, and Stern 2014).

\section{Variation in Carbon Fiber-related Policy}

In addition to the largely cost-related facility siting factors mentioned above, governmental policy can influence both (1) the decisions to locate carbon fiber manufacturing facilities and by extension the capacity located within a given economy and (2) the end-use markets for carbon fiber in certain key growth industries, such as the wind energy and automotive sectors. Section 3 describes each economy's policy framework as it relates to carbon fiber. Using the United States as a reference point, we review the policy landscape of the top-10 carbon fiber manufacturing economies (in order of manufacturing capacity) in terms of trade, manufacturing support and development, and end-use market support policies. The intent of this section is to demonstrate variation in policy that affect carbon fiber manufacturing and deployment in certain jurisdictions. Section 4 describes potential impacts in more detail.

\section{Trade Policy}

There is a significant difference between the United States and its nine international counterparts when it comes to trade policy. Carbon fiber is considered a dual-use (military and civilian) product because it could contribute to the military potential or nuclear proliferation of other nations. Each location has established an export control policy to limit the potential that carbon fiber would be used in military applications. The United States requires carbon fiber manufacturers to secure an export license for each individual carbon fiber transaction with a foreign interest. Each of the other economies allows multiple transactions on the same export license. Various industry interests have suggested this export licensing process hinders the United States in the international market by causing delays and inefficiencies in carbon fiber exports for certain products (Das et al. 2016; U.S. Department of Commerce 2015). In comparison, most jurisdictions, including the United States impose an import tariff on carbon fiber products by application. However, the United States has a somewhat higher tariff than other economies, at least in the context of acrylic precursor. This fact and the tariff schedules for other carbon fiber inputs and outputs (see Section 3) may influence the cost of carbon fiberbased products and thereby influence manufacturer's decisions to locate in certain areas.

\section{Manufacturing Support and Development}

Though there is significant variation in the structure, stringency, and content of the policy employed to promote carbon fiber manufacturing development, a common theme is present across the locations evaluated. All ten countries analyzed except Mexico currently support carbon fiber manufacturing via research and development relating to driving down carbon fiber manufacturing costs and increasing deployment (see Section 3).

Some countries, including China and South Korea have established specific carbon fiber "valleys" to serve as innovation clusters for carbon fiber research (Jilin Daily 2013; Yang 2013). The United States has charged the Institute for Advanced Composites Manufacturing 
Innovation (IACMI) with a similar research purpose among others (IACMI n.d. A). Though nearly all of these economies support some research in this space, the United States, Japan, and Taiwan have the longest histories of investment support. If these and other locations maintain or build on this research commitment, it may result in more carbon fiber deployment in existing and new markets.

\section{End-Use Market Support}

In terms of existing end-use market support, more variation was observed in the policies evaluated as they related to the two end-use sectors with significant expected growth through 2024: wind energy and the automotive industry. Though land-based wind incentives are prevalent, there was variation in support for offshore wind applications, which more commonly use carbon fiber. The four European economies (i.e., France, Germany, Hungary, and the United Kingdom), China, and Taiwan have policies that all directly support the offshore wind energy market and thus drive the carbon fiber market for wind energy applications. Japan, Mexico, the United States, and South Korea have not offered similar policy support for offshore wind. If offshore wind deployment were to expand globally, it could encourage broader deployment of carbon fiber. At the same time, increased carbon fiber content in land-based wind would also expand the market. In comparison, all ten jurisdictions have adopted vehicle emission standards that could drive carbon fiber deployment in vehicles, given its lightweight properties that improve both fuel economy and electric vehicle drive ranges. Both China and the United States have vehicle emission policies that incentivize electric vehicles, which could further promote carbon fiber markets. Subsequent policy adoption as it relates to incentivizing more efficient vehicles would likely further expand carbon fiber deployment and spur increased carbon fiber manufacturing.

\section{Menu of Policy Options to Support Carbon Fiber}

Clearly, many governments have implemented policies to support the carbon fiber industry either directly (e.g., through research and development programs) or indirectly by enacting market supporting policies such as vehicle efficiency standards. It is outside the scope of this report to clarify which policy or set of policies would result in higher carbon fiber manufacturing capacity or broader end-use markets going forward. Nevertheless, policymakers interested in expanding carbon fiber manufacturing could benefit from an understanding of the different policy approaches that have been used to expand carbon fiber manufacturing and end-use markets. To that end, this report summarizes the range of carbon fiber-related policies that have been used or proposed to achieve the goals of attracting new manufacturing, expanding manufacturing exports, and driving end-use markets. Because of data constraints, policy options to attract carbon fiber manufacturing are United States-centric, but these options with modifications may be applicable in other jurisdictions.

To attract new carbon fiber manufacturing, policymakers could consider establishing carbon fiberrelated workforce development programs similar to those employed for SGL's Automotive Carbon Fiber facility in Moses Lake, Washington (Gates 2014), offering economic development incentives like the package offered to Zoltek for their facility in St. Peters, Missouri (Office of Missouri Governor Jay Nixon 2012), and fostering the development of manufacturing clusters and co-location of facilities as exemplified by Toray's decision to locate plants in South Carolina (GoUpstate 2016). 
To support carbon fiber manufacturing and development, survey results from experts in the carbon fiber industry suggest policymakers could evaluate reforming export license requirements to allow multiple transactions, adjusting tariff schedules for carbon fiber-related materials, or increasing research and development activities to spur innovation among other options (Das et al. 2016; U.S. Department of Commerce 2015).

To promote end-use market demand for carbon fiber, policies that support further deployment of renewable and energy efficiency technologies, particularly in wind and automotive applications could positively increase manufacturing of carbon fiber. Similarly, increasing vehicle emission reduction requirements and programs may increase carbon fiber investment and deployment in the automotive sector. 


\section{Table of Contents}

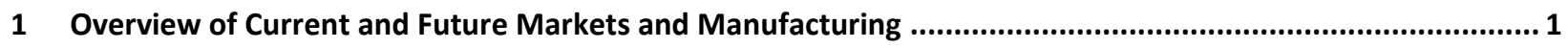

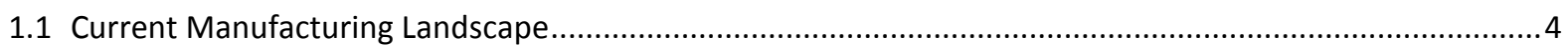

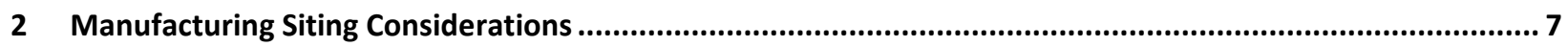

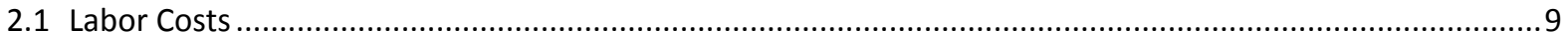

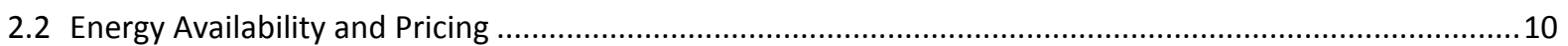

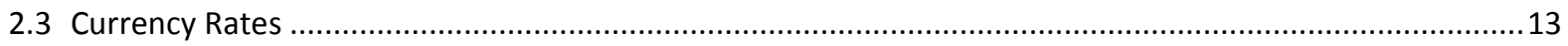

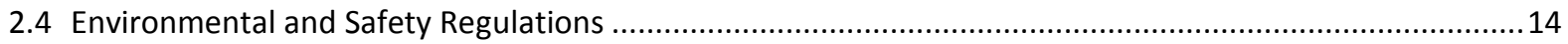

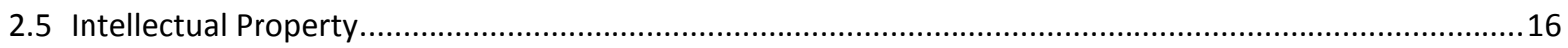

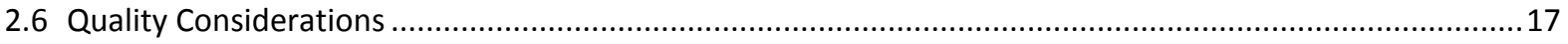

3 Summary of Policies Relevant to Carbon Fiber................................................................................ 18

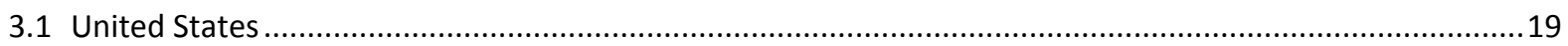

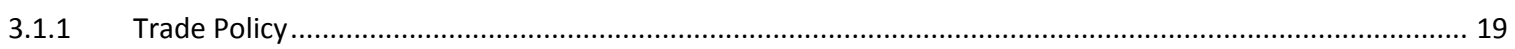

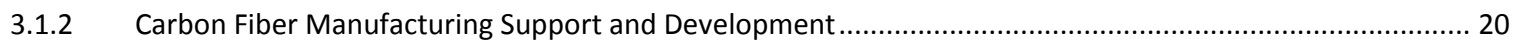

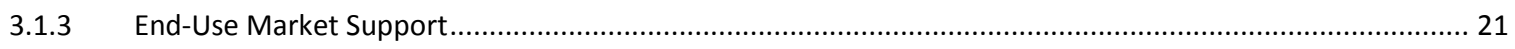

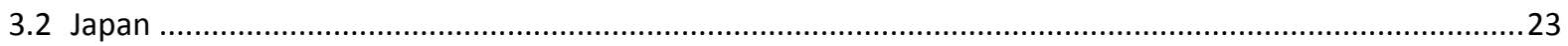

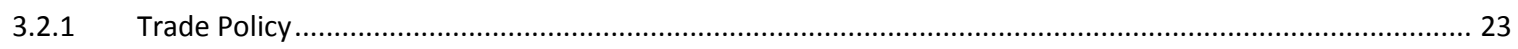

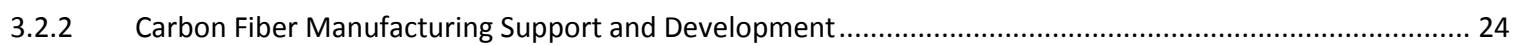

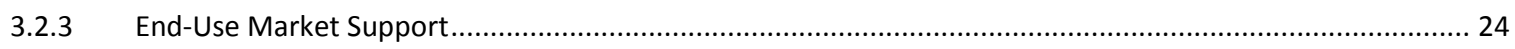

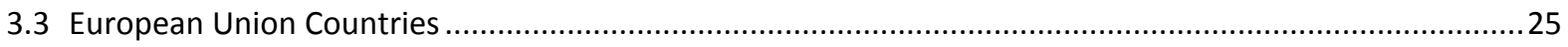

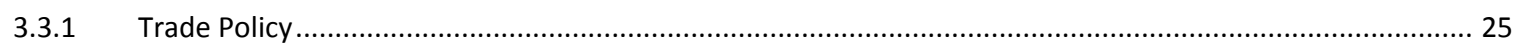

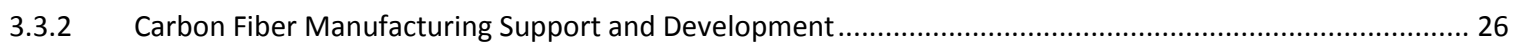

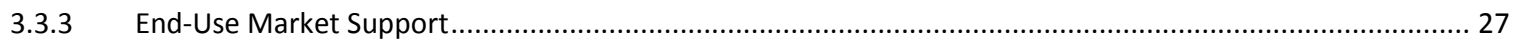

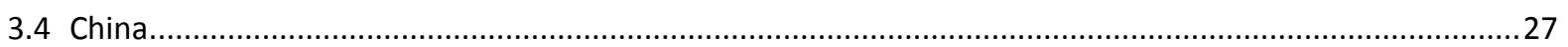

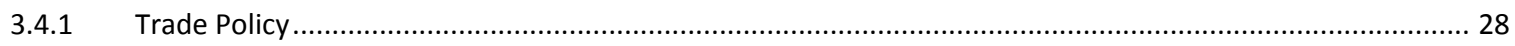

3.4.2 Carbon Fiber Manufacturing Product Support and Development ............................................................28

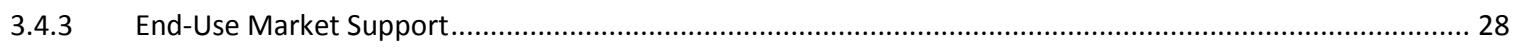

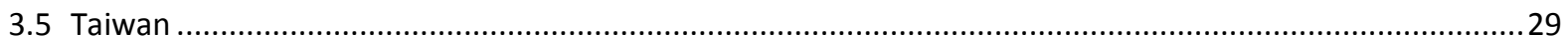

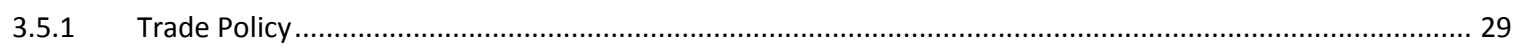

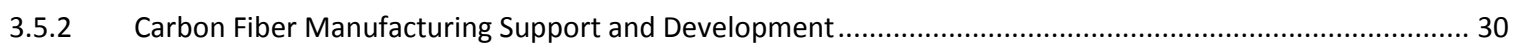

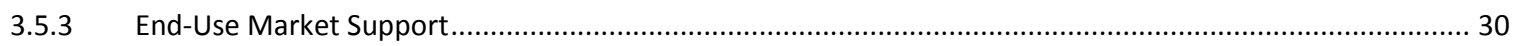

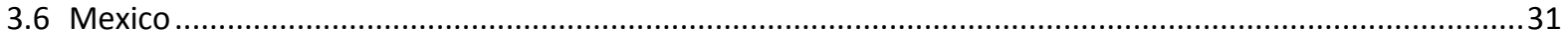

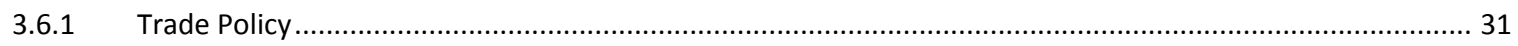

3.6.2 Carbon Fiber Manufacturing Support and Development ...................................................................... 31

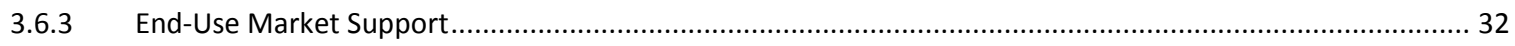

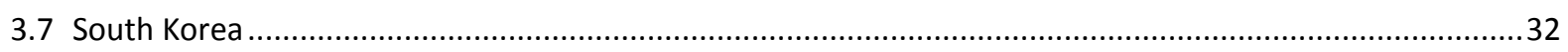

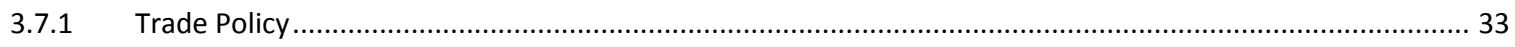

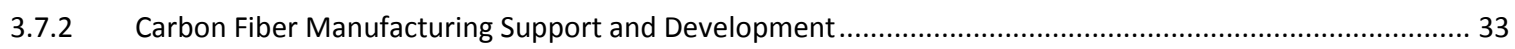

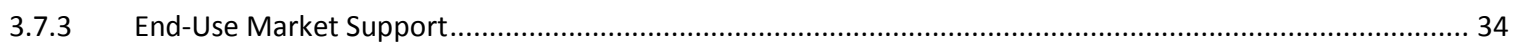

4 Menu of Policy Options to Support Carbon Fiber .......................................................................... 34

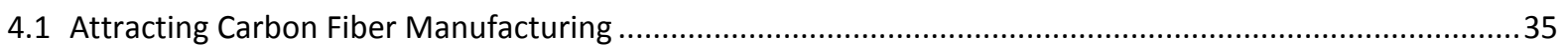

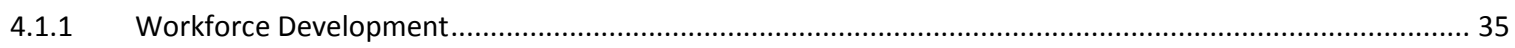

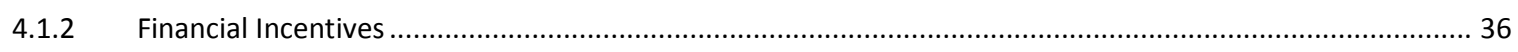

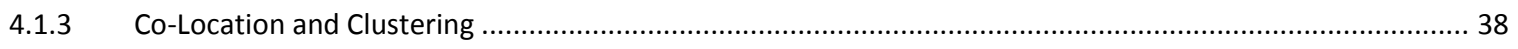




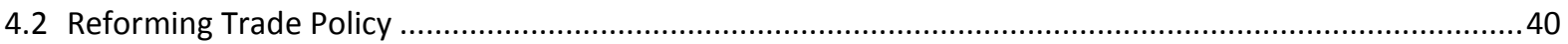

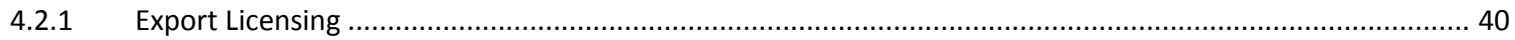

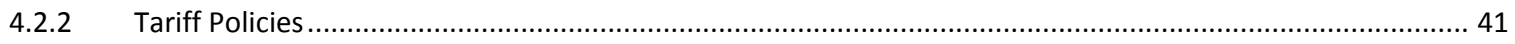

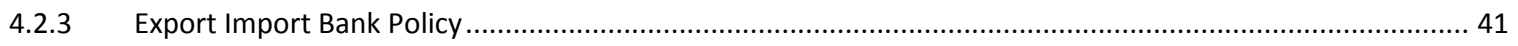

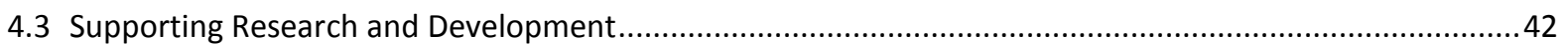

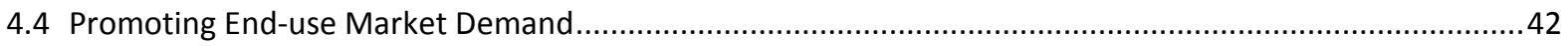

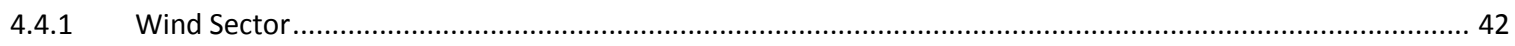

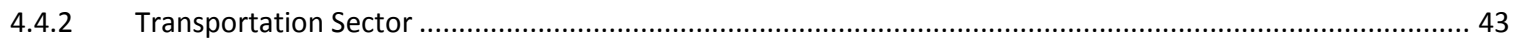

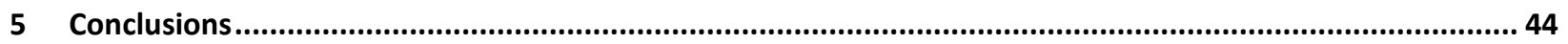

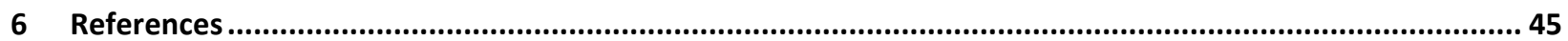




\section{List of Figures}

Figure ES-1. Projected demand for carbon fiber, by selected industrial application (metric tons) ........................ v

Figure ES-2. Location of carbon fiber manufacturing capacity worldwide ..................................................... v

Figure ES-3. Comparison of labor productivity in GDP per hour worked in 2015 (2010 USD)............................. vii

Figure ES-4. Comparison of hourly compensation costs in manufacturing, by economy in USD in 2014.............. vii

Figure ES-5. Comparison of 2014 average industrial electricity costs, by country (kWh) ................................ vii

Figure ES-6. Comparison of 2014 industrial natural gas prices, by country (\$/MMBTU) ................................... vii

Figure 1. Projected demand for carbon fiber, by selected industrial application .............................................. 2

Figure 2. Location of carbon fiber manufacturing capacity worldwide...................................................... 4

Figure 3. Geographic distribution of carbon fiber manufacturing facilities worldwide ....................................... 5

Figure 4. Location and owners of carbon fiber manufacturing facilities in the United States ................................ 5

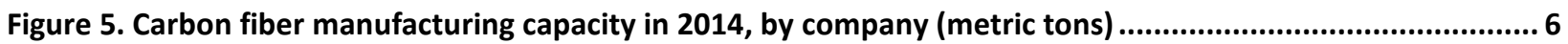

Figure 6. Harper International estimated cost structure for certain carbon fiber manufacturing ........................ 7

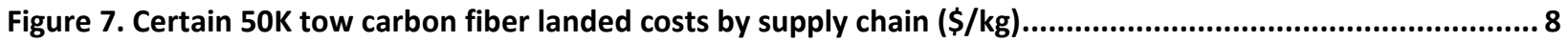

Figure 8. Comparison of hourly compensation costs in manufacturing, by economy in 2014 (USD) ..................... 9

Figure 9. Comparison of labor productivity in GDP per hour worked in 2015 (2010 USD) ............................... 10

Figure 10. Energy cost comparison for the use of all-electric ovens and furnaces versus gas ovens and electric

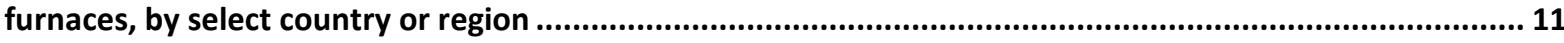

Figure 11. Comparison of $\mathbf{2 0 1 4}$ average industry electricity costs, by country .............................................. 11

Figure 12. Comparison of $\mathbf{2 0 1 4}$ bulk industrial natural gas prices, by country (\$/MMBTU) .............................. 12

Figure 13. Year-over-year currency value variation compared to the U.S. dollar ............................................... 13

Figure 14. Number of economic development incentives available to manufacturers in each state ................... 37

Figure 15. States with at least one financial incentive directed toward clean energy-related manufacturing ...... 38

\section{List of Tables}

Table 1. Global Carbon Fiber Demand Forecast (Metric Tons) ......................................................

Table 2. Sensitivity Analysis of 50K Tow CF Landed Costs for Scenario UUU .........................................8

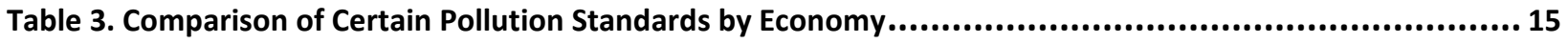




\section{Overview of Current and Future Markets and Manufacturing}

Carbon fiber consists of materials with over $92 \%$ carbon content, and it can be manufactured from a variety of materials, most commonly acrylonitrile. Acrylonitrile is derived from oil, polymerized into polyacrylonitrile, spun into precursor, and then stabilized and carbonized to produce fiber. ${ }^{1}$ Each carbon fiber filament has a diameter between 5 and 15 microns, and typically thousands of carbon fibers are bundled together into what is termed carbon fiber tow (Das et al. 2016). This carbon fiber material is used in a variety of applications, and it is valued for its combination of strength, stiffness, and light weight. Carbon fiber materials can be up to 10 and 8 times stronger than steel and aluminum, but are 5 times and 1.5 times lighter respectively (Feraboli and Masini 2004; Zoltek Corporation n.d.). Carbon fiber also offers superior resistance to fatigue and corrosion, as well as high heat resistance (Matsui 1990; Altair 2016).

These unique properties along with reductions in the cost of carbon fiber production technology, and specific market drivers, including aerospace and defense applications (Altair 2016), have resulted in rapid growth in carbon fiber manufacturing and use since the technology was introduced in the 1960s (ACS 2003). Aggregate global demand for carbon fiber grew from approximately 2 metric tons in 1971 (Matsui 1990) to approximately 83,000 metric tons in 2015 (Sloan 2015a).

Public-sector procurement of carbon fiber materials for defense applications initially drove the market. More recently, recreational and industrial applications have led to large-scale industry development in the United States and globally. Currently, the majority of the carbon fiber market is associated with three broad end-use categories:

1. Consumer and recreational products - such as bicycles, golf equipment, racquets, and marine applications

2. Aerospace applications - such as commercial and defense aircraft

3. Industrial applications - such as wind turbine blades, automotive, and pressure vessels.

These end-use markets are expected to increase carbon fiber demand to 157,000 metric tons by 2020 and to 219,000 metric tons by 2024 (Table 1). This growth reflects a compound annual average growth rate (CAGR) of $10.2 \%$. Much of the projected expansion is associated with industrial applications, which represent 82\% of projected demand by 2024 (Sloan 2015a).

\footnotetext{
${ }^{1}$ For a full explanation of the life cycle of the carbon fiber manufacturing process, see Das et al. (2016).
} 
Table 1. Global Carbon Fiber Demand Forecast (Metric Tons) ${ }^{\mathrm{a}}$

\begin{tabular}{|l|r|r|r|r|}
\hline Market & $\mathbf{2 0 1 5}$ & $\mathbf{2 0 2 0}$ & $\mathbf{2 0 2 4}$ & CAGR \\
\hline Consumer/recreational & 14,830 & 16,740 & 18,620 & $2.30 \%$ \\
\hline Aerospace & 15,460 & 22,100 & 21,650 & $3.40 \%$ \\
\hline Industrial & 52,800 & 118,490 & 178,920 & $13 \%$ \\
\hline Total & 83,090 & 157,320 & 219,200 & $10.20 \%$ \\
\hline
\end{tabular}

${ }^{a}$ Data are from Sloan 2015a.

In 2015, wind energy applications competed with aerospace applications as the largest market for carbon fiber (Figure 1). Carbon fiber expansion in the wind energy sector has been driven in part by innovation in the industry requiring longer wind blades. Carbon fiber's high strength-toweight ratio is ideally suited for advanced longer wind blades and especially those for offshore applications (Stephenson 2012; Das et al. 2016). It is expected that by 2020 the automotive industry will begin to compete with the aerospace industry as the second-largest market for carbon fiber. And, the automotive and pressure vessel categories are expected to lead the market by 2024 (Figure 1). ${ }^{2}$

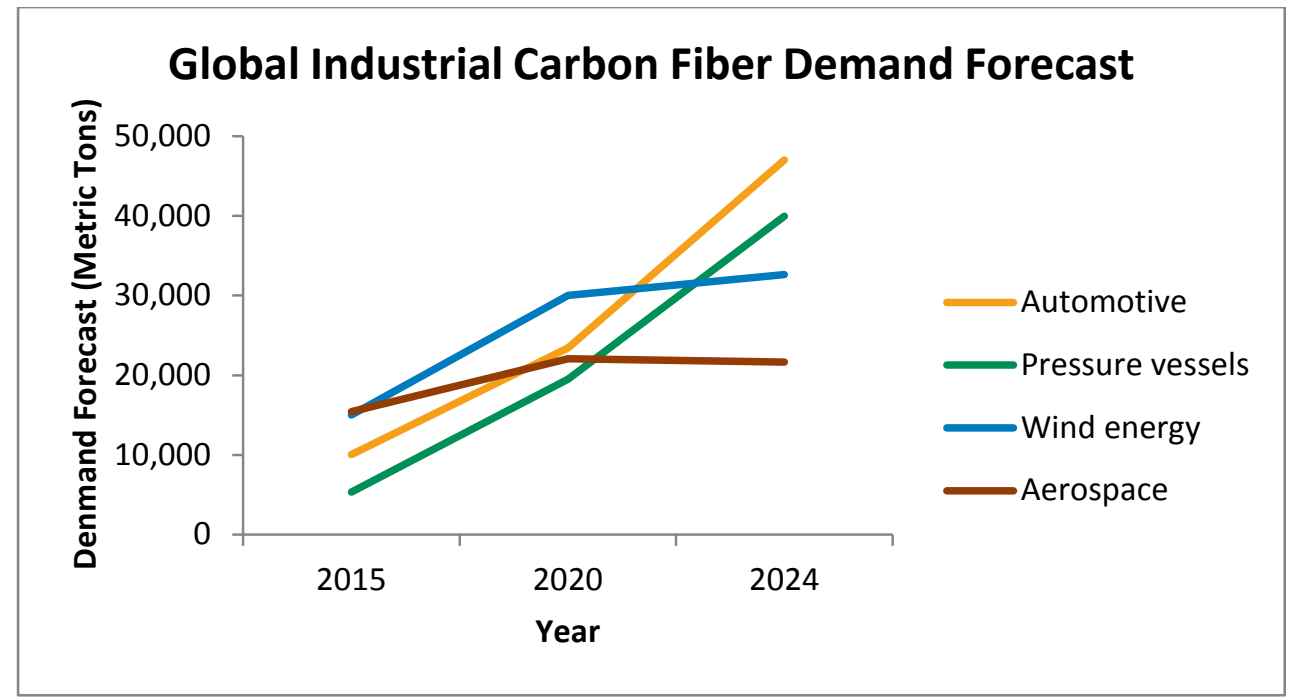

Figure 1. Projected demand for carbon fiber, by selected industrial application Data are from Sloan 2015a.

\footnotetext{
${ }^{2}$ Pressure vessels refer to containers designed to hold fluids at pressures higher than ambient atmospheric pressure, such as self-contained breathing apparatus applications, stationary natural gas and hydrogen storage, along with certain vehicle applications (Das et al. 2016).
} 
To date, the wind energy and aerospace sectors have offered the highest estimated revenue per kilogram produced at $\$ 317 /$ kilogram and $\$ 98 /$ kilogram respectively (Witten, Kraus, and Kühnel 2015). The automotive sector trails both at $\$ 87 /$ kilogram (Witten, Kraus, and Kühnel 2015). Though expected demand for the aerospace and wind sectors may slow going forward, both sectors are likely to continue to be an important revenue generator for the industry.

Overall, global nameplate carbon fiber manufacturing capacity in 2015 was estimated at 144,000 metric tons with an actual output of 93,000 tons (Sloan 2015a). The difference in capacity and output can be explained in part by limitations on capacity plant efficiency caused by form and line changes, along with quality control that spurs necessary manufacturing downtimes. Nevertheless, there may be some underutilized manufacturing capacity in the market that could help meet projected future demand. However, some expect that carbon fiber demand will exceed 157,000 tons by 2020 and new manufacturing capacity would be necessary to meet this demand (Sloan 2015a). To be clear, there is some debate regarding the expected increase in carbon fiber demand; the Sloan (2015a) estimate is the most recent. ${ }^{3}$

If the Sloan (2015a) estimate is accurate, at least an additional 13,000 metric tons of manufacturing capacity expansion from the 2015 baseline would be required to meet demand. Such a capacity expansion represents a large financial investment and a significant amount of new manufacturing jobs. To that end, Toray is investing approximately $\$ 1$ billion to build a new facility in South Carolina that would create 500 new jobs and produce 2,000 metric tons per year of carbon fiber along with precursor and prepreg (Sloan 2015b; GoUpstate 2016). ${ }^{4}$ The scope of this project is atypical of the industry. For comparison, two carbon fiber manufacturing facilities in Decatur, Alabama, currently employ a total of 500 people (Alabama Department of Commerce 2015). ${ }^{5}$ Nevertheless, Toray's investment is one example of both (1) a broader trend of overall job growth reflected in the carbon fiber industry as the industry added jobs at twice the rate of other forms of employment in 2013 (U.S. Department of Commerce 2015) and (2) the potential scale of the economic development opportunity that a new carbon fiber manufacturing facility and its associate businesses may provide.

For new carbon fiber manufacturing capacity to meet increased demand by 2020 , facilities must start coming online in the short term (two or three years). This lead time is necessary to allow time for site development, construction, and equipment procurement. Thus, this is an appropriate time to examine the leading carbon fiber manufacturing countries in relation to key manufacturing siting considerations, policy landscapes, and the role they may play in broadening markets for carbon fiber producers.

\footnotetext{
${ }^{3}$ For other estimates, see Das et al. (2016), Lucintel (2012), Red and Zimm (2012), and Industry Experts (2013).

${ }^{4}$ Prepreg is carbon fiber fabric that already includes resin (Das et al. 2016).

${ }^{5}$ Hexcel owns one of these facilities, and it recently added 20 new jobs that would pay an average annual salary of $\$ 49,000$ (Fleischauer 2015).
} 


\subsection{Current Manufacturing Landscape}

In 2015, ten jurisdictions accounted for $93 \%$ of the carbon fiber manufacturing capacity: China, France, Germany, Hungary, Japan, Mexico, South Korea, Taiwan, the United Kingdom, and the United States (Figure 2). The majority of the current facilities are located in the United States, Japan, Europe, and China.

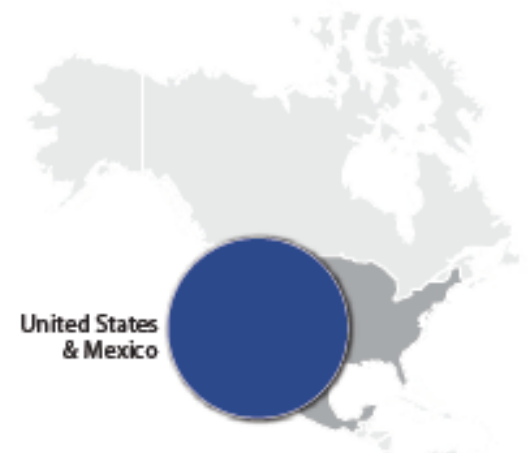

Total Carbon Fiber Production (Metric Tons)

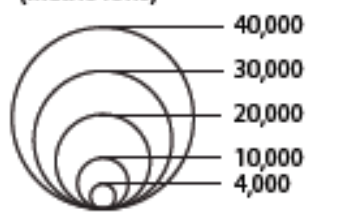

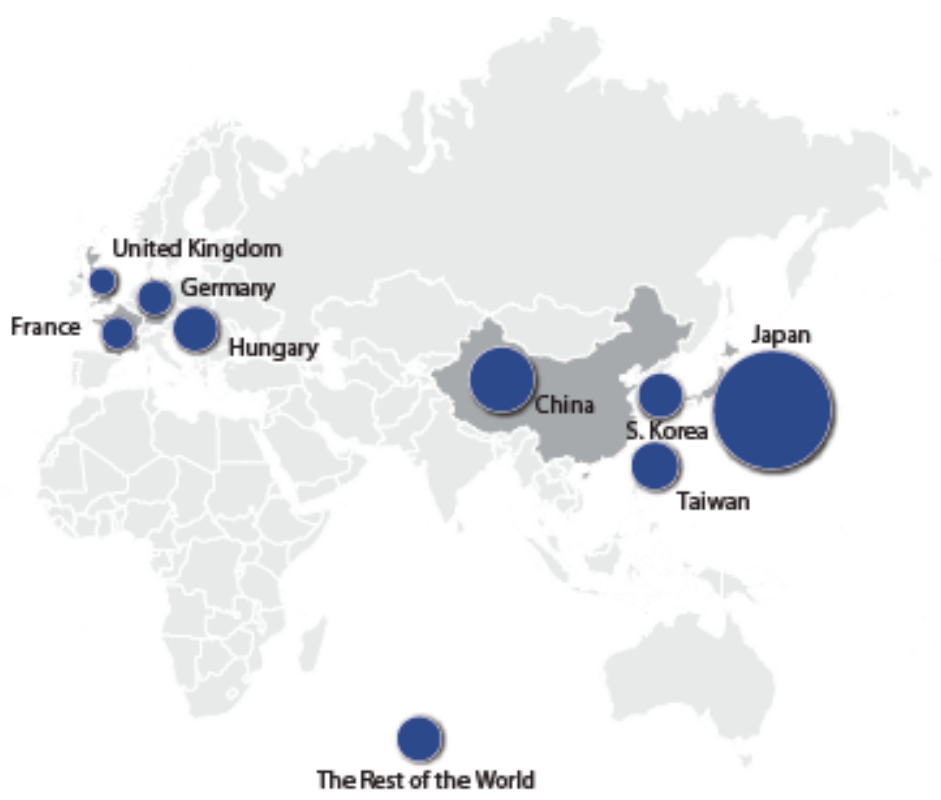

Figure 2. Location of carbon fiber manufacturing capacity worldwide

Source: Das 2016

Several other countries, including Russia, Saudi Arabia, and Turkey either are emerging or are small carbon fiber market participants. Turkey-based AKSACA Carbon Fibers is an established small player in the carbon fiber market (Das et al. 2016). It is actively considering expanding carbon fiber production in the United States, possibly to serve automobile demand related to its development agreement with Ford Motor Company (CompositesWorld 2016). And, Russia and Saudi Arabia are emerging players in the carbon fiber market. The expectation for increased capacity in Russia is largely in response to higher demand for carbon fiber in the Russian market (Gitter 2013; Das et al. 2016). While Saudi Arabia-based SABIC has expressed interest in participating in the carbon fiber market, it has not yet joined it (Das et al. 2016; Witten, Kraus, and Kühnel 2015; Composites World 2016).

Though demand may be increasing in emerging markets such as Russia, the majority of carbon fiber demand is expected to remain in Europe, North America, and Asia (Japan and China) through 2020 (Das et al. 2016). As a result, carbon fiber manufacturers serving these markets are likely to capture much of the increased demand. 
Given these demand centers, much of the existing and planned carbon fiber manufacturing facilities are located in North America, Europe, Japan, and China (Figure 3). Currently, 12 carbon fiber manufacturing facilities are operating in the United States, and over 7,500 people are employed by the industry (BLS 2016). ${ }^{6}$ Figure 4 displays these facilities along with the owner of each plant.

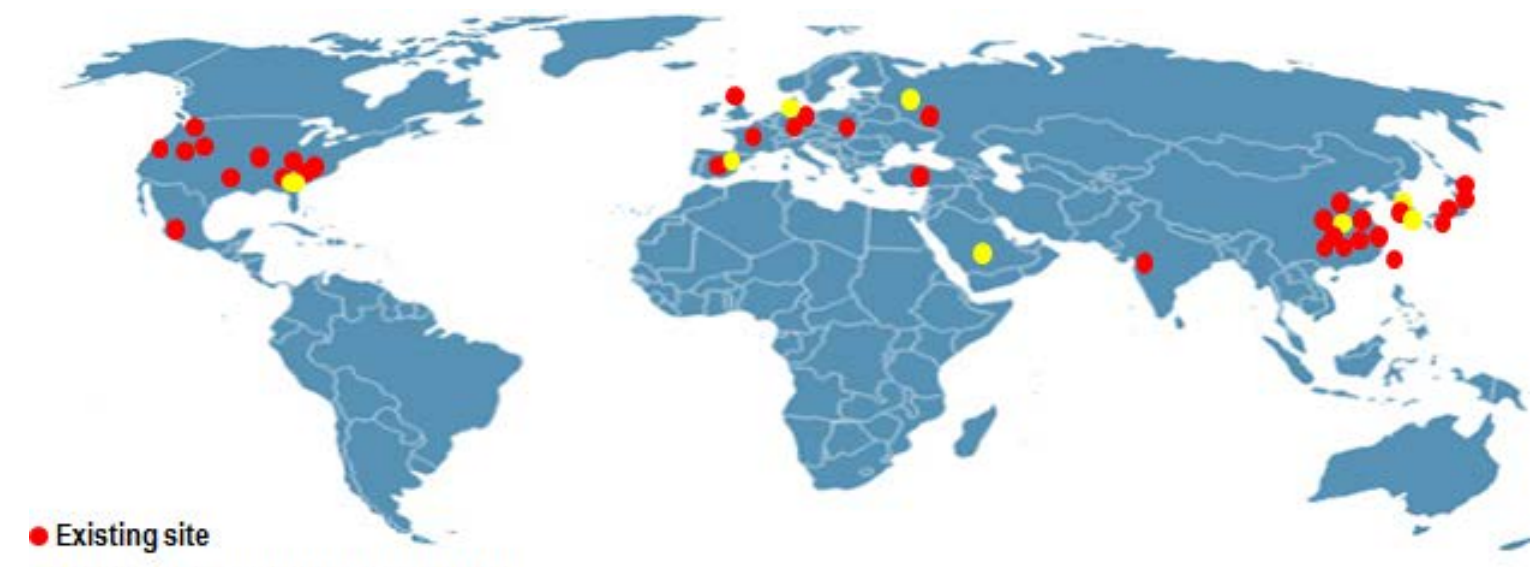

Planned site (projected to year 2015)

Figure 3. Geographic distribution of carbon fiber manufacturing facilities worldwide Source: Das et al. 2016

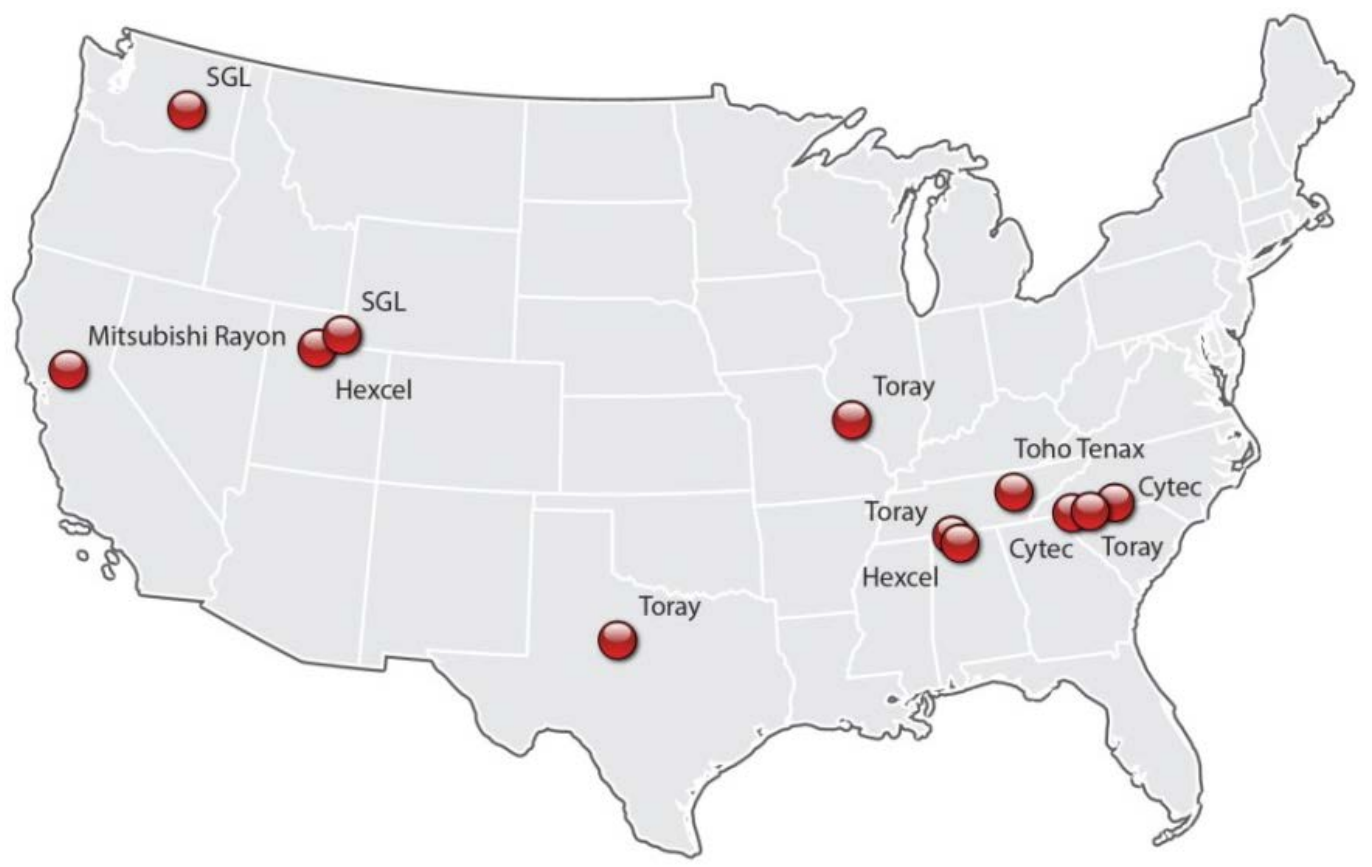

Figure 4. Location and owners of carbon fiber manufacturing facilities in the United States

\footnotetext{
${ }^{6}$ There is some diversity in the corporations that manage these plants, and not all are owned by United States-based companies. For example, Toray, a Japanese company owns four of the 12 facilities.
} 
Figure 3 and Figure 4 illustrate that few carbon fiber manufacturing facilities exist globally or domestically. Also, there are few carbon fiber manufacturing companies globally Figure 5. Toray leads manufacturers, with $35 \%$ of global capacity and the top six manufacturers control 70\% of global capacity (Witten, Kraus, and Kühnel 2015).

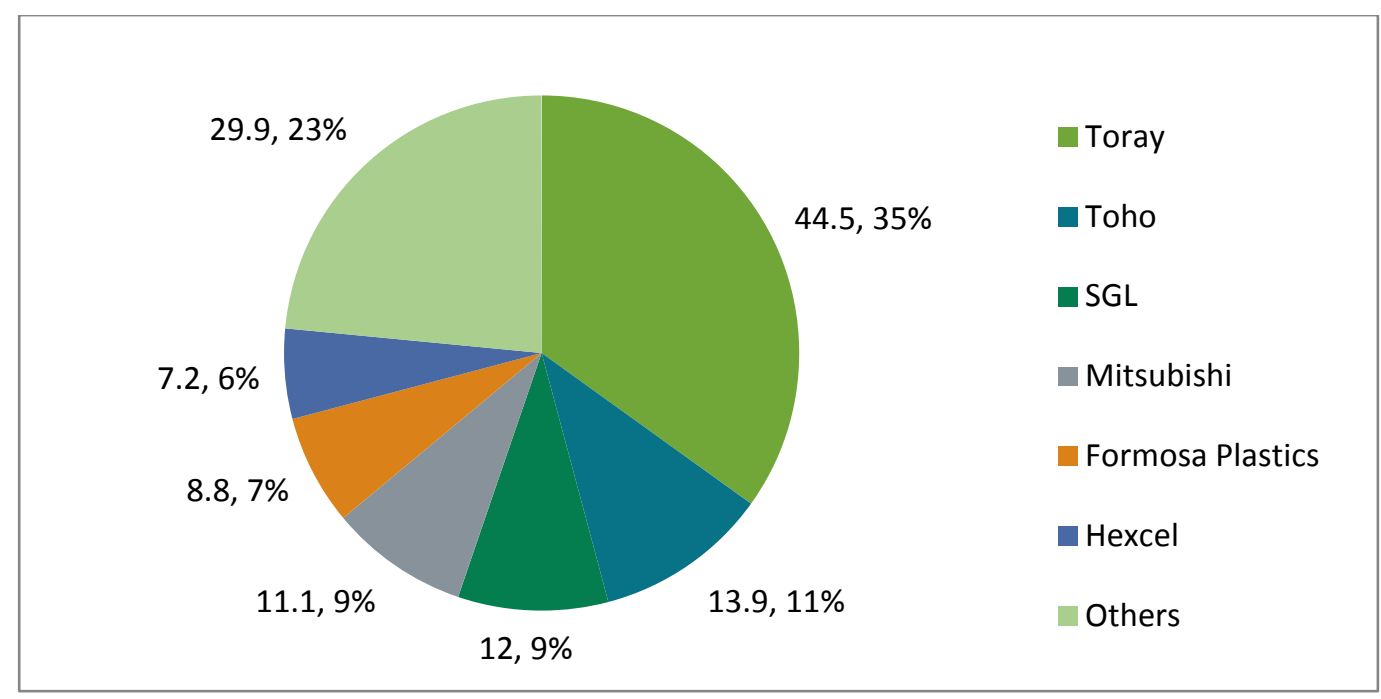

Figure 5. Carbon fiber manufacturing capacity in 2014, by company (metric tons)

Data from Witten, Kraus, and Kühnel 2015

There are three major reasons for this market structure. First, significant barriers to entry are present in the carbon fiber industry and they are related to high intellectual property and capital costs (Das et al. 2016). Second, carbon fiber is not considered a commodity product where the output from one manufacturer can be easily replaced with another; rather, carbon fiber is a specialty product and manufacturers can maintain an advantage in the market by producing consistent high-quality products by specific market application. Third, the market structure is driven in part by increasing industry consolidation, such as the acquisition of U.S.based Zoltek by Toray in 2014 (Toray 2014).

Nevertheless, where manufacturers choose to site future facilities can have direct economic impacts in those jurisdictions. With the expected global expansion of carbon fiber demand, manufacturers will have to decide where to locate new facilities. This report is a follow-on report to CEMAC's initial analysis of the competitiveness of varying carbon fiber supply chains. That report (Das et al. 2016) provided an analysis of carbon fiber, carbon fabric, and carbon fiber composite manufacturing costs for a variety of applications such as automotive, wind, and pressure vessels.

The goal of this report is to review the policies and markets of key countries and locations that manufacture carbon fiber-including China, France, Germany, Hungary, Japan, Mexico, South Korea, Taiwan, the United Kingdom, and the United States. This report documents how countries differ in several key considerations for siting carbon fiber manufacturing facilities, including energy and labor costs, currency rates, and intellectual property rights among others. Second, the report outlines the current landscape of policy that promotes carbon fiber 
manufacturing and markets within each of these countries to reveal how policy may play a role in driving carbon fiber production and deployment such as trade, renewable, and vehicle emissions policy. Finally, the report documents a series of policy pathways and considerations that could potentially increase end-use markets and carbon fiber manufacturing going forward.

\section{Manufacturing Siting Considerations}

Variation in manufacturing costs is a key consideration for prospective developers when citing new facilities. Carbon fiber manufacturing costs can vary between $\$ 10$ and 25 per kilogram for industrial grades, largely depending on the raw materials used and the type of carbon fiber produced (Das et al. 2016). A range of other cost factors also drive these estimates, as illustrated in Figure 6.

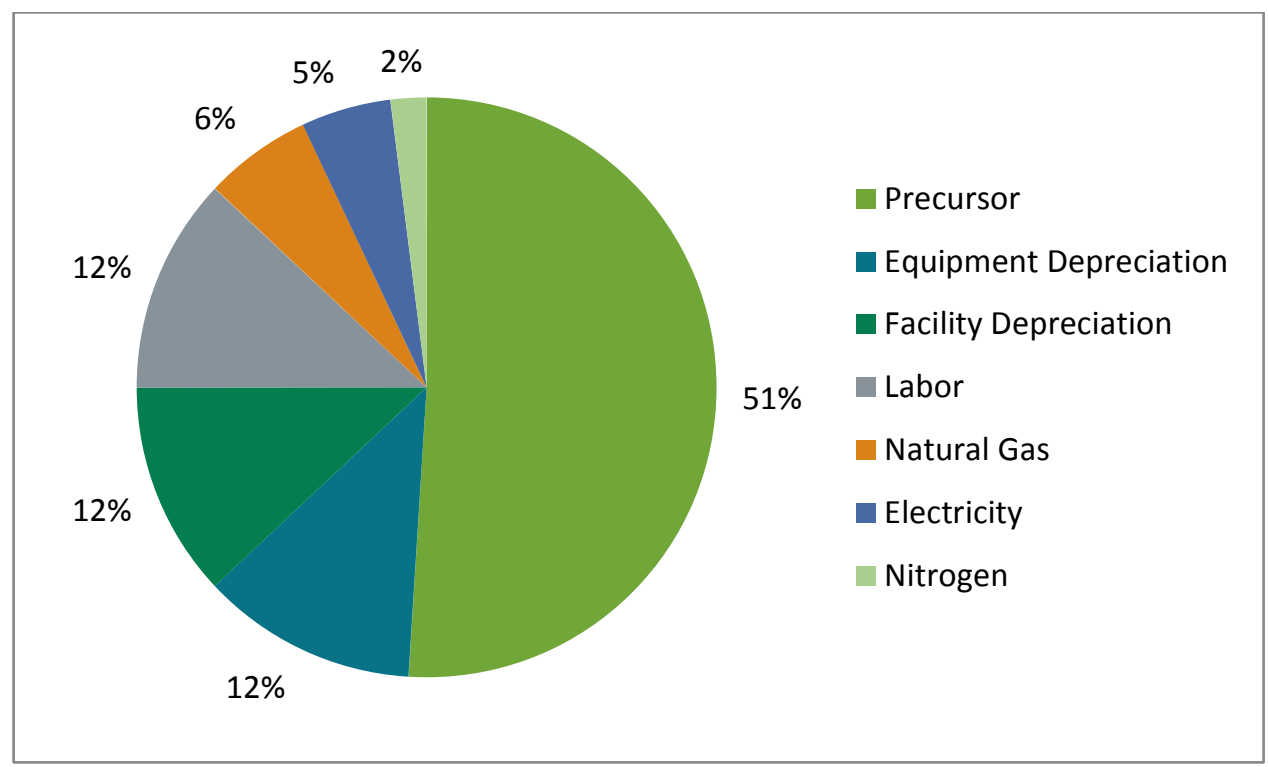

Figure 6. Harper International estimated cost structure for certain carbon fiber manufacturing

Data are from Witting 2015.

Raw material and equipment costs are somewhat constant. However, energy, labor, and other costs can vary by location. For example, Das et al. (2016) conducted several carbon fiber manufacturing cost comparisons for certain supply chains relating to vehicle manufacturing. In this context, they illustrate that based on the supple chain analyzed, the cost of carbon fiber for the automotive sector ranges from about $\$ 15 /$ kilogram to about $\$ 17 /$ kilogram (Figure 7). 


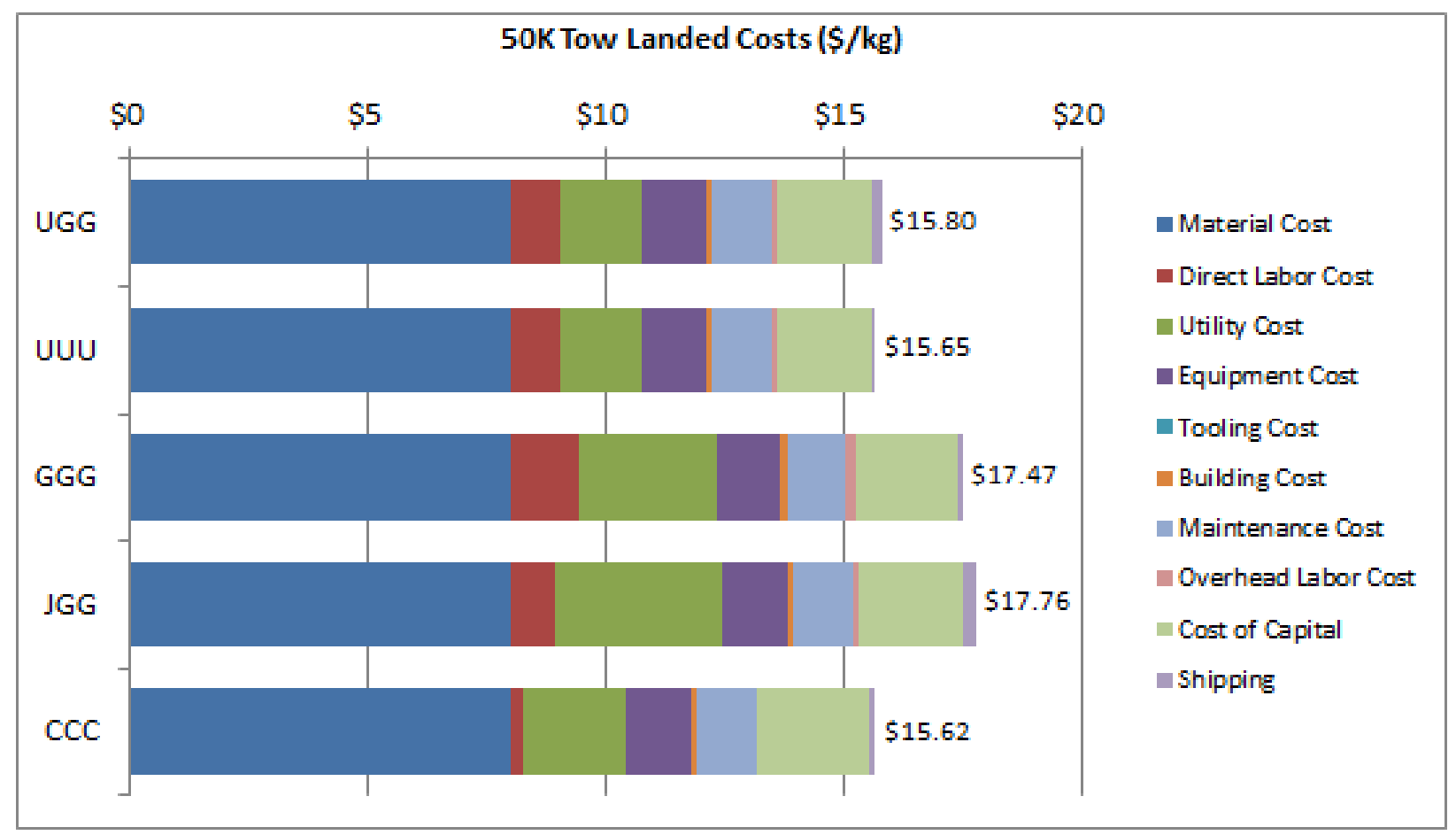

Figure 7. Certain $50 \mathrm{~K}$ tow carbon fiber landed costs by supply chain $(\$ / \mathrm{kg})$

$\mathrm{U}=$ United States, $\mathrm{G}=$ Germany, J= Japan, and $\mathrm{C}=$ China.

The first letter indicates the location of carbon fiber manufacturing, the second letter corresponds to the location of the bidirectional carbon fabric manufacturing, and the third letter corresponds to the location of end-use product manufacturing (carbon fiber reinforced polymer manufacturing).

Figure 7 shows the estimated landed cost of carbon fiber over the life of manufacturing. The impact of labor and utility costs in this example is clear. Das et al. (2016) also conduct a sensitivity analysis to describe a manufacturing supply chain solely operated in the United States that illustrates the influence of certain factors on carbon fiber cost (see Table 2).

Table 2. Sensitivity Analysis of 50K Tow CF Landed Costs for Scenario UUU

\begin{tabular}{|l|l|l|l|l|}
\hline \multirow{2}{*}{ Sensitivity Parameter } & \multicolumn{3}{l}{ Carbon Fiber Cost $\mathbf{l} / \mathbf{k g})$} \\
\cline { 2 - 3 } & Low & Baseline & High & Range \\
\hline Electricity $\$ / \mathrm{kWh}(\$ 0.040, \$ 0.069, \$ 0.120)$ & $\$ 14.99$ & & $\$ 16.80$ & $\$ 1.81$ \\
\hline Precursor $\$ / \mathrm{kg}(\$ 3.43, \$ 3.81, \$ 4.19)$ & $\$ 14.84$ & & $\$ 16.47$ & $\$ 1.63$ \\
\hline Carbon fiber line $\$ \mathrm{M}(\$ 35.0, \$ 40.0, \$ 45.0)$ & $\$ 15.18$ & \multirow{3}{*}{$\$ 15.65$} & $\$ 16.13$ & $\$ 0.95$ \\
\hline Capital recovery rate $(8.8 \%, 10.8 \%, 12.8 \%)$ & $\$ 15.24$ & & $\$ 16.09$ & $\$ 0.85$ \\
\hline Skilled direct labor wage $\$ / \mathrm{hr}(\$ 12.56, \$ 17.56, \$ 22.56)$ & $\$ 15.36$ & & $\$ 15.95$ & $\$ 0.59$ \\
\hline Natural gas $\$ / \mathrm{MMBtu}(\$ 3.00, \$ 3.76, \$ 10.00)$ & $\$ 15.62$ & & $\$ 15.96$ & $\$ 0.34$ \\
\hline
\end{tabular}


In addition to energy and labor, a variety of other factors also influence these production costs and the decision of manufacturers to locate in certain jurisdictions. This report expands on Das et al. (2016), and we consider other factors more generally, including intellectual property rights, environmental and safety requirements, and quality considerations. Though these costs have not been factored into the Das et al. (2016) supply chain analysis, they can influence carbon fiber manufacturers' permitting and regulatory costs and their overall decision to locate in certain jurisdictions.

Given the carbon fiber market is expected to expand and require additional carbon fiber manufacturing capacity, the goal of this section is to determine how the top-10 carbon fiber manufacturing locations and to compare across these locations some of the key siting variables, including labor, energy, intellectual property, quality, currency, and environment and safety considerations. This research can then highlight historical advantages across the countries and can offer an outlook for the future.

\subsection{Labor Costs}

After materials costs, labor compensation is the second-most significant driver of carbon fiber accounting for $12 \%$ of overall production costs (Figure 6 and Figure 7). These costs vary and may influence a developers' decision to locate in a given country.

Since 2012, the Conference Board has tracked differences in labor costs globally (The Conference Board 2016a). Manufacturing labor compensation is typically higher in the United States than it is in other countries with significant carbon fiber production (Figure 8). ${ }^{7}$ This reality may influence manufacturers' decisions about whether to locate in the United States.

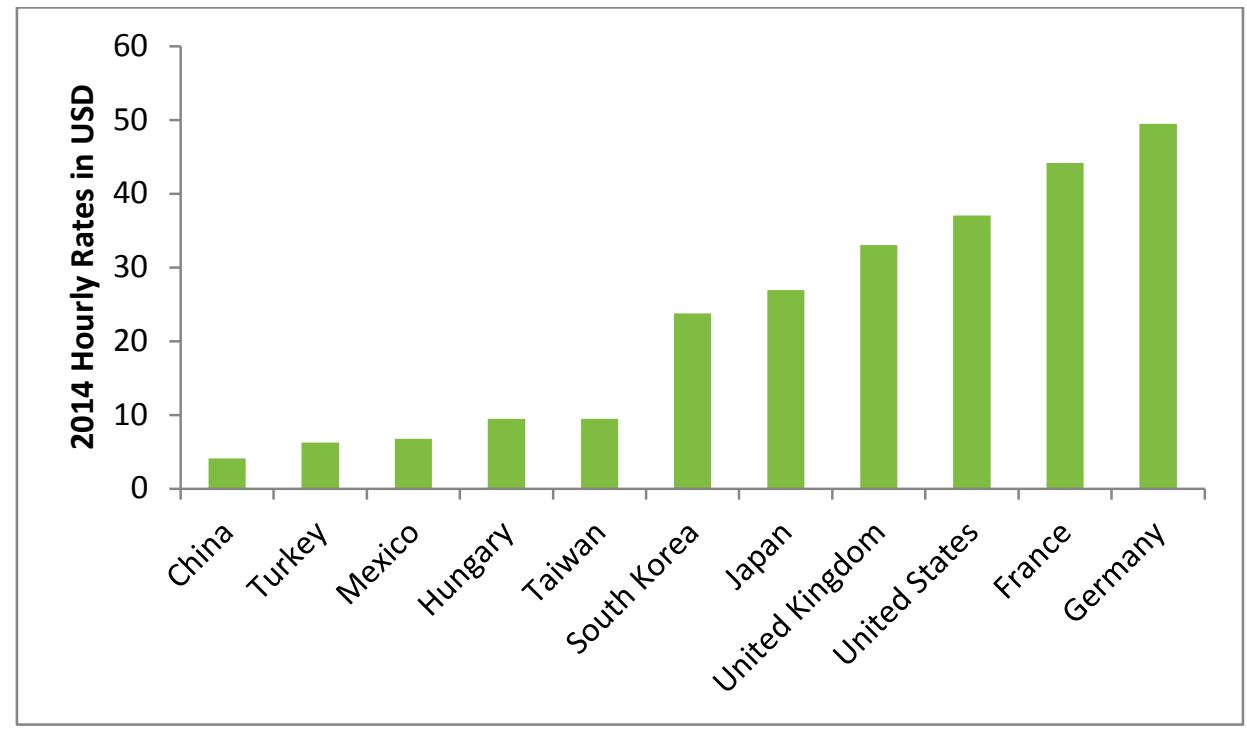

Figure 8. Comparison of hourly compensation costs in manufacturing, by economy in 2014 (USD)

Source: The Conference Board 2016a; 2016b

\footnotetext{
${ }^{7}$ Though we include China in Figure 7, these data are from 2013, and The Conference Board (2016b) cautions against direct comparisons of China and the other countries, given data gaps.
} 
However, variation in labor costs can be tempered somewhat by differences in labor productivity (Sirkin, Zinser, and Rose 2014). Figure 8 shows labor productivity by country in Gross Domestic Product (GDP) per hour worked. In 2015, the United States offered the highest labor productivity by this metric, followed by several of the European countries. These countries typically also have higher hourly labor costs. In comparison, countries such as Hungary, Mexico, and Russia have lower labor productivity rates as well as lower hourly rates. Thus, a facility located in a higher labor productivity location may require fewer workers than a similar facility in a less productive location, which can impact overall labor costs.

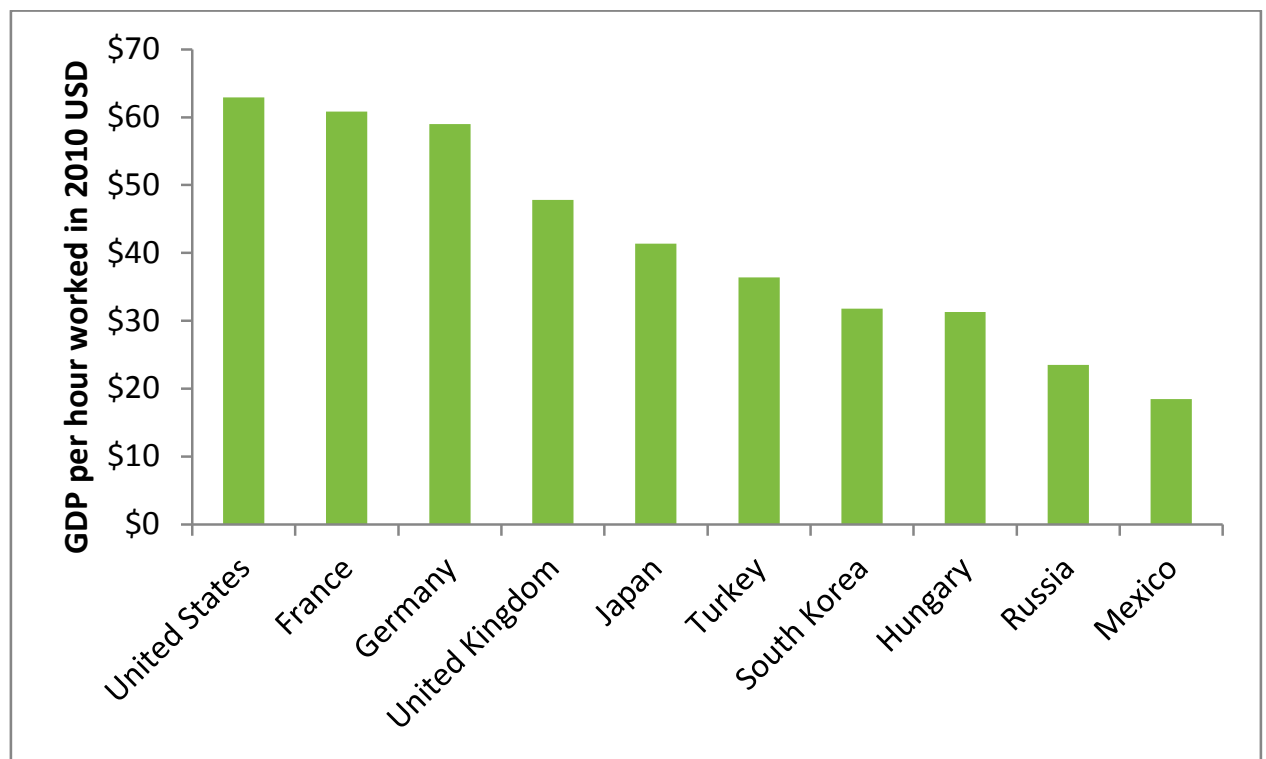

Figure 9. Comparison of labor productivity in GDP per hour worked in 2015 (2010 USD)

Source: Organisation for Economic Co-operation and Development 2017

In addition, the overall impact of labor costs on production may decline as carbon fiber manufacturing becomes increasingly automated. According to Manyika et al (2017), $60 \%$ of manufacturing processes have the potential to be automated. The carbon fiber industry is embracing automation opportunities, as exemplified by, SGL Automotive Carbon Fibers facility in Moses Lake, Washington, that includes a highly automated production line that operates nonstop 360 days per year (Gates 2014). As automation increases, hourly labor costs may decline as a driver for making siting decisions, while labor productivity may become more important. This is because manufacturers may wish to maximize the performance of workers to generate additional cost savings after automation opportunities are exhausted.

\subsection{Energy Availability and Pricing}

Energy consumption associated with carbon fiber production is another significant factor in manufacturing costs, as it accounts for about $11 \%$ of the overall cost of production (Witting 2015). In many cases, both electricity and natural gas are used in the manufacturing of carbon fiber. Ovens and furnaces are the primary consumers of energy in the carbon fiber manufacturing process. While all-electric ovens can be used, this can significantly increase manufacturing costs; see Figure 10 for a cost comparison. For this reason, nations or regions 
with low-cost energy available in the form of either electricity or natural gas may have an advantage.

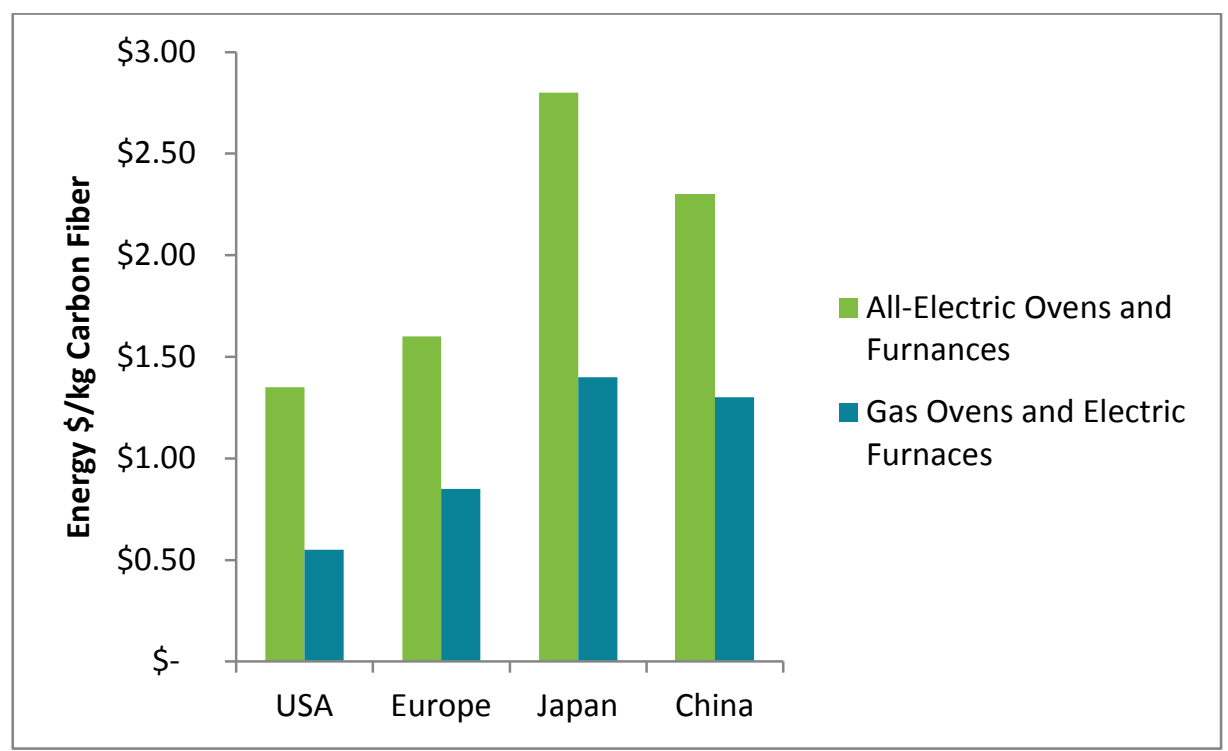

Figure 10. Energy cost comparison for the use of all-electric ovens and furnaces versus gas ovens and electric furnaces, by select country or region

Reproduced with data from Witting 2015; kg = kilogram

In terms of electricity costs, recent prices for industrial customers in the United States are 2\%-58\% lower than they are for other countries surveyed for this report (Figure 11). These low prices can be advantageous for carbon fiber manufacturers located in the United States by lowering the cost of production.

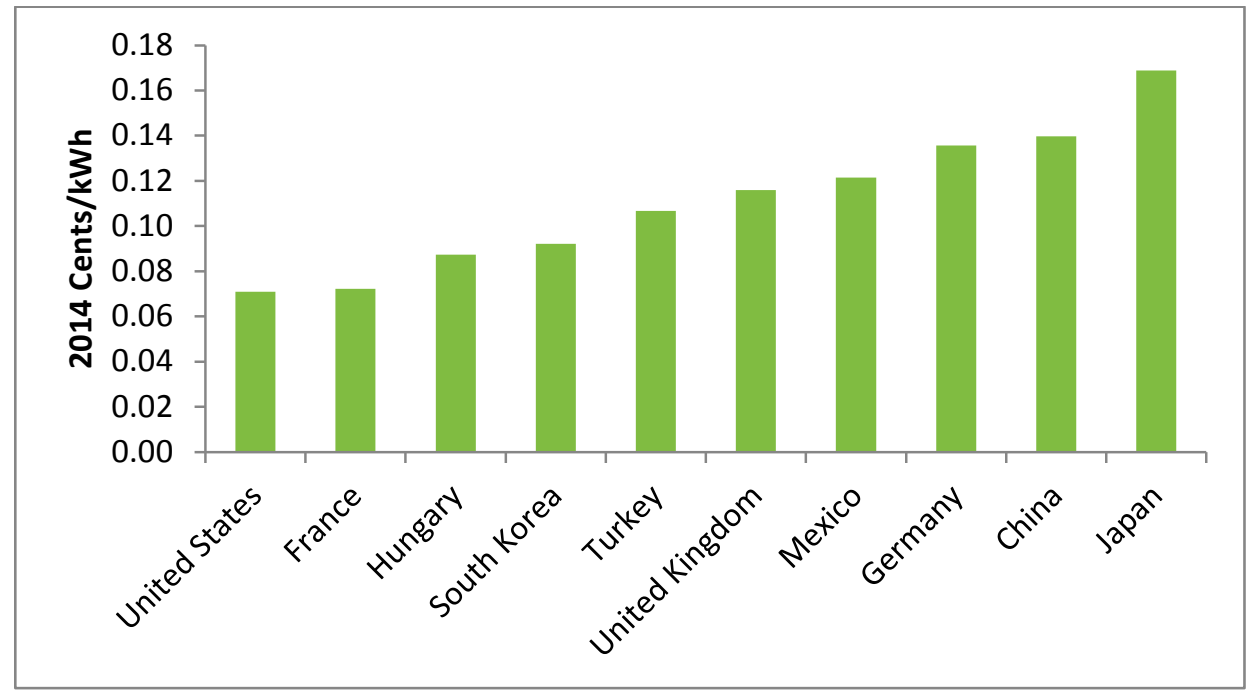

Figure 11. Comparison of 2014 average industry electricity costs, by country

The average industry electricity prices for the United States were sourced from the Energy Information Administration (EIA 2016); all international prices were generated from Bloomberg New Energy Finance (BNEF 2015) data, except for the prices for Turkey, which were generated from United Kingdom Department of Energy and Climate Change (DECC) 2016 data. kWh = kilowatt-hour. 
Recent low electricity prices in the United States have been caused in part by historically low natural gas prices enabled by the adoption of new extraction technologies (EIA 2015). Electricity prices can be somewhat volatile and historical trends are not always indicative of future costs. The U.S. Energy Information Administration (EIA) produces annual long-term projections of electricity prices based on a range of assumptions such as economic growth and resource extraction. In the EIA reference case, natural gas and coal prices increase through 2040, which may result in higher electricity prices for industry. EIA suggests that the extent that this price increase materializes depends largely on fuel prices and domestic resource extraction. For example, the EIA also modeled a scenario with high natural gas resource extraction among other assumptions, and in that scenario, electricity prices remain relatively low (EIA 2015).

To be clear, a wide range of factors may influence the future cost of electricity in the United States, and the assumptions behind the EIA projections may not hold true. Nevertheless, if electricity prices were to remain low, carbon fiber manufacturers may be encouraged to locate in the United States.

Recall that leveraging low-cost natural gas, or a hybrid system, to generate thermal energy can offer an advantage to certain carbon fiber manufacturers where natural gas is available and low-cost. ${ }^{8}$ In this context, the United States has also recently held an advantage, with 2014 prices that are $45 \%-80 \%$ lower than they are in other countries surveyed (Figure 12).

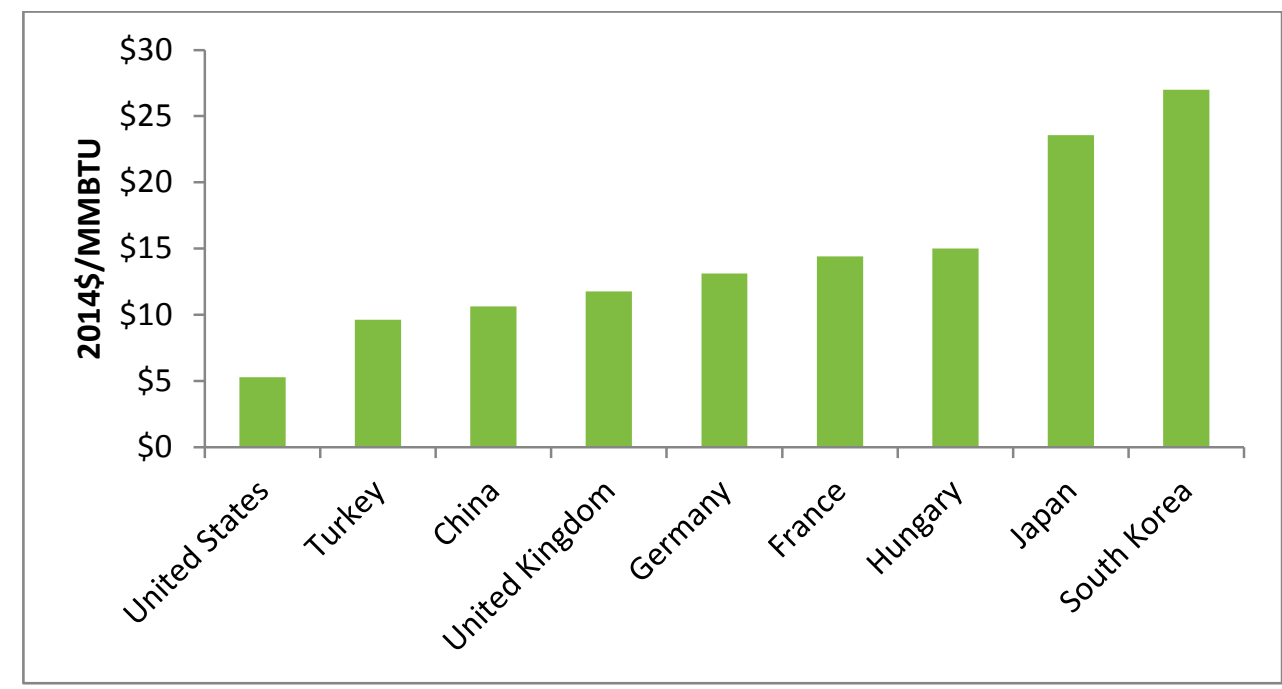

Figure 12. Comparison of 2014 bulk industrial natural gas prices, by country (\$MMBTU)

These natural gas prices were derived from IEA 2016 data, except for the data for China, which reflect the import price in April 2014 (Russell 2014) and the data for India, which was sourced from Enerdata (2014). It should be noted that natural gas is not available in many areas of some of these countries, including China, Japan, and South Korea, which are highly dependent on imported liquefied natural gas. It is also likely that natural gas prices have declined in some countries since 2014, particularly in South Korea and Japan (FERC 2016).

\footnotetext{
${ }^{8}$ In some locations, such as inland China, using natural gas may not be an option, given limited natural gas infrastructure and supply.
} 
The recent lower costs for natural gas in the United States are again associated with increased natural gas extraction (related to the aforementioned innovations in drilling technologies) (EIA 2015). As noted, EIA's reference case expects natural gas costs to increase in the United States. To be clear, predicting future natural gas prices is notoriously difficult (Logan, Medlock, and Boyd 2015) because these prices are influenced by a wide variety of factors, including weather patterns, industrial and power sector demand, innovations in extraction techniques, and exports, among others. Nevertheless, if EIA's assumptions are correct, they could influence the advantage that the United States currently holds over other countries in terms of energy costs.

\subsection{Currency Rates}

Currency rates can impact export and import calculations, and by extension, they can influence manufacturing siting decisions. Simply put, currency volatility between countries that are trading carbon fiber can impact the value of those goods, depending on the relative strength of the currencies for which the products are traded.

The U.S. Internal Revenue Service and others organization such as the World Bank track variation in foreign currency rates as compared to the U.S. dollar (IRS 2016; World Bank 2016). Using the U.S. dollar as a reference point, Figure 13 displays the annual percentage change in a set of foreign currencies to illustrate the year-over-year variation in currency value.

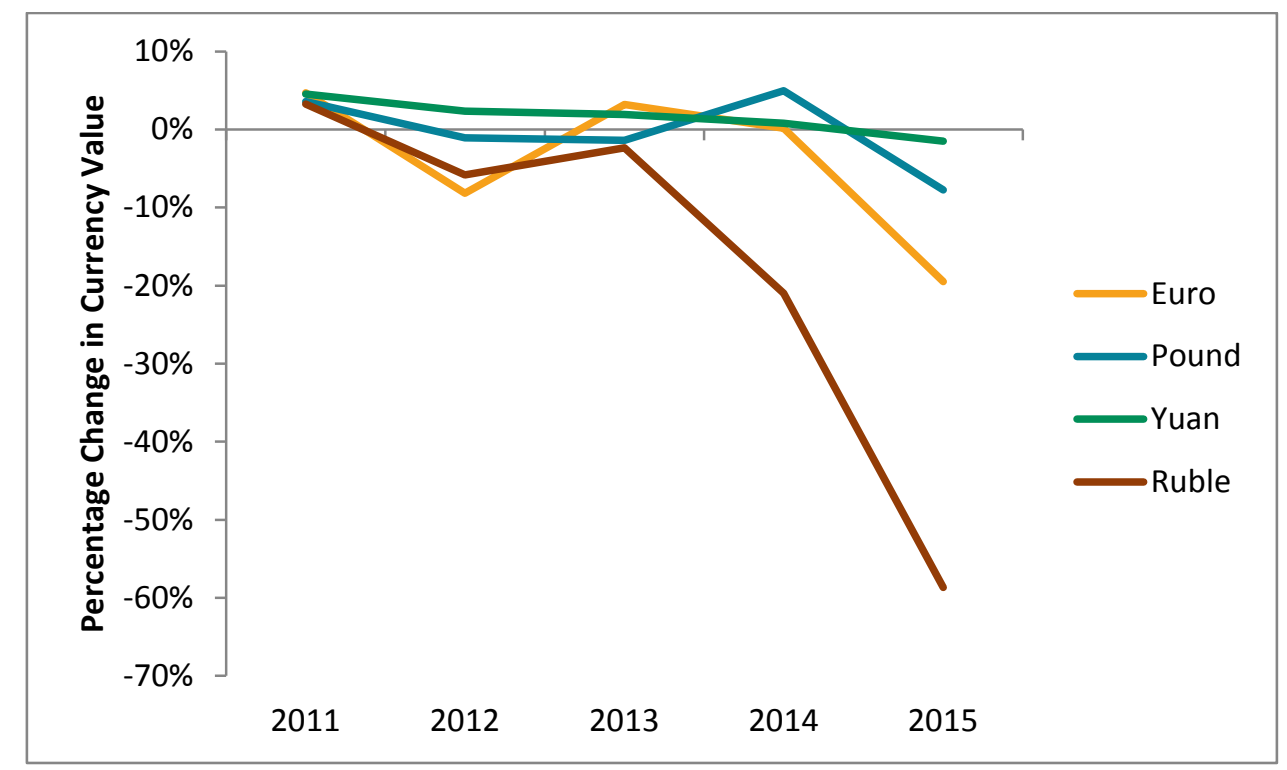

Figure 13. Year-over-year currency value variation compared to the U.S. dollar

The relative strength of the currencies for which carbon fiber is traded can influence manufacturing costs and profit margins. For example, the U.S. steel industry idled $31 \%$ of capacity in 2015, while imports increased from $28 \%$ in 2014 , to as high as $33 \%$ in 2015 , in part due to the strength of the dollar (Elmquist 2015). In the carbon fiber context specifically, the recent decreases in the value of the ruble has been suggested as one reason why carbon fiber manufacturing in Russia has increased (Hawk 2013). 
In addition, unexpected changes in currency rates may also impact carbon fiber manufacturers importing and exporting into the affected market. For example, the Euro lost $20 \%$ of its value in relation to the USD from 2014 - 2015 (See Figure 13). This resulted in near parity between the Euro and USD in 2015 (IRS 2016). If unmitigated, this could result in a scenario where European manufacturers lose value for the products they export, while limiting the opportunity for carbon fiber manufacturers from other countries to maintain a profit from participating in the European market.

Some of the impact of this volatility can be mitigated in various ways. First, if a manufacturing facility is located within the same country in which its goods are purchased, there is no currency volatility risk. If the goods are traded between countries, currency exchange risks can also be mitigated by employing certain hedging strategies. ${ }^{9}$ Though effectively minimizing these risks is possible, properly hedging against currency volatility can be challenging, particularly when unexpected exchange rate moves occur. Thus, manufacturers may be more interested in locating in countries with more stable currencies or in the same country as their key customers.

\subsection{Environmental and Safety Regulations}

As noted, environmental and safety regulation costs are not included in the supply chain analysis by Das et al. (2016). Nevertheless, these policies can influence carbon fiber manufacturers' costs, given the significant emissions and safety risks associated with production. For example, the Toray carbon fiber manufacturing facility in Decatur, Alabama, emits a range of pollutants documented in the U.S. Environmental Agency (EPA) Toxic Release Inventory, including acrylonitrile, carbon monoxide, and hydrogen cyanide (EPA 2015). The facility also emits ammonia, particulate matter, nitrogen oxides, and volatile organic compounds, among other pollutants (EPA 2015). The EPA issues regulations, such as the National Ambient Air Quality Standards (EPA 2016a) that address these air pollutants. In addition, the handling of carbon fiber during the production of carbon fiber composites can cause skin irritation and other health effects, such as lung disease (OSHA n.d.). Thus, the Department of Labor Occupational Safety and Health Administration requires manufacturing facilities to adopt certain workplace controls, such as proper ventilation and personal protective equipment during manufacturing (OSHA n.d.). These regulations may increase the costs of production or limit the ability of manufacturers to locate in certain regions (EPA 2016a).

Other jurisdictions have also enacted environmental and occupational safety laws that may impact carbon fiber manufacturing. For example, the European Union (EU) issues environment and safety regulations that impact carbon fiber manufacturing across member countries such as France and Germany (European Commission 2016a; European Agency for Safety and Health at Work 2016). In addition, each of the remaining economies (China, Japan, Mexico, South Korea,

\footnotetext{
${ }^{9}$ Hedging refers to investments such as option contracts that are intended to limit currency exchange risks that could result in losses or gains for the carbon fiber manufacturer thereby limiting corporate exposure (Papaiannou 2006).
} 
and Taiwan) has also adopted environmental and safety regulations that impact manufacturing in their jurisdiction. ${ }^{10}$

Table 3 compares certain economies' environmental standards as they relate to some key emissions associated with carbon fiber manufacturing, including carbon monoxide, nitrogen dioxide, and particulate matter. Table 3 shows there is some consistency across these standards. For example, the emission limit for carbon monoxide ranges from an average of 9 to 11 parts per million over an eight-hour period.

Table 3. Comparison of Certain Pollution Standards by Economy

\begin{tabular}{|l|c|c|c|c|c|c|}
\hline Pollutant & China & EU & Japan & Mexico & $\begin{array}{l}\text { South } \\
\text { Korea }\end{array}$ & $\begin{array}{l}\text { United } \\
\text { States }\end{array}$ \\
\hline $\begin{array}{l}\text { Carbon monoxide parts } \\
\text { per million (8-hour mean) }\end{array}$ & 10 & 9 & 10 & 11 & 9 & 9 \\
\hline $\begin{array}{l}\text { Lead micrograms per } \\
\text { cubic meter (annual) }\end{array}$ & 0.50 & 0.50 & - & 1.50 & 0.50 & 0.15 \\
\hline $\begin{array}{l}\text { Particulate matter diameter } \\
\text { less than10 in parts per } \\
\text { million (24-hour mean) }\end{array}$ & 50 & 50 & 100 & 120 & 50 & 150 \\
\hline $\begin{array}{l}\text { Particulate matter of } \\
\text { diameter less than 2.5 } \\
\text { annual mean micrograms } \\
\text { per cubic meter }\end{array}$ & 15 & 25 & 15 & 15 & 25 & 15 \\
\hline
\end{tabular}

The carbon monoxide standards for China are based on an average hourly rate (Zhao et al 2016), and those for Japan are based on a per day average (Japan Ministry of the Environment n.d.). This report did not identify a Japanese standard for lead micrograms per cubic meter (annual) (Japan Ministry of the Environment n.d.). In Mexico, lead emissions cannot exceed the standard in any three-month period (ICCT and DieselNet 2013). The U.S. and EU standards are sourced from Kuklinska, Wolska, and Namiesnik (2015), and South Korea's are from the South Korea Ministry of Environment (n.d.).

\footnotetext{
${ }^{10}$ See Japanese Occupational Safety and Health law at https://www.jniosh.go.jp/icpro/jicosh-old/english/law/ and Japanese Air Pollution Control Act and other environmental regulation at http://www.env.go.jp/en/coop/pollution.html. See China's recently amended Environmental Protection Law that addresses air pollution in that country and the language of that law, which is available at http://www.china.org.cn/english/government/207462.htm and the country's health and safety laws, which is available at http://www.npc.gov.cn/englishnpc/Law/2007-12/10/content 1383440.htm. Mexico's General Law of Ecological Balance and Environmental Protection establishes air pollution and environmental protection requirements for that country and the language of the law is available at http://www.wipo.int/edocs/lexdocs/laws/en/mx/mx028en.pdf. A summary of Mexico's Federal Labor Law that establishes worker health and safety requirements is available at http://www.diputados.gob.mx/LeyesBiblio/pdf/125 120615.pdf. South Korea sets Atmospheric Environmental Standards for certain air pollutants as documented at http://eng.me.go.kr/eng/web/index.do?menuld=253 and health and safety standards are shaped by the Occupational Safety and Health Act available at http://english.kosha.or.kr/english/cmsTiles.do?url=/cms/board/board/Board.jsp?communityKey=B0488\&menuld=1240. Finally, Taiwan's Air Pollution Control Act among others establishes air quality and environmental protection requirements in that country. A summary of this and other environmental laws in Taiwan are available at http://www.ey.gov.tw/en/cp.aspx?n=0775D186E2307F53. Taiwan's Occupational Safety and Health Act establishes labor safety requirements and is available at http://www.osha.gov.tw/media/2703/occupational-safety-and-health-act.pdf.
} 
Though policies may be similar, inconsistent enforcement can result in potentially lower costs for manufacturers in some locations. For example, enforcement challenges have been cited as an issue in China despite the increased stringency of its amended environmental protection law (Zhang and Cao 2015). Thus, these environmental costs may impact carbon fiber manufacturing differently depending on the facility's location.

For carbon fiber manufacturing, emerging policies addressing greenhouse gases (GHGs) can have impacts on production costs. The EU and South Korea have adopted policies to address these emissions. The EU established the Emissions Trading System in 2005. It covers $45 \%$ of the EU's greenhouse gas emissions and requires a 20\% reduction from 1990 emissions by 2020 and at least $40 \%$ by 2030 . More recently, the $E U$ is considering reducing the 2030 requirement to 43\% below 2005 levels by 2030 (European Commission 2016b). In 2015, South Korea launched its carbon emission cap and trade program, and it has targeted a $37 \%$ reduction in carbon emissions from business-as-usual levels by 2030 (Cho 2015). The program covers electricity generators and other companies that may further spur renewable energy development (Cama 2015).

The extent to which these policies proliferate may influence carbon fiber manufacturing facilities, as the production process can produce significant GHG emissions (Das 2011). Depending on the type of carbon fiber manufactured, production can emit 24-31 kilograms of carbon dioxide equivalents per kilogram of product (Das 2011). For reference, these emissions are significantly higher than those for stamped steel, which is used predominately in the automotive sector and emits 4.4 kilograms of carbon dioxide equivalents per kilogram. ${ }^{11}$

Because carbon fiber emissions are correlated with energy use, they can vary depending on the source of energy procured (Das 2011). For example, Cytec Carbon Fibers' facility in Piedmont, South Carolina generated over 29,000 metric tons of GHGs in 2014 (EPA 2016b), the same year a Hexcel Corporation facility in Decatur, Alabama emitted over 36,000 metric tons of GHGs (EPA 2016c). SGL's Automotive Carbon Fiber facility in Moses Lake, Washington, is powered predominately by hydroelectric power, which significantly reduces its carbon footprint (Gates 2014). If certain economies adopt GHG emission legislation or regulations, existing facilities and future manufacturers may be impacted, depending on the content of the policy and how the facility procures energy. ${ }^{12}$

\subsection{Intellectual Property}

As stated in Section 1.2, the barriers to entry to the carbon fiber manufacturing industry are quite high, partly because of the high specialization of the manufacturing process, particularly for carbon fiber precursor (Das et al. 2016). Developing the skills and experience to make a high quality product can be difficult and expensive, and companies are protective of the advances

\footnotetext{
${ }^{11}$ Carbon fiber composite materials have somewhat lower lifecycle emissions than steel (Das 2011).

${ }^{12}$ Some states, such as California have already imposed GHG regulations that could impact the carbon fiber industry. See the California Air Resources Board's "Cap-and-Trade Program" page at https://www.arb.ca.gov/cc/capandtrade/capandtrade.htm.
} 
made on these fronts. As a result, some manufacturers may choose to locate facilities in countries that provide a high level of protection for their existing trade secrets or intellectual property. They may also choose to locate in one of these countries, as the manufacturers may be better able to capitalize on and protect research and development investments to lower their costs or improve their products. The ability to better capitalize on these investments could provide a competitive advantage for some manufactures.

The U.S. Chamber of Commerce tracks intellectual property rights policy via its Global Intellectual Property Center. The U.S. Chamber of Commerce also ranks countries based on the stringency of their policy in the International IP Index (U.S. Chamber of Commerce 2016). The United States ranks highest on the International IP Index, followed by many of the European economies, Japan, and South Korea. Taiwan, Mexico, Russia, China, and Turkey are ranked significantly lower than the United States (U.S. Chamber of Commerce 2016).

\subsection{Quality Considerations}

The nature of carbon fiber as a specialty product (Section 1.2) may also influence where new carbon manufacturing is located. In the specialty product market, customers recognize the quality and associated value of a certain manufacturer's product, and they do not make purchase decisions based solely on price. This is particularly relevant in the aerospace industry, where end users tend to sign long-term contracts with well-established suppliers (Das et al. 2016). This gives incumbents a significant market advantage, as the costs of switching materials or suppliers can be very high. For example, the data and tests required for aerospace material qualification often require millions of dollars and several years (Brice 2011). Because of such quality considerations, existing manufacturers might have an advantage, as some customers may be unwilling to switch to a new market entrant, even for a lower-priced product. This dynamic could promote expansion at existing facilities to serve increasing demand, which has happened at the Moses Lake facility in Washington state (Witten, Kraus, and Kühnel 2015; Gates 2014). 


\section{Summary of Policies Relevant to Carbon Fiber}

Policy decisions executed by government influence the manufacturing siting factors outlined above while also impacting the demand for carbon fiber. The U.S. government's decision to incorporate carbon fiber technology into defense applications initially spurred demand for carbon fiber. In the contemporary market, policy decisions relating to trade, carbon fiber manufacturing, and carbon fiber end-use markets more generally can influence manufacturers' decisions to locate in certain countries. These policies can serve as either barriers or enablers for carbon fiber production.

One of the more common barriers focuses on trade restrictions and export controls, which limit international market opportunities. For example, export controls can spur countries to develop domestic carbon fiber manufacturing capabilities to serve domestic and especially military demand. Supports such as public research and development programs and direct governmental procurement provide significant support to the carbon fiber manufacturing industry. And, some policies can enable increased carbon fiber demand in end-use applications.

The wind energy and automotive industries were two key industrial sector applications through 2024 (see Section 1.1). ${ }^{13}$ Both can be highly impacted by governmental policy directives. The deployment of wind turbines is supported by governmental policies such as renewable portfolio standards and feed-in-tariffs that are intended to drive adoption, although the economics of wind turbines are becoming independent of incentive policies. The specifics of these policies have a significant impact on the number of wind turbines deployed and thus the utilization of carbon fiber. Carbon fiber is particularly important for very large turbines such as the models used in offshore applications and increasingly in land-based applications (Das et al. 2016; EWEA 2016). As both offshore and land-based wind turbine blade length increases, the carbon fiber content of these blades may also increase. Vehicle emissions standards can have a similar impact on carbon fiber use in the automotive industry, as carbon fiber is one of many materials that can be used to lower the weight of a vehicle and this improve fuel economy. In addition, the adoption of carbon fiber-based pressure vessels in the automotive sector for natural gas and fuel cell vehicles has also fueled the expansion of that market (Das et al. 2016).

The goal of this section is to evaluate existing policy that impacts carbon fiber manufacturing and market development across the 10 largest carbon fiber manufacturing economies including, in order of manufacturing capacity, the United States, Japan, China, France, Germany, Hungary, and the United Kingdom, Taiwan, Mexico, and South Korea. The countries within the $\mathrm{EU}$, as of this writing, were grouped together, given the central authority to implement certain EU-wide policy. ${ }^{14}$

\footnotetext{
${ }^{13}$ In addition, the adoption of carbon fiber-based pressure vessels in the automotive sector to achieve vehicle fuel economy and emissions standards has also fueled the expansion of that market (Das et al. 2016).

${ }^{14}$ Though the United Kingdom recently voted to leave the EU, it had not completed its exit as of this writing. Therefore, the United Kingdom is included in the broader EU section, though its policies may change once the country officially leaves the EU.
} 


\subsection{United States}

The United States is the global leader in carbon fiber manufacturing, with 31.7 metric tons of capacity (Witten, Kraus, and Kühnel 2015; Reinforcedplastics 2014). The United States has an unusual export licensing policy with its requirement to request export-licensing permits for each transaction of carbon fiber. This requirement has been cited as a potential barrier to increased U.S. exports in the carbon fiber market (U.S. International Trade Commission 2010; Manufacturing \& Technology News 2010; Fowler 2013; U.S. Department of Commerce 2015). Despite this barrier, strong U.S. support for research and development along with complementary policy driving end-use markets relating to wind energy, automotive, and defense applications have encouraged the development of a domestic and international carbon fiber market.

\subsubsection{Trade Policy}

The U.S. Department of Commerce restricts the export of goods and technology, including carbon fiber that could contribute to the military potential or nuclear proliferation of other nations. The only carbon fiber goods exempt from licensing requirements are those specially designed for purely civilian applications, including sporting goods, automotive, machine tools, and medical applications. ${ }^{15}$

Export licenses are specific to both companies and countries. A manufacturer must apply for a separate license for every transaction or contract, and each license lasts for two years. As a result, a manufacturer can only estimate its exports in intervals of two years for specific customer relationships. If the product will be developed into an intermediate good, additional license requirements apply because products may be traded again or "re-exported." ${ }^{16}$ Carbon fiber related products such as acrylonitrile, acrylic fiber precursor, ${ }^{17}$ and end-use products are all subject to the harmonized tariff schedule. The type of product imported influences the tariff rates, which ranges from $7.5 \%$ for acrylic fiber precursor to $0 \%$ for carbon fiber end-use products. $^{18}$

Companies can apply for an exemption from the duty for the amount of precursor used in carbon fiber products by submitting an application to establish or join an existing Foreign Trade Zone (FTZB 2015). These applications are reviewed on a case-by-case basis by the Foreign-Trade Zones Board (FTZB), and this review can take time, particularly when an application is contested (Fowler 2013). To date, at least two carbon fiber manufacturers (Mitsubishi Rayon and SGL Automotive Carbon Fibers LLC) have been granted exemptions (FTZB 2015). Despite the availability of this designation, manufacturers have often highlighted these and other trade-

\footnotetext{
${ }^{15}$ See 15 CFR Part 774 at http://www.ecfr.gov/cgibin/retrieveECFR?gp=1\&SID=a41bcf51d3ce08efabe3c9fb75852da3\&ty=HTML\&h=L\&n=15y2.1.3.4.45\& $r=P A R T$.

${ }^{16}$ See 15 CFR Part 774 at http://www.ecfr.gov/cgibin/retrieveECFR?gp=1\&SID=a41bcf51d3ce08efabe3c9fb75852da3\&ty=HTML\&h=L\&n=15y2.1.3.4.45\&r=PART.

${ }^{17}$ Acrylic fiber is the raw material needed to produce carbon fiber.

${ }^{18}$ U.S. International Trade Commission. “5501.30.00." Harmonized Tariff Schedule of the United States (2016). https://hts.usitc.gov/view/Chapter\%2055?release=chapter98. Also, see HS Codes 29261000, 392190. 5903, and 68151000 at https://hts.usitc.gov/?query=6815.
} 
related issues as barriers for carbon fiber exports (U.S. International Trade Commission 2010; Manufacturing \& Technology News 2010; Fowler 2013; U.S. Department of Commerce 2015).

In 2009, President Obama convened an interagency review of the U.S. export control system, which resulted in the Export Control Reform initiative (U.S. Department of State 2015). Its goals were to clarify existing policy related to exporting of goods with national security implications and to develop a single licensing agency for those materials with significant national security implications. By 2017, the initiative clarified policy and streamlined definitions for 18 of the 21 Commerce Control List products, in an effort to reduce confusion about permitting requirements and permitting delays. The initiative did not develop a single licensing agency prior to Obama's departure from office (Goodman 2017).

Finally, the Export Import Bank of the United States (EXIM) supports industry exports by filling gaps in private export finance (EXIM 2016). EXIM is an export credit agency that was set up to provide government support through direct or indirect financing related to exporting goods to other countries. The United States is a member country and signatory of the Organization for Economic Cooperation and Development (OECD) export credits arrangement. The arrangement is an agreement that seeks to limit and regulate government subsidies for exports. The goal is to ensure, to the extent possible, exporters compete on the basis of quality and competitiveness of goods in the global market. This arrangement, along with congressional legislation, structures the authority and activities of EXIM. The Export Import Bank has supported a wide range of industries, including the aerospace industry and more recently the renewable energy sector among others (EXIM n.d.). A recent political controversy regarding the role of EXIM has limited its ability to aid U.S. exporters and has potentially made the bank and by extension U.S. exporters less competitive (EXIM 2016).

\subsubsection{Carbon Fiber Manufacturing Support and Development}

Despite the issues relating to foreign trade, significant public funds have supported research and development that focuses on carbon fiber technologies, including an estimated \$25 million-\$45 million since the 1990s (Yin 2012). The U.S. Department of Energy (DOE) is supporting some U.S.-based efforts to advance these technologies, and in 2013, Oak Ridge National Laboratory (ORNL) with support from DOE opened the $\$ 34.7$ million Carbon Fiber Technology Facility in Oak Ridge, Tennessee (ORNL 2016a). The facility's objectives are to forge public-private collaborations to accelerate the development and deployment of lower-cost carbon fiber materials and to create a new generation of strong, lightweight composite materials (ORNL 2016a).

In 2015, the DOE also supported the development of the Institute for Advanced Composites Manufacturing Innovation (IACMI) a public private partnership that includes as partners the National Renewable Energy Laboratory and Oak Ridge National Laboratory (ORNL), among others (Blue 2015). IACMI's mission is to drive down the costs of carbon fiber-reinforced polymer manufacturing costs by $50 \%$ and energy consumption by $75 \%$ within ten years (Blue 2015). The National Renewable Energy Laboratory (NREL) supports this mission through research focused on improving carbon fabric placement in wind turbines through automation 
among other research priorities (IACMI n.d. B). In comparison, ORNL conducts research related to carbon fiber manufacturing processes (Chapin 2015; IACMI n.d. A). Outside of IACMI, the Sandia National Laboratories Wind Energy Technologies Program also conducts research related to integrating carbon fiber into turbine blades to produce longer, stronger, and lighter blades for land-based and offshore wind projects (Sandia National Laboratories n.d.; Hill 2016).

The U.S. Department of Defense also funds carbon fiber research and development through the Manufacturing Technology (ManTech) program. Many of the manufacturing advancements made via the ManTech program have been spun off into commercial markets (Executive Office of the President 2012). Finally, the National Institute of Standards and Technology funded the Consortium for Accelerated Innovation and Insertion of Advanced Composites in 2014 via its Advanced Manufacturing Office to develop both a research roadmap to identify and validate emerging cross-cutting technologies and an innovation manufacturing ecosystem to bring these technologies to market (Georgia Tech 2016; NIST 2016).

\subsubsection{End-Use Market Support}

\subsubsection{Renewable Energy Targets and Incentives for Wind Energy}

In addition to the significant research and development relating to carbon fiber, certain renewable energy policies across the United States also incentivize wind energy, which is one of the largest and growing end-use markets.

Though the United States does not currently have national renewable energy targets for electric service providers, 29 states and the District of Columbia have established renewable portfolio standard (RPS) programs, which require a certain percentage of the state's electricity generation mix be procured from renewable energy sources, including wind energy. These standards cover $55 \%$ of the U.S. retail electricity market, and wind energy has been the most common technology used to maintain compliance with these standards. More than half of all growth in the renewable market in the United States is attributed to these programs (Barbose 2016).

Another driver of the wind energy market in the United States is the federal production tax credit (PTC). ${ }^{19}$ Initially enacted via the Energy Policy Act of 1992, this incentive has enabled wind energy manufacturers to compete more effectively in the electricity market (Mai et al. 2016). In 2015, Congress enacted the Consolidated Appropriations Act of 2016, which extends the PTC in a step-down fashion until 2020, when the credit is eliminated. The extension of this credit is expected to have significant near-term impacts on wind production through the early 2020s, incentivizing from 29 gigawatts (GW) to 45 GW of additional wind capacity (Mai et al. 2016).

\footnotetext{
${ }^{19}$ Historical fluctuations in PTC policy have affected U.S.-based manufacturers of carbon fiber materials. In 2012, when the PTC was set to expire at the end of the year, the CEO of St. Louis, Missouri-based manufacturer Zoltek commented that investors were holding back on projects until the policy outlook was more certain (Kurtovic 2013).
} 
Even with these incentives in place, the offshore wind industry has been slow to develop in the United States. However, the first plant began operating off the coast of Rhode Island in late 2016 (Schlossberg 2016). If more plants follow, carbon fiber deployment in the wind sector could increase.

\subsubsection{Vehicle Emissions Regulations}

National vehicle emissions regulations have also promoted the use of carbon fiber in the U.S. automotive industry. In 2012, the EPA and the National Highway Traffic Safety Administration (NHTSA) published the 2017 and Later Model Year Light-Duty Vehicle Greenhouse Gas Emissions and Corporate Average Fuel Economy Standards (EPA and DOT 2012), which require the fuel economy of cars and light-duty trucks to increase to an equivalent of 54.5 miles per gallon by model year 2025 (EPA and DOT 2012). This target reflects a GHG emission target of 163 grams of $\mathrm{CO}_{2}$ per mile $\left(\mathrm{g} \mathrm{CO}_{2} / \mathrm{m}\right)$, or 101 grams of $\mathrm{CO}_{2}$ per kilometer $\left(\mathrm{g} \mathrm{CO}_{2} / \mathrm{km}\right)$.

Fuel economy and vehicle weight are inversely related, and carbon fiber offers superior means to reduce weight without compromising strength. For this reason, vehicle manufacturers may look to carbon fiber to achieve compliance with the NHTSA regulation. ${ }^{20}$ In addition, the rule includes incentives for electric vehicle deployment (EPA and DOT 2012). These incentives may spur additional carbon fiber investment, as carbon fiber is considered useful in electric vehicle manufacturing to attain a longer all-electric driving range (Das et al. 2016).

The NHTSA rule also includes a mid-term review process to confirm or revise the standards associated with model years 2022 to 2025 (NHTSA 2016). This process began in June 2016 and could influence the fuel economy requirements, which may impact carbon fiber demand for this sector.

\subsubsection{U.S. Department of Defense Procurement}

The U.S. Department of Defense acquisition restriction mandates that if a product contains carbon fiber, the carbon fiber used must be manufactured in the United States or Canada. ${ }^{21}$ This requirement appears to be unique to the United States, which is significant, as the defense sector is a key component of the carbon fiber market; in 2014, the aerospace and defense sector accounted for $\$ 950$ million in carbon fiber sales or about $48 \%$ of total sales (Witten, Kraus, and Kühnel 2015). The U.S. Department of Commerce (2015) identified 15 aircraft, rockets, and missiles purchased by the U.S. government that use carbon fiber, including the F-35 Joint Strike Fighter, the Apache Helicopter, the Trident Missile, and the Atlas Rocket. Overall, the U.S. Department of Commerce report identified 237 products supplied to 181 unique U.S. government programs, which illustrates the significant impact of this sector, at least in the U.S. context.

\footnotetext{
${ }^{20}$ Manufacturers also consider and adopt several other materials for light weighting such as aluminum and highstrength steel.

${ }^{21}$ See "Buy American Act: Restriction on Acquisition of Polyacrylonitrile (PAN) Carbon Fiber" at http://www.acq.osd.mil/dpap/dars/dfars/html/r20050113/252225.htm\#252.225-7022.
} 


\subsection{Japan}

Japan is the second-largest carbon fiber manufacturer, with 25 metric tons of capacity (Witten, Witten, Kraus, and Kühnel 2015). Japan has export licensing requirements that allow multiple exports via one license, which is more flexible than the United States approach. This may influence the significant net export margin for Japanese carbon fiber. Much like the United States has done, Japan has supported significant research and development in the carbon fiber sector while supporting at least some domestic end-use markets such as the automotive sector.

\subsubsection{Trade Policy}

Because carbon fiber is considered a dual-use (military and civilian) product in Japan, export licenses are necessary. Yet, Japan's market has been historically export-focused, ${ }^{22}$ and this focus is supported in part by a simplified application process for bulk export licenses.

With the license, an exporter can make multiple exports of controlled but less-sensitive items to 27 specific countries ${ }^{23}$ for three years (Center for Information on Security Trade Control 2015). Japan's more flexible exporting process may be a significant driver of the country's net carbon fiber exports (Das 2016).

Japan also imposes some import duties on carbon fiber-related materials that range from $0 \%$ to $8 \%$, depending on the product and the country. ${ }^{24}$ For example, imports from World Trade Organization countries outside the EU face a tariff of $6.6 \%$ for acrylic tow (a bundle of untwisted acrylic fibers), which may influence import demand. In comparison, Japan does not apply tariffs to imports of certain carbon fibers and articles of carbon fibers. ${ }^{25}$

Japan has an export import bank (Nippon Export and Investment Insurance) that is a similar to that of the United States (EXIM 2016). In comparison to its Japanese counterpart, the U.S. Export Import Bank Advisory Committee, which is composed of professionals representing export-related interests, considers EXIM far less competitive in tied and untied financing along with domestic content requirements (EXIM 2016). The increase in untied financing ${ }^{26}$ in particular, which is associated with financing outside of the OECD export credits arrangement, has been cited as a significant concern for EXIM and U.S. exporters more generally (EXIM 2016).

\footnotetext{
${ }^{22}$ About $80 \%$ of Japan's domestic production of carbon fiber materials is exported (Japan Carbon Fiber Manufacturers Association 2013).

${ }^{23}$ These countries include Argentina, Australia, Austria, Belgium, Bulgaria, Canada, Czech Republic, Denmark, Finland, France, Germany, Greece, Hungary, Ireland, Italy, South Korea, Luxemburg, Netherlands, New Zealand, Norway, Poland, Portugal, Spain, Sweden, Switzerland, the United Kingdom, and the United States.

${ }^{24}$ See HS Codes 29261000, 392190, 55013000, 5903, and 6815100000 at http://www.customs.go.jp/english/tariff/2016 6/index.htm.

${ }^{25}$ See HS Codes 55013000 and 6815100000 at http://www.customs.go.jp/english/tariff/2016 6/data/e 55.htm and http://www.customs.go.jp/english/tariff/2016 6/data/e 68.htm.

${ }^{26}$ Untied financing refers to financing that does not directly support exports from domestic producers. One example is a "pull loan," where a bank offers unconditional financing for a foreign entity's project, with the agreement that the foreign entity will consider working with domestic producers for future product needs (EXIM 2016).
} 


\subsubsection{Carbon Fiber Manufacturing Support and Development}

Historically, a combination of publically funded research and development, direct grants to industry, and public-private partnerships have helped enable the development of a strong domestic carbon fiber manufacturing industry in Japan. Most recently, a consortium including Toyota and Toray was awarded a grant of four billion yen (\$38 million USD) to research vehicles constructed entirely of carbon fiber (High-Tech Industry in Japan 2013). Several tens of billion yen in continuing support is expected to be allocated to this consortium over the next 5-10 years.

The Japanese government also had a subsidy for "domestic location promotion projects," which was established to promote industry following the earthquake and tsunami of 2011 (Japan Ministry of Economy, Trade, and Industry 2011a). Toray received support from this subsidy to expand production capacity by 1,000 metric tons per year at a plant in Japan. The expansion was part of a larger 2012 announcement that the company is planning a capacity expansion of 6,000 metric tons, with $50 \%$ of the total investment being made in Japan (Toray 2012).

In Japan, corporate structures are dominated by keiretsu, which is a term that describes the business relationship between multiple member companies achieved through interlocking shares (Twomey 2009). There are two types of keiretsu: vertical and horizontal. The horizontal firms often have a bank at the center, while the vertical firms center on a manufacturing industry. The large Japanese manufacturing companies involved in the carbon fiber industry are part of one of the major conglomerates (e.g., Toray is part of Sumitomo Mitsui Bank). Benefits of the system include access to stable financing, insulation from short-term market pressures, and mutual assistance (McGuire 2009). It is possible that this corporate structure has helped Toray capture and retain the position of the largest global carbon fiber manufacturer.

\subsubsection{End-Use Market Support}

\subsubsection{Renewable Energy Targets and Incentives for Wind Energy}

Japan also supports carbon fiber end-use markets, including the wind energy sector. Japan established an RPS program in 2002, which required electric retailers to produce 16 terawatthours (TWh) of renewable energy by 2014. After this target date, Japan replaced its RPS with a feed-in-tariff program that includes land-based and offshore wind energy systems (Japan Ministry of Economy, Trade, and Industry 2011b; IEA 2015). Japan also has significant offshore wind energy potential, and any future policy to promote this resource could further drive carbon fiber markets (Arent et al. 2012).

\subsubsection{Vehicle Emissions Regulations}

Given their stringency, Japanese regulations on vehicle emissions may also drive end-use markets. The Ministry of Economy, Trade, and Industry has the authority to set fuel economy standards in Japan. In 2015, new passenger vehicles were required to achieve an average emissions rate of $139 \mathrm{~g} \mathrm{CO}_{2} / \mathrm{km}$. By 2020, new passenger vehicles must achieve an average rate of $115 \mathrm{~g} \mathrm{CO}_{2} / \mathrm{km}$ (ICCT 2015). These requirements could increase the market for carbon fiber in the automotive sector, given the strength and light weight of the material (McKinsey \& Company 2012). 


\subsection{European Union Countries}

The EU European Commission has regulatory authority over some aspects of member countries, including vehicle emission regulation, while member countries may have their own unique authority over certain trade and research and development priorities. For our purposes here, we highlight some of the key policies driving carbon fiber manufacturing and markets in the region, and we highlight some notable policy from the largest carbon fiber manufacturers in the EU, including France, Germany, Hungary, and the United Kingdom. Collectively, the EU is the third-largest carbon fiber manufacturing capacity globally, with 23.1 metric tons of capacity (Witten, Kraus, and Kühnel 2015).

In general, EU countries have more flexible export licensing requirements than the United States does. In addition, the EU has also supported carbon fiber research and development though perhaps not as significantly as the United States or Japan has. Regardless, the EU and its member countries have been strong end-use market drivers, particularly in terms of offshore wind.

\subsubsection{Trade Policy}

As opposed to being administered by the EU, licenses are issued and controlled by each exporting country's relevant government agency. In general, the European countries' policies regulating carbon fiber exports are less restrictive than those of the United States because licenses may allow exporters to send products to multiple countries and multiple end-users. Additionally, when an exporter's business expands, the business often does not need to file for a new export license if a pre-existing relationship exists.

Hungary, Germany, France, and the United Kingdom (in order of capacity) account for most of the carbon fiber manufacturing in the EU, and each country offers a license that can be used for exporting products globally (U.S. International Trade Commission 2010; GAO 2010; BAFA 2013; Ministere du Redressement Productif 2013). Also, it has been noted that paperwork processing times are shorter in the EU than they are in the United States (and some other countries). For example, in testimony before the U.S. International Trade Commission, Zoltek's Chief Operating Officer, Karen Bomba, described her company's experiences. Zoltek (which was acquired by Toray in 2014) produces carbon fiber in Hungary and the United States, and processing times for an export license average about 7-8 days in Hungary and 35-45 days in the United States (U.S. International Trade Commission 2010). ${ }^{27}$

\footnotetext{
${ }^{27}$ Zoltek (now Toray) also produces acrylic fiber in Mexico. The company acquired a facility there in 2007 (Reuters 2007 ).
} 
Though EU member nations have their own export licensing requirements, tariffs apply on a regional basis. Import tariffs on carbon fiber products range from $0 \%$ to $6.5 \%$, which is a range similar to that of other countries. ${ }^{28}$ An import tariff on acrylonitrile of up to $6.5 \%$ is levied against imports from selected countries, but no specific carbon fiber tariffs are in effect (European Commission 2016c; 2016d).

Each of the countries evaluated in this section have an export import bank similar to that of the United States (EXIM 2016). EXIM is considered less competitive than its counterparts in Germany, France, and the United Kingdom in relation to tied aid and shipping policy. ${ }^{29}$ EXIM is also at a disadvantage when compared to Germany and France in relation to untied aid (EXIM 2016).

\subsubsection{Carbon Fiber Manufacturing Support and Development}

The EU has also supported carbon fiber research and development. Much of this support has historically been carried out via the EU Framework Programme for Research and Innovation (European Commission 2016e). The carbon fiber industry has benefited from this research framework. For example, in the $7^{\text {th }}$ EU Framework Programme, the EU committed $€ 6$ million to the Functionalized Innovative Carbon Fibers Developed from Novel Precursors with Cost Efficiency and Tailored Properties (FIBRALSPEC) project, which focuses on improving the function and reducing the cost of carbon fiber (Materials Today 2016; Fibralspec 2016). The project will also attempt to develop new pathways to reuse carbon fiber (Materials Today 2016).

The EU's Horizon 2020 program is the successor to the $7^{\text {th }}$ Framework Programme, with $€ 80$ billion of funding for research projects from 2014 to 2020 (European Commission 2016f). Carbon fiber manufacturers could benefit from a range of funded projects, including the Graphene Flagship effort within the Future and Emerging Technologies section that could open new markets and drive down production costs (European Commission 2016f). The Graphene Flagship project in particular is focused on commercializing graphene, a type of carbon fiber, within ten years (Graphene Flagship 2016).

The individual member countries of the EU also conduct research related to carbon fiber. For example, Germany's Federal Ministry of Education and Research Leading-Edge Cluster program supports carbon fiber projects, including the Carbon Fiber with Enhanced Elongation project (Sherman 2015; Sloan 2015c). ${ }^{30}$

\footnotetext{
${ }^{28}$ The duty for acrylonitrile imported from a third country is $6.5 \%$, though this tariff is $0 \%$ for most direct imports. See tariff codes 292610, 392190, 550130, 5903, and 68151010 at http://ec.europa.eu/taxation_customs/dds2/taric/taric consultation.jsp?Lang=en.

${ }^{29}$ Though the EXIM Bank Advisory Committee documents that Hungary has two banks similar to EXIM, the committee does not directly compare EXIM's competitiveness to these entities in its report (EXIM 2016).

${ }^{30}$ Germany's Federal Ministry of Education and Research has also supported the work of MAI Carbon Cluster Management $\mathrm{GmbH}$ to drive down the cost of carbon fiber production 90\% (Beck 2014).
} 


\subsubsection{End-Use Market Support}

\subsubsection{Renewable Energy Targets and Incentives for Wind Energy}

EU support of the wind energy sector serves as the largest driver for offshore wind energy and carbon fiber end-use applications in the wind energy sector globally. The EU's 2009 Renewable Energy Directive sets a 2020 target of a $20 \%$ share of energy coming from renewable sources such as wind energy. ${ }^{31}$ This directive is unlike U.S. RPS programs in that it encompasses not just electricity but also heating and cooling, and transportation (European Commission 2015). To achieve the 20\%-by-2020 target, specific targets are set for member states.

Collectively, EU member states are expected to procure $34 \%$ of all electricity generation from renewable sources by 2020 . In 2014, they procured $26 \%$ of their electricity generation from renewables. Wind energy production has seen the largest generation increase since the adoption of this directive (European Commission 2015). Offshore wind in particular, for which carbon fiber is best suited, has seen significant market expansion in Europe, including over three gigawatts (GW) of expansion in 2015 alone (EWEA 2016).

EU member states also offer incentives specific to the renewables sector (U.S. International Trade Commission 2013). For example, Germany instituted a series of feed-in-tariffs for renewable energy sources in 2011 and 2012 (Norton Rose Fulbright 2013). And, Germany is now transitioning to design reverse auctions to continue to incentivize renewable energy development (Morris 2015).

\subsubsection{Vehicle Emissions Regulations}

The EU also sets mandatory emission reduction targets for new cars that have also served to drive the deployment of carbon fiber in the automotive sector. The EU set the most recent targets for 2015 and 2021 (European Commission 2016g). The 2015 target requires cars built in 2015 to emit no more than $130 \mathrm{~g} \mathrm{CO}_{2} / \mathrm{km}$. All new vehicles in 2021 must emit no more than $95 \mathrm{~g} \mathrm{CO}_{2} / \mathrm{km}$, which is $40 \%$ below 2007 fleet emission levels. The EU has the authority to continue to set these regulations beyond 2021 if they deem regulation appropriate (European Commission 2016g).

\subsection{China}

China is the fourth-largest global producer of carbon fiber, with 12.8 metric tons of capacity (Witten, Kraus, and Kühnel 2015). China has some of the most flexible export licensing requirements and the most protective tariff policies to support domestic carbon fiber production. Also, China has announced a strong commitment to increasing its carbon fiber market share. In addition, China has the greatest offshore wind energy deployment goal-10 GW by 2020-of any country reviewed in this report (Chen 2016). This along with their vehicle emission standards could significantly impact carbon fiber end-use markets.

\footnotetext{
${ }^{31}$ See Directive 2009/28/EC of the European Parliament and of the Council of 23 April 2009 on the Promotion of the Use of Energy from Renewable Sources, which Amended and Subsequently Repealed Directives 2001/77/EC and 2003/30/EC (Text with EEA Relevance) , which is available at http://eur-lex.europa.eu/legalcontent/EN/AUTO/?uri=CELEX:02009L0028-20151005\&qid=1464702064176.
} 


\subsubsection{Trade Policy}

Carbon fiber is considered a dual-use (military and civilian) product in China and export licenses are required. China's Category A Export General License allows a registered exporter to export items to one or several end-users in one or several countries. The license is valid for three years; however, to be eligible, an exporter must have applied for at least 40 licenses in the past two years and been engaged in the export of dual-use items for at least two years (Xie and Ma 2011). Import duties on carbon fiber products range from $3 \%$ to $17.5 \%$. ${ }^{32}$ For example, China applies a $3 \%$ tariff on acrylonitrile and $15 \%-17.5 \%$ on imports of carbon fiber products, depending on the use (WTO 2014a; 2014b).

Both China's Export Import Bank and Sinosure offer financing for domestic exporters (EXIM 2016). Unlike the countries discussed in Sections 3.1-3.3, China is neither a member of OECD nor a signatory on the OECD export credits arrangement. China has made significant investments outside those regulated via the OECD export credits arrangement, and these banks are considered more competitive than EXIM across 10 of the 11 categories reviewed (EXIM 2016).

\subsubsection{Carbon Fiber Manufacturing Product Support and Development}

In November 2013, China's Ministry of Industry and Information Technology developed a threeyear action plan to accelerate the development of a domestic carbon fiber manufacturing industry (China Securities Journal 2013). To accomplish its goals of a more concentrated and competitive industry, the ministry plans to use policy measures to boost technology innovation, promote industrial restructuring, and enhance carbon fiber adoption in downstream industries.

Since issuing the plan, an integrated industrial chain from precursors to end product was built within Jilin City, which is also known as "China's Carbon Valley" (Jilin Daily 2013). In addition, the Chinese Academy of Sciences and its partners produced its first carbon fiber composite yacht, fulfilling a commitment under their action plan (Shanghai Advanced Research Institute 2014). In 2015, China published its $13^{\text {th }}$ five-year plan, which specifically emphasizes carbon fiber via the Made in China Initiative (PwC 2015). This initiative includes specific goals for promoting carbon fiber production from 2016 to 2020 (China Daily 2016).

\subsubsection{End-Use Market Support}

\subsubsection{Renewable Energy Targets and Incentives for Wind Energy}

China's renewable energy policies have supported both land-based and offshore wind deployment, which can indirectly support the carbon fiber industry. China's 2005 Renewable Energy Law established the Renewable Energy Development Fund, which offers subsidies for renewable energy, including wind (Ministry of Commerce, People's Republic of China 2013). In particular, this fund supports the wind energy feed-in-tariff (Yang 2015).

Also in China's most recent five-year plan, the government included a goal to reduce carbon pollution associated with electricity production (PwC 2015). In particular, China plans to invest

\footnotetext{
${ }^{32}$ See tariff codes 292610, 392190, 550130, 5903, and 681510 at http://tariffdata.wto.org/ReportersAndProducts.aspx.
} 
6.6 trillion USD in a range of clean energy technologies, including wind (PwC 2015). China has also set a wind capacity expansion goal of $20 \mathrm{GW}$ in 2016, which is in line with the country's commitment to generate 200 GW of wind by 2020 (Liu 2016; Bloomberg News 2015). It has also established a goal of installing $10 \mathrm{GW}$ of offshore wind by 2020 . The country has struggled to achieve interim targets related to this offshore wind commitment. Nevertheless, through 2015 it had installed $1 \mathrm{GW}$ of capacity (Chen 2016). If China were to achieve its renewable priorities and in particular its offshore wind goal, it could further drive carbon fiber deployment.

\subsubsection{Vehicle Emissions Regulations}

China also sets mandatory fuel economy standards for passenger vehicles, which may support carbon fiber deployment in the automotive sector. China has set these standards since 2004, and the most recent targets were established in 2014 for vehicles manufactured from 2016 to 2020 (UNEP 2015). By 2020, vehicles are expected to achieve a target of about $117 \mathrm{~g} \mathrm{CO}_{2} / \mathrm{km}$ (ICCT 2014). As is the case in the United States, these standards include incentives for alternative fuel vehicles such as fuel cell and all electric vehicles (UNEP 2015). The quantity of electric vehicles deployed in China to meet these standards could further influence carbon fiber markets, given the value of this material in increasing all-electric driving ranges.

\subsection{Taiwan}

Taiwan is the fifth-largest carbon fiber producer globally, with 8.8 metric tons of capacity (Witten, Kraus, and Kühnel 2015). It offers a three-year export control license that is similar to China's. And, it has high import tariffs for certain carbon fiber products. Taiwan also has promoted the development of domestic carbon fiber manufacturing and technology development, as exemplified by its development of carbon fiber bike frames (Jan and Chen 2006). Furthermore, Taiwan has implemented policies to drive end-use markets especially offshore wind.

\subsubsection{Trade Policy}

Taiwan requires an export license for carbon fiber goods, owing to its dual-use nature. Its Internal Control Program designation allows a three-year license to be issued, and it applies to multiple countries, buyers, and end users (Taiwan Bureau of Foreign Trade 2012).

Taiwan imposes an import tariff of $0 \%-15 \%$, depending on the carbon fiber product. ${ }^{33}$ For example, Taiwan charges $0 \%-10 \%$ on acrylic tow ${ }^{34}$ and $0 \%-15 \%$ on carbon fiber materials and products. ${ }^{35}$ Any carbon fiber imports from the United States are subject to a $10 \%$ tariff. ${ }^{36}$ Taiwan's Export-Import Bank of the Republic of China serves a similar function to that of EXIM, but EXIM (2016) does not review its competitiveness in relation to this bank. Taiwan is also not

\footnotetext{
${ }^{33}$ See tariff codes 29261000, 392190, 55013000, 5903, and 68151000 at http://portal.sw.nat.gov.tw/PPL/RedirectorNonLoginAction?appld=APGQ\&privilegeld=GC451.

${ }^{34}$ Taiwan Customs Administration Tariff Database. See Chapter 55, "Man-made Staple Fibres." http://portal.sw.nat.gov.tw/PPL/RedirectorNonLoginAction?appld=APGQ\&privilegeld=GC451.

${ }^{35}$ Taiwan Customs Administration Tariff Database. See Chapter 68, "Non-electrical Articles of Graphite or Other Carbon." http://portal.sw.nat.gov.tw/PPL/RedirectorNonLoginAction?appld=APGQ\&privilegeld=GC451.

36 Ibid.
} 
a member of the OECD and does not participate in the OECD export credits arrangement (EXIM 2016).

\subsubsection{Carbon Fiber Manufacturing Support and Development}

The government of Taiwan provides direct support to the carbon fiber industry through sponsored research and development, public-private partnerships, and direct industry support. Taiwan's Industrial Technology Research Center, a government-sponsored enterprise, is the largest applied technology research and development institute in Taiwan (Medders 2011). It develops technologies through research and development projects and then transfers the technologies to industrial firms through licensing or sale of intellectual property rights (or through a spin-off company). Most research and development is taken on by the research center, as firms are usually too small to support research budgets, and some commercial products manufactured in Taiwan today (e.g., bike frames) were supported by the research center (Jan and Chen 2006). In 2010, the government also announced the Carbon Fiber Development Stability Plan and the Taiwan Carbon Fiber Composite Materials Research and Development Alliance to further drive carbon fiber research (Tsai 2010).

\subsubsection{End-Use Market Support}

\subsubsection{Renewable Energy Targets and Incentives for Wind Energy}

Taiwan has also taken steps to support land-based and offshore wind energy deployment that could increase carbon fiber deployment. Taiwan's Renewable Energy Development Act mandates renewable energy deployment, and the Bureau of Energy has developed specific targets for expansion of both land-based and offshore wind capacity among other technologies (Ministry of Economic Affairs 2013). ${ }^{37}$ Taiwan intends to expand wind energy production via the Thousand Wind Turbines program, with the goal of installing 450 land-based and 800 offshore wind turbines by 2030 (Ministry of Economic Affairs 2015). The act also establishes a feed-intariff program and a renewable energy development fund to subsidize projects and research. In 2015, Taiwan increased the target for offshore wind from 3,000 megawatts (MW) to 4,000 MW by 2030. Taiwan expects to begin adding offshore wind turbines to achieve these goals in 2020 (Ministry of Economic Affairs 2015).

\subsubsection{Vehicle Emissions Regulations}

Taiwan regulates vehicle fuel economy by class of vehicle engine. ${ }^{38}$ The Ministry of Economic Affairs implements these standards, and the most recent standards were finalized in 2014. The ministry plans to establish new standards in 2017 (Liang 2014). Taiwan does not have a significant domestic vehicle manufacturing industry (OICA n.d.). ${ }^{39}$

\footnotetext{
${ }^{37}$ See the language of the Renewable Energy Development Act at http://www.taiwanembassy.org/ ct.asp?xltem $=370137 \&$ ctNode $=2237 \& m p=1$.

${ }^{38}$ See the language of Fuel Economy Standards and Regulations at http://law.moj.gov.tw/eng/LawClass/ LawAll.aspx?PCode=J0130009.

${ }^{39}$ The other 8 countries are all in the top 13 vehicle manufacturers globally, while Taiwan ranks $28^{\text {th }}$ (OICA n.d.).
} 


\subsection{Mexico}

Mexico is the sixth-largest producer of carbon fiber, with 7.6 metric tons of capacity (Reinforcedplastics 2014). It issues one-year export licenses as the United States does, though with the option to renew for an additional year. In contrast to many of the other countries in this report, Mexico does not have a slate of policies that directly support the carbon fiber industry, although policies do exist to support end-use markets. This may be explained in part by the fact that most of the carbon fiber capacity in Mexico is located at one large facility, which may have located in the region because of its proximity to the U.S. market. Going forward, this proximity may spur additional investment in Mexico, but it is not clear that Mexico will implement policy to further support carbon fiber manufacturing.

\subsubsection{Trade Policy}

In 2011, Mexico established an export control system for dual-use items, including carbon fiber. ${ }^{40}$ The Directorate General of Foreign Trade within the Secretariat of Economy issues export licenses for the duration of one year, but they can be extended for an additional year if the contract does not change. Mexico applies $0 \%-10 \%$ tariffs on certain carbon fiber products. ${ }^{41}$ Imports of carbon fiber products are subject to $0 \%$ tariffs, while certain imported impregnated textile fabrics are subject to a $10 \%$ tariff. $^{42}$ Mexico's Banco Nacional de Comercio Exterior offers export import bank services, and the country is not a member of OECD or a signatory of the OECD export credits arrangement (EXIM 2016). EXIM also does not evaluate its competitiveness in relation to this bank (EXIM 2016).

\subsubsection{Carbon Fiber Manufacturing Support and Development}

Mexico represents somewhat of an anomaly in the major carbon fiber manufacturing nations, given we identified only one program that directly supported carbon fiber manufacturing or research and development. Mexico supports the Helicópteros y Vehículos Aéreos Nacionales project to develop graphene, which is 200 times stronger than steel for use in defense aerospace applications (ProMexico 2015). This is a part of a larger effort to increase aerospace-related manufacturing in Mexico (ProMexico 2015).

The general lack of policy-but significant carbon fiber capacity-in Mexico may be explainable by two factors: (1) most of the carbon fiber production in Mexico is associated with one manufacturing facility and (2) this plant may benefit from its proximity to the significant carbon fiber market in the United States. In 2007, Zoltek (now owned by Toray) purchased and retooled a textile acrylic fiber manufacturer in Guadalajara, Jalisco, Mexico to produce acrylic precursor for carbon fiber production to meet North American demand (Reuters 2007). In 2015, Zoltek began expanding the facility to double capacity to 5,000 tons per year (Zoltek Corporation 2015). The facility is expected to meet increasing demand for carbon fiber from the

\footnotetext{
${ }^{40}$ See http://dof.gob.mx/nota detalle.php?codigo=5196224\&fecha=16/06/2011.

${ }^{41}$ See Mexico Tariff Schedules 29261001, 550130, 5903, 392190, and 6815 at

http://tariffdata.wto.org/ReportersAndProducts.aspx.

${ }^{42}$ See Mexico Tariff Schedules 6815 and 5903 at http://tariffdata.wto.org/ReportersAndProducts.aspx.
} 
wind and automotive industries, and specifically the Mexican automobile industry (Zoltek Corporation 2015).

\subsubsection{End-Use Market Support}

\subsubsection{Renewable Energy Targets and Incentives for Wind Energy}

In 2012, Mexico enacted the General Law on Climate Change, which established a goal of reducing nationwide emissions 50\% from 2000 emissions by $2050 .{ }^{43}$ In 2015, Mexico adopted the Energy Transition Law in an effort to achieve this target. ${ }^{44}$ The law stipulates that electric service providers and large companies must procure $25 \%$ of generation from clean energy sources by $2018,30 \%$ by 2021, and $35 \%$ by 2024 (Pickrell 2015). Before adopting this law, Mexico outlined a wind plan to install $9.5 \mathrm{GW}$ of wind capacity by 2018 (McGovern 2015). Thus, wind will likely feature significantly in achieving these clean energy targets. Though Mexico has over 1,200 GW of offshore wind potential (Arent et al. 2012), it does not have a policy directed specifically at offshore wind deployment. Electricity providers could invest in offshore wind to achieve compliance with the Energy Transition Law, and if this investment were to materialize, it would drive carbon fiber deployment.

\subsubsection{Vehicle Emissions Regulations}

In 2013, Mexico became the first Latin American country to adopt mandatory fuel economy standards for light-duty vehicles (ICCT 2013). The standards regulate the emissions from model year 2014-2016 vehicles, requiring manufacturers to achieve a fleet average fuel economy of $14.6 \mathrm{~km} / \mathrm{L}$ in 2016 (ICCT 2013). This program's requirements through 2016 are substantially similar to those of the United States (Maxwell 2015). In 2015, Mexico adopted new public vehicle fleet efficiency requirements (El Financiero 2015), but it has not established new lightduty vehicle fuel economy standards. If Mexico were to adopt subsequent fuel economy standards, it could support additional carbon fiber adoption.

\subsection{South Korea}

With 7.5 metric tons of carbon fiber manufacturing capacity, South Korea is the eighth-largest global producer. It allows multiple exports via one comprehensive license, and it notably does not impose carbon fiber tariffs, at least for imports from the United States. South Korea also promotes research and development via the "carbon fiber valley" approach employed by China and Taiwan. In general, South Korea has less offshore wind energy potential, so the country's renewable energy goals may not support significant carbon fiber deployment. However, the stringency of the nation's vehicle emission standards may promote significant carbon fiber deployment in the automotive sector.

\footnotetext{
${ }^{43}$ See the language of the General Law on Climate Change at

https://www.iea.org/media/workshops/2015/15thghgtradingworkshop/GeneralClimateChangeLaw_Englishversion.pdf.

${ }^{44}$ See the language of the law in Spanish at http://www.diputados.gob.mx/LeyesBiblio/pdf/LTE.pdf.
} 


\subsubsection{Trade Policy}

South Korea requires material deemed "strategic items" to receive an export license. ${ }^{45}$ This includes dual-use items, such as carbon fiber. ${ }^{46}$ These licensing requirements are managed by the Minister of Trade, Industry, and Energy and its Yestrade export license system (Lee 2013). Certain companies can apply for and receive comprehensive export licenses without meeting the requirement to procure individual export licenses (Lee 2013).

South Korea applies tariffs of $0 \%-13 \%$, based on the product and the country from which it is imported. ${ }^{47}$ For example, South Korea imposes $0 \%-13 \%$ on acrylic tow, depending on the country from which it is imported. Imports of acrylic tow from the United States and the EU have a $0 \%$ tariff. $^{48}$ South Korea also imposes a tariff of $0 \%-8 \%$ on carbon fiber. United States imports of these products are also subject to a $0 \%$ tariff. $^{49}$

The Export-Import Bank of Korea supports domestic exports in South Korea, and the country both is a member of the OECD and complies with the OECD arrangement (EXIM 2016). Despite participating in the OECD export credits arrangement, about half of all of South Korea's transactions are associated with unregulated financing (EXIM 2016). Overall, EXIM is considered less competitive than its Korean counterpart across 6 of the 11 metrics analyzed, including a designation as far less competitive when it comes to untied financing (EXIM 2016).

\subsubsection{Carbon Fiber Manufacturing Support and Development}

In a similar vein to what China and Taiwan have done, South Korea has designated Jeonju city and Jeonbuk Province "Carbon Valley," which has served as the hub for carbon fiber production and research (Yang 2013). The Institute of Machinery and Carbon Composites and the Institute of Advanced Composite Materials are focused on carbon composite research in this region (Yang 2013).

In 2014, South Korea partnered with Hyosung to develop a carbon fiber manufacturing hub to significantly increase domestic carbon fiber production and exports (Materials Today 2014). As a part of this partnership, Hyosung will expand annual production at one facility from 2,000 to 14,000 metric tons by 2020 . Within this factory, the provincial government will establish a center for small companies and start-ups to generate new carbon fiber products and markets.

\footnotetext{
${ }^{45}$ See Foreign Trade Law Chapter 3, "Export and Import" at http://www.import.or.kr/viewContents.do;jsessionid =1830a3fa6ba3\$03\$1Bz\$̧?action=view\&subid=4\&fPageNum=14\&mnld=law01.

${ }^{46}$ See the language of the Strategic Materials Import \& Export Notice at http://www.law.go.kr/admRulLsInfoP.do?chrClsCd=010202\&admRulSeq=2000000023976.

${ }^{47}$ See South Korea Tariff Schedules 29261001, 550130, 5903, 392190, and 6815 at http://tariffdata.wto.org/ReportersAndProducts.aspx. Also see: HS Code: 5501301000 acrylic tariff schedule at http://www.customs.go.kr/kcshome/tariff/CustomsTariffView.do and 6815102000 carbon fiber tariff schedule at http://www.customs.go.kr/kcshome/tariff/CustomsTariffView.do.

${ }^{48}$ See HS Code: 5501301000 acrylic tariff schedule at http://www.customs.go.kr/kcshome/tariff/CustomsTariffView.do.

${ }^{49}$ See both HS Code: 6815102000 carbon fiber tariff schedule at http://www.customs.go.kr/kcshome/tariff/CustomsTariffView.do and 6815102000 carbon fiber tariff schedule at http://www.customs.go.kr/kcshome/tariff/CustomsTariffView.do
} 
These entities can receive funding from the government via the C'incubation or "thinkubation" fund, and they can also receive Carbon Valley matching funds (Materials Today 2014).

\subsubsection{End-Use Market Support}

\subsubsection{Renewable Energy Targets and Incentives for Wind Energy}

In 2009, South Korea published its national strategy to achieve green growth through 2050 (Presidential Commission on Green Growth n.d.). This plan calls for doubling renewable energy production from about $3 \%$ in 2009 to $6 \%$ in 2020 . The plan also calls for increased research and development in green technologies and boosting manufacturing and exports of such technologies (Presidential Commission on Green Growth n.d.).

As required in its green growth plan, South Korea established a national RPS in 2013 (Bana 2013). The RPS requires the 13 largest utilities in the country to procure $10 \%$ of their electricity generation from renewable sources by 2022; the program also offers a feed-in-tariff for renewable energy production. At the outset of the program, much of the increased renewable investment focused on solar photovoltaics.

South Korea has lower offshore wind energy potential (about 2,000 TWh per year) than many of the other countries surveyed for this report (Arent et al. 2012). If utilities in the country were to leverage this offshore wind resource to achieve renewable energy requirements, it could promote the use of carbon fiber.

\subsubsection{Vehicle Emissions Regulations}

South Korea also regulates fuel economy from motor vehicles with their most recent targets, which are in effect from 2016 to $2020 .{ }^{50}$ South Korea requires passenger vehicles under 3,500 $\mathrm{kg}$ to achieve an average emission target of $97 \mathrm{~g} \mathrm{CO}_{2} / \mathrm{km}$ by $2020 .^{51}$ This reflects one of the most stringent emission requirements of all the countries considered, and it may encourage significant carbon fiber deployment in vehicles.

\section{Menu of Policy Options to Support Carbon Fiber}

It is clear that a variety of factors influence manufacturers' decisions to locate in certain jurisdictions and that policy can impact these decisions while also shaping carbon fiber markets. However, it is outside the scope of this report to identify policies or sets of policies that will result in higher carbon fiber manufacturing capacity or broader end-use markets. Nevertheless, policymakers interested in expanding carbon fiber manufacturing could benefit from an understanding of the different policy approaches that have been used to achieve these goals. To that end, this report documents the range of policies that have been used or proposed to expand carbon fiber manufacturing or manufacturing more broadly. This section divides these

\footnotetext{
${ }^{50}$ See the notice of automotive average energy efficiency standards, GHG emission standards, and criteria applied and management at http://www.law.go.kr/admRulLsInfoP.do?admRulSeq=2100000009634.

${ }^{51}$ Ibid.
} 
policies into the following categories: attracting carbon fiber manufacturing, reforming trade policy, supporting research and development, and promoting end-use markets.

Because of data collection constraints, tracking all the policies adopted or proposed to achieve these goals across all ten economies was not possible. This is especially true for policies relating to attracting carbon fiber manufacturing. As a result, this section focuses on policies adopted or proposed in the U.S. context as a means to build the policy menu. Many of these policies have also been adopted in other locations, and this section includes these examples when they are available. For the other policy options, this report offers a more global perspective.

\subsection{Attracting Carbon Fiber Manufacturing}

In the United States-where governing powers are divided among the federal, state, and local governments - the subnational governments have the most control over incentivizing certain manufacturing development within their jurisdictions. ${ }^{52}$ These governments have established policies to attract carbon fiber manufacturing and build new market opportunities through workforce development programs, financial incentives, and strategic clustering initiatives. This section discusses each of these focus areas in turn.

\subsubsection{Workforce Development}

Ensuring a state's workforce is equipped with the knowledge and skills to complete the tasks associated with the state's economic drivers is important for fueling economic development. State governments have been somewhat active in enacting education and workforce policies to promote clean energy and carbon fiber manufacturing in particular.

According to the Center for New Energy Economy, from 2013 to 2015, 17 U.S. state legislatures enacted 24 policies related to education and workforce development in the advanced energy space (CNEE 2013; Hoffer et al. 2014; Hoffer et al. 2016a). ${ }^{53}$ Much of this legislation develops a range of incentives, programs, or grants for certain workforce development activities such as Arkansas' SB 368, which was enacted in $2015 .^{54}$

Washington state's Job Skills Program was created via legislation in 1983 (Workforce Training and Education Coordinating Board 2016), and the state leveraged this program to administer grants for workforce training to support the initial development of SGL Automotive Carbon Fiber's facility in Moses Lake, Washington, along with its expansion in 2014 (Gates 2014; Good Jobs First 2015a). The SGL Group noted the important role that Big Bend Community College played in helping the company secure qualified local talent to run the facility (The Odessa Record 2011). Similarly, Cytec Industries also highlighted state workforce training programs and

\footnotetext{
52 The federal government can support state and local governments' activities through research and development, policy decisions, and international trade agreements. These levers of influence are discussed in more detail later in this section.

53 The Center for New Energy Economy defines advanced energy (which includes renewable, nuclear, and natural gas fuels) at http://www.aeltracker.org/p/about.

${ }^{54}$ For the language of this bill, see http://www.arkleg.state.ar.us/assembly/2015/2015R/Bills/SB368.pdf.
} 
local technical colleges as a justification for expanding its facility in Greenville, South Carolina (Borie 2007).

The valuable role that local entities can play in supporting workforce development and carbon fiber manufacturing is not unique to these cases. For example, Roane State Community College in Harriman, Tennessee, offers courses in carbon fiber composite materials hosted at ORNL's Carbon Fiber Technology Facility (Roane State Community College n.d.). Outside of community colleges, local governments can also play a role in workforce development. For example, the American Job Center provides workforce development programs that are both employee- and employer-focused across three counties in Colorado (Jefferson County n.d.).

Despite these examples, 34 of the 98 carbon fiber industry respondents in the U.S. Department of Commerce (2015) survey highlighted difficulty in hiring trained engineers, scientists, and research and development staff with practical experience in the field. ${ }^{55}$ To address this need, state and local governments could consider supporting carbon fiber-related education and training programs to encourage carbon fiber manufacturers to site facilities in their area. The federal government can also support these and other clean energy workforce development programs via grant funding to states and localities. ${ }^{56}$

\subsubsection{Financial Incentives}

To encourage certain industries to locate in their states-and thereby support economic development goals-many state governments offer manufacturers tax credits and financial incentive packages. Biggins Lacy Shapiro \& Company track state economic incentive policies directed at incentivizing new manufacturing along with relocation (BLS \& Company 2016). These incentives can help close the gap potentially caused by labor cost and currency differences, thereby aiding in the justification for locating in a certain jurisdiction. The quantity of available incentives by state, as documented by BLS \& Company is displayed in Figure 14.

\footnotetext{
${ }^{55}$ A total of 98 organizations responded to the survey including carbon fiber producers, distributors, weavers, prepreggers, composite product manufacturers, and other carbon fiber-related businesses (U.S. Department of Commerce, 2015, p. 8)

${ }^{56}$ For example, the U.S. Department of Labor's TechHire Grant competition program provides support for innovative approaches to help lower-skilled workers receive training for higher skilled jobs in the advanced manufacturing sector. For more information, see https://www.dol.gov/general/grants/funding-ops.
} 


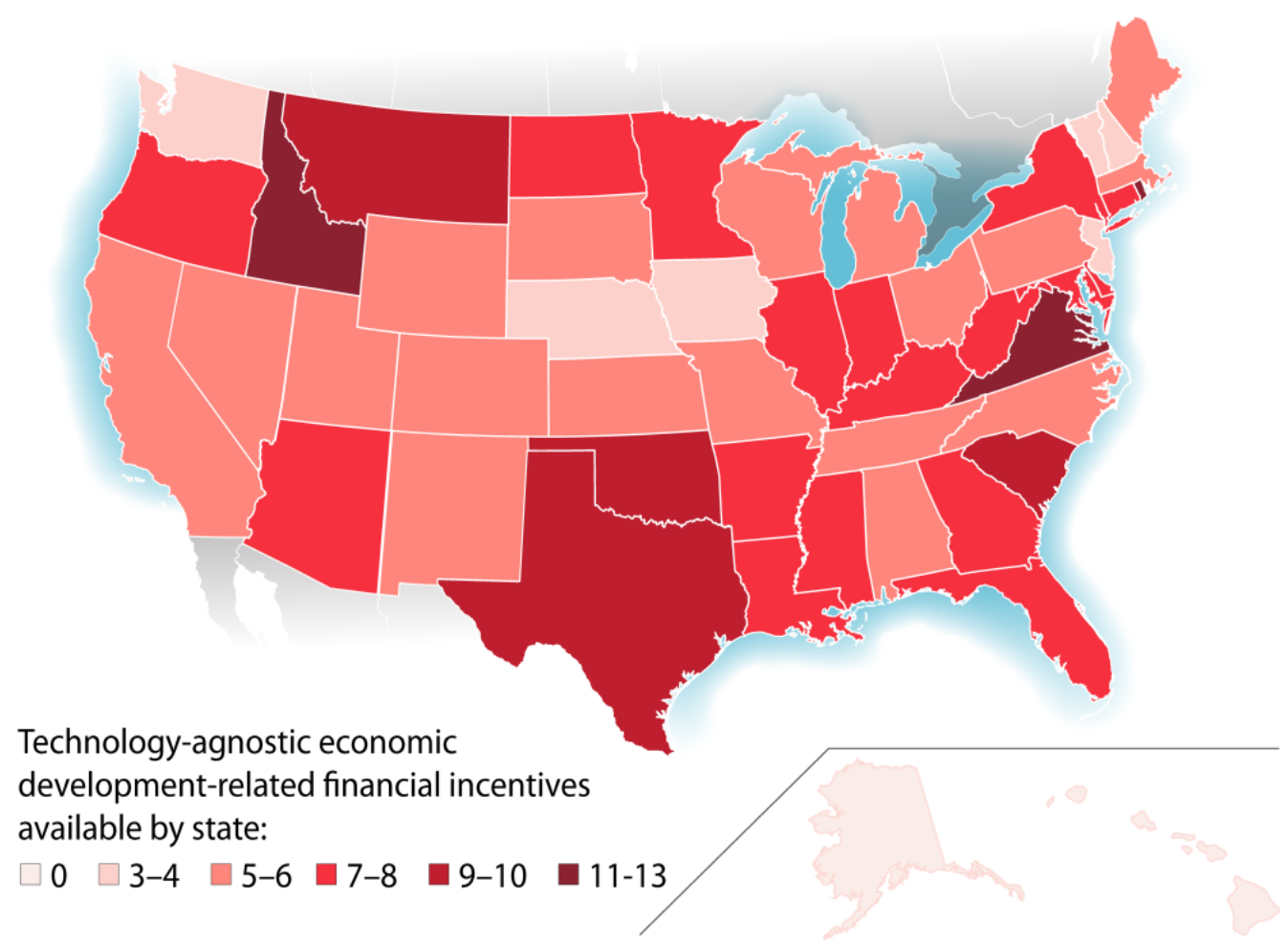

Figure 14. Number of economic development incentives available to manufacturers in each state Source: Cook 2017

As Figure 14 illustrates, Idaho, Rhode Island, Virginia, Montana, Oklahoma, South Carolina, and Texas lead the U.S. states in terms of the total number of incentives available to promote economic development. South Carolina leveraged one of these incentive programs to encourage Toray to locate its newest carbon fiber manufacturing facility in Moore, South Carolina (Good Jobs First 2015b). Similarly, in 2012, Zoltek (now owned by Toray) leveraged a $\$ 3.3$ million economic development package to expand its carbon fiber facility in St. Peters, Missouri, adding 155 new jobs in the process (Office of Missouri Governor Jay Nixon 2012).

Some states offer specific incentives for clean energy-related manufacturing to locate in their states. The Database of State Incentives for Renewables and Efficiency (DSIRE) tracks these incentives across 19 states, as illustrated in Figure 15 (DSIRE n.d.). States interested in encouraging carbon fiber manufacturing in their states could consider adding carbon fiber manufacturing to these incentive programs, or they could prioritize carbon fiber projects when distributing these or other economic development incentives. 


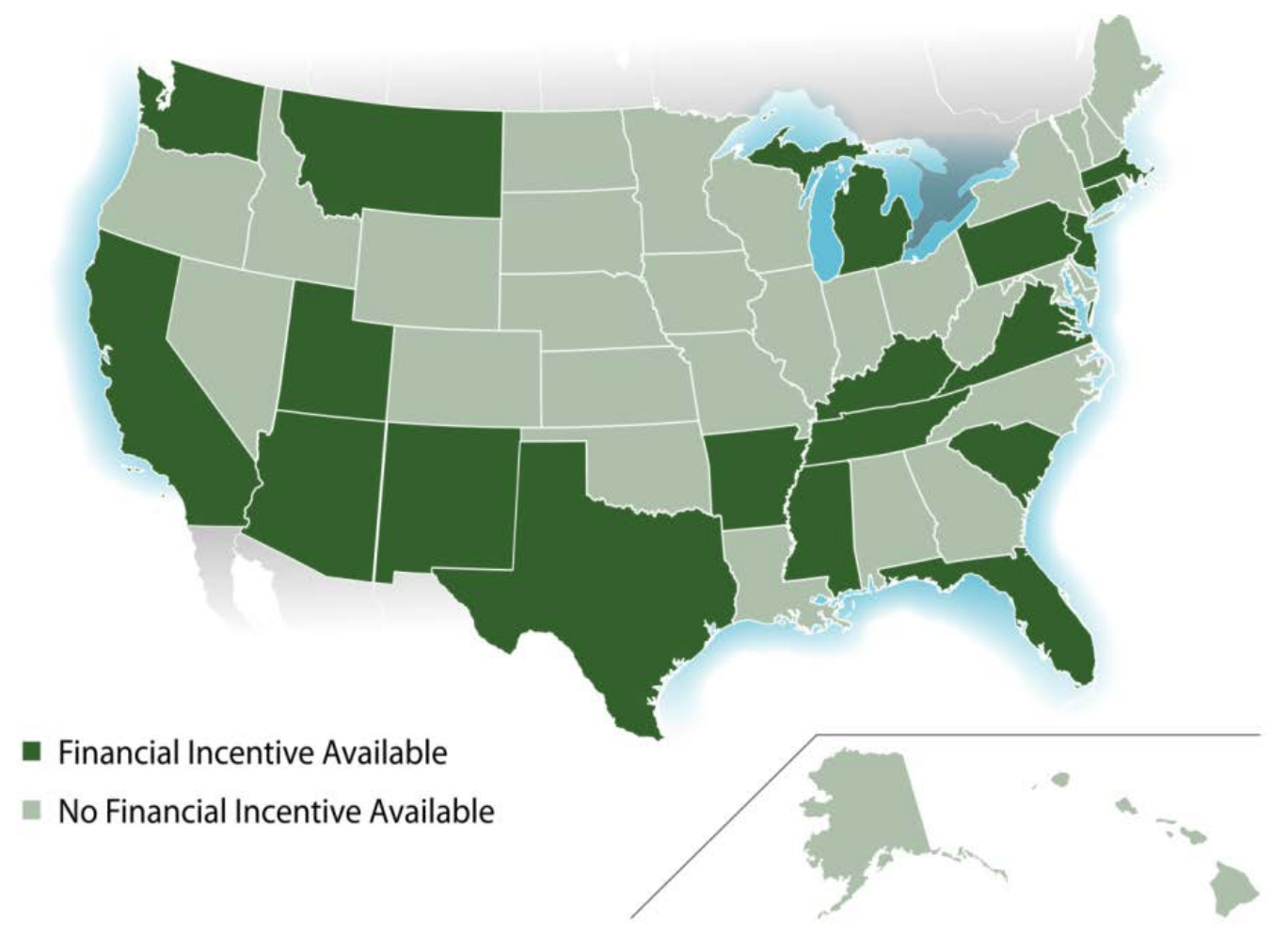

Figure 15. States with at least one financial incentive directed toward clean energyrelated manufacturing

Source: Cook 2017

Local governments can also play a role in offering financial incentives to lure manufacturers to locate in their jurisdictions. Local incentives have also influenced the decisions of carbon fiber manufacturers Zoltek, Toho Tenax, and SGL Group to site facilities in St. Peters, Missouri (Korando 2011), Rockwood, Tennessee (The Roane Alliance 2007), and Moses Lake, Washington (The Odessa Record 2011), respectively. In the case of Zoltek, St. Peters, Missouri, authorized \$20 million in industrial revenue bonds to finance the project and offered a Chapter 100 tax abatement indexed to job expansion (Korando 2011).

\subsubsection{Co-Location and Clustering}

Though financial incentives may have encouraged carbon fiber manufacturers to locate in certain jurisdictions, manufacturers have noted the importance of also locating near end users. For example, Toray located in Moore, South Carolina, in part because it was near its end user, a Boeing plant in North Charleston, South Carolina (GoUpstate 2016). Zoltek also noted the valuable location of St. Peters, Missouri, in serving the growing wind industry in the midsection of the United States (Korando 2011). This type of co-location is valuable given the reduction in transportation and other logistical costs.

Because of these advantages, some communities have attempted to position themselves as technology manufacturing hubs. The idea of a manufacturing hub can be derived from the 
clustering concept of economic development whereby a collection of similar industries are colocated (Delgado, Porter, and Stern 2014). Silicon Valley is one of the most commonly cited examples of such a cluster that encourages strong economic growth, and it and other clusters have been empirically demonstrated to generate higher employment and innovation (Delgado, Porter, and Stern 2014).

Spartanburg County, within which the new Toray plant is under construction and South Carolina more generally, position themselves in this way (South Carolina Department of Commerce 2014). In addition, Reno, Nevada, and neighboring communities rebranded the region as a technology hub and succeeded in signing a deal with Tesla for its much-heralded Gigafactory (Respaut 2015). The state of Nevada also conducted a logistics analysis and argued Tesla could save $\$ 300$ million over 20 years if it located in Nevada rather than elsewhere (Nevada Governor's Office of Economic Development 2015). It is also important to note that this particular deal included an unprecedented amount of financial incentives from the state of Nevada that totaled about $\$ 1.3$ billion (Damon 2014).

Developing similar carbon fiber manufacturing clusters or technology hubs may spur innovation to reduce carbon fiber production costs while potentially generating new opportunities for carbon fiber composites. Carbon fiber hubs are already operating in some locations, including China and South Korea (Jilin Daily 2013; Yang 2013). And, some U.S. states and localities are considering this option. For example, policymakers in Washington state have voiced support for establishing a cluster around the Moses Lake facility (Gates 2014). In addition, some localities on the East Coast are vying to serve as a hub for offshore wind turbine blade manufacturing, as they anticipate an increase in offshore wind deployment (Bandyk 2016). Such communities could serve valuable co-location benefits for the carbon fiber industry in driving down costs as they relate to this end-use market and potentially others.

Co-locating clusters near existing electric power, aerospace, and transportation hubs may produce additional co-benefits as they relate to wind turbine blade, aerospace, and automotive carbon fiber adoption and innovation. ${ }^{57}$ This type of co-location may be advantageous in the wind energy sector. And, it may be particularly advantageous in the offshore wind subsector because manufacturing of long carbon fiber wind blades is more cost effective when it occurs nearer offshore wind turbine installations due to the logistical challenges of transporting longer blades (Das et al. 2016).

\subsubsection{Fostering Private-to-Private Partnerships}

Developing clusters may also support private-to-private partnerships that can serve to increase carbon fiber adoption and reduce costs. One of the more successful examples of this type of collaborative effort is BMW's joint venture with SGL to supply carbon fiber for its " $\mathrm{i}$ " model vehicles. And, when BMW acquired an 18\% stake in SGL (Das et al. 2016), it took an ownership stake in their supplier to help control their production needs for their "i" model vehicles.

\footnotetext{
${ }^{57}$ The Harvard Business School in partnership with the U.S. Department of Commerce and the U.S. Economic Development Administration tracks existing industry clusters. See http://clustermapping.us/.
} 
Another example of a private-to-private partnership is Toray's acquisition of a $20 \%$ stake in Plasan Carbon Composites that grants Toray greater access to the U.S. automobile market and provides Plasan with greater access to Toray's technology. In the aerospace sector, companies typically negotiate long-term contractual supply agreements. Toray and Boeing, Toray and Airbus, Hexcel and Boeing, and Cytec and Airbus have all signed such agreements. However, the presence of similar partnerships is still informal in the wind energy sector (Das et al. 2016).

Outside these direct ownership and contractual agreement structures, some in the automotive industry have developed research and development partnerships. These are common across domestic automobile manufacturers and carbon fiber manufacturers, including Chrysler, Ford, and General Motors (Das et al. 2016). Of all these automobile partnerships, the Ford partnership with DowAksa, which is supported by DOE, is most developed (Ford 2015).

State and local governments could serve as facilitators for such partnerships by convening workshops, seminars, and conferences to engender broader discussion and collaboration between these industries, especially those governments in regional proximity. West Virginia has held energy summits every year since 2007, and these could serve as a framework that states could adopt or refashion to discuss carbon fiber issues and technologies (West Virginia Department of Commerce n.d.; Cook 2017).

\subsection{Reforming Trade Policy}

As already noted, export licensing, import tariffs, and export financing support can influence carbon fiber manufacturers' positions in the global marketplace. In this context, industry experts surveyed offered some perspective regarding possible policy considerations for improving the position of U.S.-based manufacturers (Das et al. 2016; U.S. Department of Commerce 2015). These survey results suggest policymakers could consider developing more flexible export licensing requirements, loosening certain tariffs, and addressing EXIM bank disadvantages to better position domestic producers in global markets. Though the surveys were tailored to the U.S. context given our findings in Section 3, policymakers across a variety of jurisdictions could consider policy changes relating to trade policy to achieve similar results.

\subsubsection{Export Licensing}

Given the estimated excess carbon fiber manufacturing capacity in North America $(+7,747$ metric tons in 2012), manufacturers in the United States may be more well positioned to export carbon fiber going forward than their counterparts in Europe (Das et al. 2016). However, North American manufacturers are likely to face competition from Asia, which also has significant estimated excess capacity ( $+11,307$ metric tons in 2012) (Das et al. 2016). Changes in export license policy could influence whether manufacturers from certain locations capture estimated demand growth.

Export licenses for domestic U.S. manufacturers appear to be the most restrictive among the leading economies producing carbon fiber products. For example, the United States is the only country (among those surveyed) that does not have a version of a multiple export license. It is unclear whether this is by design or a transition from an early defense-focused industry 
in the United States resulted in export licensing protocols that are more restrictive and have since persisted.

Regardless of the rational for these requirements, several respondents to the U.S. Department of Commerce (2015) survey said these requirements negatively impacted their ability to compete, given higher administrative costs, long lead times, and lost sales. Given these conclusions, policymakers could consider revising licensing requirements as one way to encourage domestic carbon fiber manufacturing. ${ }^{58}$ In comparison, about $35 \%$ of the 98 survey respondents suggested that government support to reveal global export opportunities and help with export licensing issues could also increase exports (U.S. Department of Commerce 2015). Thus, policymakers could consider offering more guidance on licensing requirements-rather than changing requirements - to help domestic manufacturers compete.

\subsubsection{Tariff Policies}

In addition to export requirements, tariff policy impacts carbon fiber manufacturing. In the U.S. context, about $10 \%$ of survey respondents in Das et al. 2016 suggested that the U.S. industry is subject to a potential disadvantage because of its import tariff. At 7.5\%, the U.S. import tariffs on acrylic fiber is one of the highest worldwide. Policymakers could consider reducing or eliminating this import tariff, which could potentially increase exports from some carbon fiber manufacturers in the United States. ${ }^{59}$ This is not the only pathway to mitigate the impact of this tariff. Some carbon fiber manufacturers, including Toray, Cytec, and Hexcel have addressed this issue by producing acrylic precursor in the United States (Das et al. 2016). This production is not subject to the import tariff, and emphasizing co-location or clustering may mitigate the issue. Finally, other manufacturers that do not produce precursor domestically could apply for foreign trade zone status to reduce or eliminate tariff requirements relating to their precursor purchases. As noted in Section 3, this process can take time, so policymakers could consider options to streamline this procedure.

\subsubsection{Export Import Bank Policy}

Export import banks are a common policy tool across the economies evaluated in this report. Thus, policy considerations related to the U.S. market may more easily travel to other jurisdictions. The lapse in the U.S. EXIM authority in 2015 along with the lack of a quorum on the EXIM Board of Directors has made it impossible for the body to approve large-scale financing projects (i.e., those over $\$ 10$ million) (EXIM 2016). ${ }^{60}$ At the same time, other economies have become more aggressive in financing increased exports, particularly through unregulated and untied financing (EXIM 2016). The authority for EXIM was extended through 2019 (EXIM 2016), but gaining a quorum on the Board of Directors may improve the

\footnotetext{
${ }^{58}$ However, policymakers will have to balance these priorities with those of national security, particularly given recent attempts to steal weapons-grade carbon fiber (U.S. Department of Justice 2012; U.S. Immigration and Customs Enforcement 2013; U.S. Department of Justice 2016).

${ }^{59}$ This tariff may be supported by the domestic textile industry, which may influence policymakers.

${ }^{60}$ Senator Richard Shelby has used his authority as Chairman of the Senate Banking Committee to block nomination of a third member of the board to meet quorum requirements (Calmes 2016).
} 
competitiveness of EXIM, which could in turn encourage domestic manufacturing exports. In addition, addressing untied financing differences between a domestic bank and its counterparts could reduce comparative advantages of available financing packages for competing manufacturers across jurisdictions.

\subsection{Supporting Research and Development}

As already noted, defense-related research and development spurred the initial carbon fiber market. Industry representatives suggest that continued government research and development investment in new manufacturing processes, carbon fiber composite materials, and carbon fiber recycling could yield positive benefits for reducing the cost of existing carbon fiber products and generating new markets going forward. For example, about $35 \%$ of survey respondents argued that government-supported research and development is necessary to drive innovation, because of high research and development investment costs (U.S. Department of Commerce 2015). One recent example of government-funded innovation in this space is a new technology developed by ORNL to produce carbon fiber from heavy tow textile acrylic fiber (ORNL 2016b). This new process has the potential to reduce manufacturing costs by $50 \%$, and it is now available for license (ORNL $2016 \mathrm{~b}$ ).

Industry experts also suggest that research relating to carbon fiber composite materials is important because parts designed for the aerospace, wind energy, and automotive sectors can be more profitable for developers than the carbon fiber material alone because significantly more value is added in the final product (Das et al. 2016). These higher-value products can also require more sophisticated labor, which might result in more local jobs and higher wages. About half of the 32 respondents in the Das et al. (2016) survey asserted that the United States is well positioned to succeed in this space relative to the other large market players.

Finally, carbon fiber recycling is one emerging area in which research could prove valuable in reusing carbon fiber and its associated waste products. The Composite Recycling Technology Center in the state of Washington broke ground in 2015 with the mission to develop new products from scrap carbon fiber composite prepreg (Lauzon 2015). Given examples such as this one, additional research into carbon fiber product development may increase the attractiveness of certain locations as manufacturing hubs and end-use markets.

\subsection{Promoting End-use Market Demand}

Though industry experts anticipate increased demand for carbon fiber in the wind energy and automotive industries in the near term, policymakers can take action to encourage or drive this expansion by fostering larger markets for carbon fiber composites in each of these sectors.

\subsubsection{Wind Sector}

The increased efficiencies associated with taller wind towers and longer blades have promoted the use of carbon fiber in the wind industry. As turbines increase in size, carbon fiber content is likely to increase, given its light weight, durability, and strength. Thus, as wind capacity increases, carbon fiber demand may increase. Wind capacity has been historically driven by renewable energy procurement requirements along with the attractive tax and financing 
incentives offered to the wind energy sector. For example, eight of the top carbon fiber manufacturing economies have renewable energy mandates (though these are at the subnational level in the United States). The remaining two locations (Japan and China) also have renewable energy incentives such as feed-in-tariff programs. Subsequent policy activity to increase renewable procurement goals or extend financial incentives may encourage wind energy deployment and thereby drive carbon fiber demand.

Given that offshore wind turbines are significantly larger than land-based applications, to ensure an economic return on investment, the application of carbon fiber is most common in this subsector. Each of the top carbon fiber manufacturers has technical offshore wind energy generation potential and six (the EU economies, China, and Taiwan) have adopted offshore wind procurement targets. Further policy to promote offshore wind development, or research to reduce technology costs, could increase carbon fiber markets.

\subsubsection{Transportation Sector}

Fuel economy standards globally have incentivized vehicle manufacturers to reduce the weight of their vehicles and introduce new alternative fuel vehicles (e.g., electric vehicles) to achieve compliance with the laws. Because carbon fiber is lighter than aluminum and steel, it can serve vehicle manufacturers' fuel economy goals without sacrificing strength or stiffness. International efforts to increase these standards would likely increase the potential market for carbon fiber in the automotive sector.

In addition, some fuel economy standards such as those in the United States and China incentivize the adoption of electric vehicles and the lightweight nature of carbon fiber is critical for attaining a longer all-electric driving range (Das et al. 2016). If other locations adopt similar electric vehicle incentives, carbon fiber demand could increase. Policymakers could also consider adopting zero emission vehicle standards like those that have emerged in the United States. Eight states largely along the West Coast and in the Northeast have committed to deploying 3.3 million electric and hydrogen fuel cell vehicles by 2025 (Multi-state ZEV Task Force n.d.). ${ }^{61}$ If this type of program were adopted within a national context, it could also support carbon fiber manufacturing.

\footnotetext{
${ }^{61}$ In line with this commitment, the state of California instituted its Low Carbon Fuel Standard, which requires transportation fuel providers to reduce the carbon intensity of their fuel $10 \%$ by 2020 (CARB 2016). The California Air Resources Board manages the program and offers fuel providers the option to purchase credits from alternative fuel providers and users that emit less than the targets, which includes users of electric vehicles (CARB 2016).
} 


\section{Conclusions}

The carbon fiber market is expected to increase through 2024 and to require additional capacity to meet demand. The United States, Japan, and other economies have historically been both hubs for carbon fiber manufacturing and drivers of demand. Increasingly, new competitors such as China and Russia have emerged that are focused on capturing a larger share of the carbon fiber market.

Our analysis of the top-10 carbon fiber manufacturing locations in terms of manufacturing siting considerations offers key insights regarding factors manufacturers may consider when siting new facilities and locations compare. For example, in 2014 the United States offered some of the lowest electricity and natural gas costs, which is advantageous, given the energy-intensive nature of the process.

Favorable policies adopted by governments that directly or indirectly support carbon fiber manufacturing can also influence siting considerations and carbon fiber end-use markets in each country. For example, China and South Korea have established specific carbon fiber "valleys" to serve as innovation clusters for carbon fiber research, which may support the development of new markets. And, all the economies we analyzed have adopted vehicle emission standards that could expand existing carbon fiber deployment in the automotive sector. Going forward, policymakers may wish to consider a range of options to capture future carbon fiber manufacturing and expand markets for existing manufacturers.

To attract future carbon fiber manufacturing facilities, policymakers could consider (1) developing workforce development programs that address the needs of the carbon fiber industry, (2) devising financial incentives to encourage carbon fiber manufacturers to locate in specific regions, and (3) promoting clustering and co-locating carbon fiber manufacturing with end uses to spur innovation and increase efficiencies.

To promote development of carbon fiber manufacturing, policymakers could also consider (1) reforming export license requirements, (2) building awareness regarding existing license requirements, (3) reducing or eliminating acrylic tow precursor tariffs, and (4) expanding government support for research and development.

To spur carbon fiber end-use market demand, policymakers could consider (1) developing offshore wind procurement requirements, (2) supporting research to drive down offshore wind costs, (3) increasing vehicle emission standards to further promote light-weighting, and (4) adopting zeroemissions vehicle requirements.

To be clear, these are just some options focused on specific policies and factors that could influence carbon fiber manufacturing. Other policy options that would increase carbon fiber deployment especially in aerospace and pressure vessel applications likely exist. In addition, this research does not evaluate the direct role or effect that certain policies have had on driving manufacturing investments and end-use market expansion. Ultimately, this report can serve as a foundation to build a more comprehensive analysis of the opportunities for carbon fiber market expansion and the role that policy can play to achieve manufacturing goals. 


\section{References}

ACS (American Chemical Society). 2003. High Performance Carbon

Fibers. http://www.acs.org/content/acs/en/education/whatischemistry/landmarks/carbonfiber s.html.

Alabama Department of Commerce. 2015. Alabama Aims to Expand Role in Aerospace Supply Chain. http://www.madeinalabama.com/2015/06/alabama-aims-expand-role-aerospacesupply-chain/.

Altair. 2016. Fiber Reinforced Composites. http://altairenlighten.com/in-depth/fiber-reinforcedcomposites/.

Arent, Douglas, Patrick Sullivan, Donna Heimiller, Anthony Lopez, Kelly Eurek, Jake Badger, Hans Ejsing Jorgensen, Mark Kelly, Leon Clarke, and Patrick Lucklow. 2012. Improved Offshore Wind Resource Assessment in Global Climate Stabilization Models. Golden, CO: National Renewable Energy Laboratory. NREL/TP-6A20-55049. http://www.nrel.gov/docs/fy13osti/55049.pdf.

AWEA (American Wind Energy Association). 2016. Big Brands and other Emerging Customers Signed for More than Half of New Wind Power Capacity Contracted in

2015. http://www.awea.org/MediaCenter/pressrelease. aspx?ltem Number=8711.

BAFA (Bundesamt fur Wirtschaft und Ausfuhrkontrolle). 2013. Brief Outline on Export Controls Licensing Requirements, Application Procedure, Information

Sources. https://www.sipri.org/sites/default/files/Germany-BAFAexport control brief outline.pdf.

Bana, Sarosh. 2013. "Factfile: RPS Framework Drives South Korean Market." Renewable Energy Focus. http://www.renewableenergyfocus.com/view/31556/factfile-rps-framework-drivessouth-korean-market/.

Bandyk, Matthew. 2016. "US Offshore Wind Industry Looks to Build Foundations." SNL News.

Barbose, G. 2016. U.S. Renewables Portfolio Standards 2016 Annual Status Report. Lawrence Berkeley National Laboratory. Berkeley, CA. LBNL-1005057. https://emp.lbl.gov/sites/all/files/ lbnl-1005057.pdf.

Beck, Mary. 2014. "Carbon Fiber Prices Could Drop by as much as 90 Percent." Composites Manufacturing. http://compositesmanufacturingmagazine.com/2014/10/carbon-fiber-pricesdrop-much-90-percent/.

Bernstein, Jared, and Dean Baker. 2015. "The Strong Dollar is Hurting U.S. Manufacturing. There's a Lesson in There for the TPP." The Washington

Post. https://www.washingtonpost.com/posteverything/wp/2015/05/11/the-strong-dollar-ishurting-u-s-manufacturing-theres-a-lesson-in-there-for-the-tpp/. 
BLS (Bureau of Labor Statistics). 2016. "NAICS 335991 Carbon and Graphite Product Manufacturing." Quarterly Census of Employment and

Wages. http://www.bls.gov/cew/datatoc.htm.

BLS \& Company (Biggins Lacy Shapiro \& Company). 2016. "State Economic Development Incentives." Knowledge Center. http://www.blsstrategies.com/content.asp?id=120.

Bloomberg News. 2015. "China's Climate Goal Calls for Aggressive Push on Solar, Wind." Bloomberg News. http://www.bloomberg.com/news/articles/2015-07-01/china-s-climate-goal-calls-foraggressive-push-on-solar-wind.

BNEF (Bloomberg New Energy Finance). 2015. Average Annual Power Price Data.

Borie, Kara. 2007. Cytec Announces Expansion in Greenville. http://www.greenvilleeconomicdevelopment.com/mydocuments/Cytec Press Rele ase.pdf.

Brice, Craig A. 2011. Unintended Consequences: How Qualification Constrains Innovation. Hampton, VA: National Aeronautics and Space Administration Langley Research Center. http://ntrs.nasa.gov/archive/nasa/casi.ntrs.nasa.gov/20110013659.pdf

---. 2015. IACMI Overview. http://iacmi.org/wp-content/uploads/2015/11/IACMI-OverviewNov-2015-Website.pptx.

Bureau of Foreign Trade, Taiwan Ministry of Economic Affairs. 2012. Regulations Governing Export and Import of Strategic High-Tech

Commodities. http://www.trade.gov.tw/english/Pages/Detail.aspx?nodelD=298\&pid=417204\&d I DateRange=all\&txt SD=\&txt ED=\&txt Keyword=\&Pageid=0.

CARB (California Air Resources Board). 2016. "LCFS Basics." Last reviewed May 10, 2016. http://www.arb.ca.gov/fuels/lcfs/background/basics.htm.

Calmes, Jackie. (2016). "A Single Senator Stymies the Export-Import Bank." The New York Times. http://www.nytimes.com/2016/06/28/business/international/a-single-senator-stymiesthe-export-import-bank.html.

Cama, Timothy. 2015. "South Korea Launches Carbon Cap-and-Trade System."

TheHill. http://thehill.com/policy/energy-environment/229168-south-korea-launches-carboncap-and-trade-system.

Center for Information on Security Trade Control. 2015. Overview of Japan's Export Controls (Fourth Edition). http://cistec.or.jp/english/export/Overview4th.pdf.

Chen, Kathy. 2016. "China's Offshore Wind Power Plans Lag, 2020 Target under Threat." Reuters. http://www.reuters.com/article/china-wind-power-idUSL8N19F1NN.

Chapin, Erin. 2015. "UT-Led IACMI Formally Launches at Inaugural Meeting in Knoxville." Tennessee Today. http://tntoday.utk.edu/2015/06/17/utled-iacmi-formally-launches-inaugural-meetingknoxville/. 
China Daily. 2016. "Support to Made in China 2025 to Unveil." China

Daily. http://www.chinadaily.com.cn/regional/bda/2016-01/04/content 22924815.htm.

China Securities Journal. 2013. "MIIT Unveils Plan to Promote Development of Carbon Fiber Industry." China Securities

Journal. http://www.cs.com.cn/english/ei/201311/t20131112 4204162.html

Cho, Meeyoung. 2015. "South Korea to Cut 2030 Greenhouse Gas Emissions by 37 Percent from BAU Levels." Reuters. http://www.reuters.com/article/us-climatechange-southkoreaidUSKCNOPA04N20150630.

CNEE (Center for the New Energy Economy). 2013. 2013 Year in Review: State Advanced Energy Legislation. http://www.aeltracker.org/graphics/uploads/CNEE-2013-Year-in-Review-StateAdvanced-Energy-Legislation December-2013.pdf.

CompositesWorld. 2016. "Supply and Demand: Advanced Fibers (2016)."

CompositesWorld. http://www.compositesworld.com/articles/supply-and-demand-advancedfibers-2016.

Cook, Jeffrey J. 2017. Clean Energy-Related Economic Development Policy across the States: Establishing a 2016 Baseline. Golden, CO: National Renewable Energy Laboratory. NREL/TP-6A2067656. http://www.nrel.gov/docs/fy17osti/67656.pdf.

Damon, Anjeanette. 2014. “Inside Nevada’s \$1.25 Billion Tesla Tax Deal." Reno GazetteJournal. http://www.rgj.com/story/news/2014/09/04/nevada-strikes-billion-tax-break-dealtesla/15096777/.

Das, Sujit. 2016. "Carbon Fiber." In 2015 Research Highlights. Golden, CO: National Renewable Energy Laboratory. NREL/BR-6A50-65312, ORNL/SR-

2016/98. http://www.nrel.gov/docs/fy16osti/65312.pdf.

- - . 2011. "Life Cycle Assessment of Carbon Fiber-Reinforced Polymer Composites."

The International Journal of Life Cycle Assessment. 16:268-

282. http://link.springer.com/article/10.1007/s11367-011-0264-z.

Das, Sujit, Josh Warren, Devin West, and Susan M. Schexnayder. 2016. Global Carbon Fiber

Composites Supply Chain Competitiveness Analysis. Golden, CO: National Renewable Energy

Laboratory. ORNL/SR-2016/100, NREL/TP-6A50-

66071. http://www.nrel.gov/docs/fy16osti/66071.pdf.

DECC (Department of Energy and Climate Change). 2016. "Industrial Electricity Prices in the IEA (QEP

5.3.1). https://www.gov.uk/government/uploads/system/uploads/attachment data/file/55603 5/table 531.xls.

Delgado, Mercedes, Michael E. Porter, and Scott Stern. 2014. "Clusters, Convergence, and Economic Performance." Research Policy 43(10):1785-

1799. http://www.sciencedirect.com/science/article/pii/S0048733314001048. 
DSIRE (Database of State Incentives for Renewables and Efficiency). n.d. "Find Policies \& Incentives by State." http://www.dsireusa.org/.

EIA (U.S. Energy Information Administration). 2015. Annual Energy Outlook 2015 with Projections to 2040. http://www.eia.gov/forecasts/aeo/pdf/0383(2015).pdf.

-- - 2016. Table 5.3. Average Price of Electricity to Ultimate Customers: Total by End-Use Sector, 2006 - March 2016 (Cents per

Kilowatthour). http://www.eia.gov/electricity/monthly/xls/table 5 03.xlsx.

El Financiero. 2015. "Sener Issued Guidelines for Energy Efficiency." EI

Fiannciero. http://www.elfinanciero.com.mx/economia/sener-emite-lineamientos-de-

eficiencia-energetica.html.

Elmquist, Sonja. 2015. "Strong Dollar Hurting U.S. Steel Mills as Imports Flood Market."

Bloomberg. http://www.bloomberg.com/news/articles/2015-03-25/strong-dollar-hurting-u-s-

steel-mills-as-imports-flood-market.

Enerdata. 2014. Implications of the Gas Price Increase in

India. http://www.enerdata.net/enerdatauk/press-and-publication/energy-news-001/gas-

prices-increase-india-implications 30493.html.

EPA (U.S. Environmental Protection Agency). 2015. Air Pollutant Report. https://echo.epa.gov/airpollutant-report?fid=110007232752.

- - . 2016a. "NAAQS Table." Last updated July 5, 2016. https://www.epa.gov/criteria-airpollutants/naaqs-table.

-- - 2016b. “Cytec Carbon Fibers LLC." https://ghgdata.epa.gov/ghgp/service/facilityDetail/ 2014? id=1011456\&ds=E\&et=undefined\&popup=true.

-——. 2016c. "Hexcel Corporation." https://ghgdata.epa.gov/ghgp/service/facilityDetail/ 2014? $\mathrm{id}=1003385 \&$ ds=E\&et=undefined \&popup=true.

EPA and DOT (U.S. Department of Transportation). 2012. "2017 and Later Model Year Light-Duty Vehicle Greenhouse Gas Emissions and Corporate Average Fuel Economy." Federal Register 77(199): 62624-63200. http://www.nhtsa.gov/staticfiles/rulemaking/pdf/cafe/201725 CAFE Final Rule.pdf.

European Agency for Safety and Health at Work. n.d. E-Fact 80: Hazard Identification Checklist: Occupational Safety and Health (OSH) risks in the wind energy sector. https://osha.europa.eu/sites/default/files/publications/documents/E-fact\%2080\%20\%20EN.pdf.

European Commission. 2015. Report from the Commission to the European Parliament, the Council, the European Economic and Social Committee and the Committee of the Regions Renewable Energy Progress Report. http://eur-lex.europa.eu/resource.html

?uri=cellar:4f8722ce-1347-11e5-8817-01aa75ed71a1.0001.02/DOC 1\&format=PDF. 
- - . 2016a. "Air Quality Standards."

Environment. http://ec.europa.eu/environment/air/quality/standards.htm.

- - . 2016b. The EU Emissions Trading System (EU

ETS). http://ec.europa.eu/clima/publications/docs/factsheet ets en.pdf.

- - . 2016c. "TARIC Measure Information. Chapter 29. Organic

Chemicals." http://ec.europa.eu/taxation customs/dds2/taric/measures.jsp?Lang=en\&SimDate =20160907\&Taric=292610\&LangDescr=en.

- - . 2016d. "TARIC Measure Information. Chapter 68. Articles of Stone, Plaster, Cement Asbestos, Mica, or Similar Materials. Non-Electrical Articles of Graphite or Other Carbon - Carbon Fibres and Articles of Carbon

Fibres." http://ec.europa.eu/taxation customs/dds2/taric/measures.jsp?Lang=en\&SimDate=20

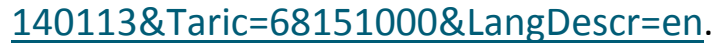

- - . 2016e. "What is Horizon 2020?" Horizon

2020. https://ec.europa.eu/programmes/horizon2020/en/what-horizon-2020.

- - . 2016f. "Future and Emerging Technologies." Horizon

2020. https://ec.europa.eu/programmes/horizon2020/en/h2020-section/future-and-emergingtechnologies.

- - . 2016g. "Reducing CO2 Emissions from Passenger Cars." Climate

Action. http://ec.europa.eu/clima/policies/transport/vehicles/cars/index en.htm.

EWEA (European Wind Energy Association). 2016. The European Offshore Wind Industry: Key Trends and Statistics 2015. http://www.ewea.org/fileadmin/files/library/publications/statistics/ EWEA-European-Offshore-Statistics-2015.pdf.

Executive Office of the President National Science and Technology Council. 2012. A National Strategic Plan for Advanced Manufacturing. Washington D.C.: Executive Office of the President. https://www.whitehouse.gov/sites/default/files/microsites/ostp/iam advancedman ufacturing strategicplan 2012.pdf.

EXIM (Export Import Bank of the United States) (2016). Report to the U.S. Congress on Global Export Credit

Competition. http://www.exim.gov/sites/default/files/reports/2015EXIMCompetitiveReportFIN AL-v3.3.pdf.

- - . n.d. Annual Report 2015. http://www.exim.gov/sites/default/files/reports/annual/EXIM2015-AR.pdf.

Feraboli, Paoli, and Attilio Masini. 2004. Development of Carbon/Epoxy Structural Components for a High Performance Vehicle. Composites Part B: Engineering. (35)4: 323-

330. http://www.sciencedirect.com/science/article/pii/S1359836804000344. 
FERC (Federal Energy Regulatory Commission). 2016. World LNG Estimated Landed

Prices. http://www.ferc.gov/market-oversight/mkt-gas/overview/ngas-ovr-Ing-wld-pr-est.pdf.

Fiberalspec. 2016. Fibralspec Project. http://www.fibralspec.net/project/.

Fleischauer, Eric. 2015. "Hexcel Expansion will add 20 jobs." Decatur

Daily. http://www.decaturdaily.com/news/hexcel-expansion-will-add-jobs/article 19f776fca6a8-11e4-be61-9b5c4b4edac7.html.

Ford. 2015. Ford Accelerates Carbon Fiber Research to Drive Innovation in Manufacturing Technology. https://media.ford.com/content/fordmedia/fna/us/en/news/2015/01/12/fordaccelerates-carbon-fiber-research.html.

Fowler, Bob. 2013. "Tariff, Red Tape May Close Rockwood Plant."

Knoxnews. http://www.knoxnews.com/business/tariff-red-tape-may-close-rockwood-plant-ep358372419-355900721.html.

FTZB (Foreign-Trade Zones Board). 2015. $76^{\text {th }}$ Annual Report of the Foreign-Trade Zones Board to the Congress of the United States. http://enforcement.trade.gov/ftzpage/annualreport/ar2014.pdf.

GAO (U.S. Government Accountability Office). 2010. Export Controls: Observations on Selected Countries' Systems and Proposed Treaties. Washington D.C.: U.S. Government Accountability Office. http://www.gao.gov/new.items/d10557.pdf.

Gardiner, Ginger. 2014. "Recycled Carbon Fiber Update: Closing the CFRP Lifecycle Loop." CompositesWorld. http://www.compositesworld.com/articles/recycled-carbon-fiber-updateclosing-the-cfrp-lifecycle-loop.

Gates, Dominic 2014. "BMW Plans Big Expansion of Moses Lake Carbon-Fiber Plant." The Seattle Times. http://www.seattletimes.com/business/bmw-plans-big-expansion-of-moses-lakecarbon-fiber-plant/.

Georgia Tech. 2016. CAIIAC. http://www.manufacturing.gatech.edu/caiiac-0.

Gitter, Mishter. 2013. "The Carbon Fiber Revolution." Fort Russ. http://www.fortruss.com/2015/03/russia-becoming-major-carbon-fiber.html.

Good Jobs First. 2015a. "SGL Auto. Carbon Fiber." Subsidy

Tracker. http://subsidytracker.goodjobsfirst.org/subsidy-tracker/wa-sgl-auto-carbon-fiber.

Good Jobs First. 2015b. "Toray Carbon Fibers America, Inc." Subsidy

Tracker. http://subsidytracker.goodjobsfirst.org/subsidy-tracker/sc-toray-carbon-fibersamerica-inc.

Goodman, Colby. 2017. Key Questions about the U.S. "Export Control Reform Initiative." Center for International Policy. http://securityassistance.org/fact sheet/key-questions-about-us-exportcontrol-reform-initiative. 
GoUpstate. 2016. "State, Local Leaders Break Ground on \$1.4B Toray Plant in Moore."

GoUpstate. http://www.goupstate.com/article/20160119/ARTICLES/160119651/1083/ARTICLES

?p=all\&tc=pgall.

Graphene Flagship. 2016. About Graphene Flagship. http://graphene-

flagship.eu/project/Pages/About-Graphene-Flagship.aspx.

Hawk, J. 2013. "Russia Becoming a Major Carbon Fiber Manufacturer." Fort Russ. http://www.fortruss.com/2015/03/russia-becoming-major-carbon-fiber.html.

High-Tech Industry in Japan. 2013. "A Government-Subsidized Project to Make a Carbon Fiber Vehicle Practicable in 2020 Starts Soon." High-tech Industry in

Japan. http://hightechindustryinjapan.blogspot.com/2013/06/no-739-government-subsidizedproject-to.html.

Hill, Joshua S. 2016. "Mammoth 50 MW Wind Turbine Blades Could Revolutionize Offshore Wind in US. CleanTechnica. https://cleantechnica.com/2016/01/29/mammoth-50-mw-wind-turbineblades-revolutionise-offshore-wind-us/.

Hoffer, Katherine Heriot, Jeff Cook, Chris Edmonds, Jane Culkin, Alison Smith, Jeff Lyng, Tom Plant, Ian Kelly, and Ben Brunmeier. 2016a. 2015 Year in Review: State Advanced Energy

Legislation. http://www.aeltracker.org/graphics/uploads/2015-Year-in-Review-State-AdvancedEnergy-Legislation.pdf.

Hoffer, Katherine Heriot, Jeffrey J. Cook, J. Culkin, C. Edmonds, J. Lyng, D. Manning, and T. Plant. 2016b. Part 3: Driving Renewable Energy Markets: The Conventional

Approach. http://cnee.colostate.edu/wp-content/uploads/2016/08/Paper-3-

DrivingRenewableEnergyMarkets TheConventionalApproach 8-24-16.pdf.

Hoffer, Katherine Heriot, Jeff Cook, Jeff Lyng, Tom Plant, and Ben Brunmeier. 2014. 2014 Year in Review of State Advanced Energy Legislation. Center for the New Energy

Economy. http://www.aeltracker.org/graphics/uploads/CNEE-2014-Advanced-Energy-

Legislation-End-of-Year-Summary.pdf.

IACMI (Institute for Advanced Composites Manufacturing Innovation). n.d. A. Researcher ProfileM\&P Technology. http://iacmi.org/technology-areas/composite-materials-and-processtechnology-area/researcher-profile-mp-technology/.

- - . n.d. B. Wind Turbines. http://iacmi.org/technology-areas/wind-turbines-applicationcenterl.

ICCT (International Council on Clean Transportation). 2013. Mexico's Light-duty Vehicle $\mathrm{CO}_{2}$ and fuel economy standards. http://www.theicct.org/sites/default/files/publications/ICCTupdate_Mexico_LDVsta ndards july2013.pdf. 
- - . 2014. Light-Duty Vehicle Efficiency

Standards. http://www.theicct.org/sites/default/files/info-tools/pvstds/China PVstdsfacts dec2014.pdf.

- - - 2015. Light-Duty Vehicle Efficiency

Standards. http://www.theicct.org/sites/default/files/info-tools/pvstds/Japan PVstdsfacts jan2015.pdf.

ICCT (International Council on Clean Transportation) and DieselNet. 2013. Mexico: Air Quality Standards. http://transportpolicy.net/index.php?title=Mexico: Air Quality Standards.

IEA (International Energy Administration). 2016. Natural Gas Information 2016

edition. http://www.iea.org/statistics/relateddatabases/naturalgasinformation/.

Industry Experts. 2013. Carbon Fibers and Carbon Fiber Reinforced Plastics (CFRP): A Global Market Overview. Hyderabad: Industry Experts.

IEA (International Energy Administration). 2015. Feed-in Tariff for Electricity Generated from Renewable Energy. http://www.iea.org/policiesandmeasures/pams/japan/name-30660-en.php.

Ikenson, Dan. 2003. Threadbare Excuses: The Textile Industry's Campaign to Preserve Import Restrictions. Cato Institute. http://object.cato.org/sites/cato.org/files/pubs/pdf/tpa-025.pdf.

IRS (U.S. Internal Revenue Service). 2016. Yearly Average Currency Exchange Rates Translating Foreign Currency into U.S. Dollars. https://www.irs.gov/individuals/internationaltaxpayers/yearly-average-currency-exchange-rates.

Jan, Tain-Sue, and Yijen Chen. 2006. "The R\&D System for industrial development in Taiwan. Technology Forecasting and Social Change (73): 559-

574. http://parsproje.com/tarjome/modiriyat/146.pdf.

Japan Carbon Fiber Manufacturers Association. 2013. Activities of the Statistics Working Group. http://www.carbonfiber.gr.jp/english/aboutus/stat/index.html

Japan Ministry of Economy, Trade, and Industry. 2011a. "Projects Adopted for the First Invitation to FY 2011 "Subsidy for Domestic Location Promotion

Projects." http://www.meti.go.jp/english/press/2012/0203 02.html.

- - . 2011b. Feed-in Tariff Scheme for Renewable

Energy. http://www.meti.go.jp/english/policy/energy environment/renewable/pdf/summary20 1109.pdf.

Japan Ministry of the Environment. n.d. Environmental Quality Standards in Japan - Air Quality. https://www.env.go.jp/en/air/aq/aq.html.

Jefferson County. n.d. American Job Center. http://www.jeffco.org/workforce-jcwfc.asp.

Jilin Daily. 2013. "Jilin City Actively Creates “China Carbon Valley." Jilin

Daily. http://english.jl.gov.cn/News/GeneralNews/201311/t20131118 1568278.html. 
Korando, Russell. 2011. "Zoltek to Open Facility in St. Peters." St. Louis Port-

Dispatch. http://www.stltoday.com/suburban-journals/stcharles/news/zoltek-to-open-facilityin-st-peters/article 25a519c8-334e-5cd1-b363-d1aa44c165f3.html.

Kuklinska, Karolina, Lidia Wolska, Jacek Namiesnik. 2015. "Air Quality Policy in the U.S. and the EU: A Review." Atmospheric Pollution Research 6(1):129-

137. http://www.sciencedirect.com/science/article/pii/S1309104215302592.

Kurtovic, A. 2013. "Wind Tax Credit Extension Could Boost St. Louis Companies." St. Louis Business Journal. http://www.edcscc.com/pubs/Wind tax credit extension could boost St Louis com panies January2013.pdf.

Lauzon, Michael. 2015. "New Recycling Center Targets Second Life for Scrap Carbon Fiber." Plastics News. http://www.plasticsnews.com/article/20150925/NEWS/150929931/newrecycling-center-targets-second-life-for-scrap-carbon-fiber.

Lee, Jaewon. 2013. "South Korea's Export Control System."

SIPRI. http://books.sipri.org/files/misc/SIPRIBP1311.pdf.

Liang, Qunicy. 2014. "Taiwan to Promulgate New Vehicle Fuel-Consumption."

CENS. http://www.cens.com/cens/html/en/news/news inner 47267.html.

Liu, Coco. 2016. "Facing Grid Constraints, China Puts a Chill on New Wind Energy Projects." Inside Climate News. https://insideclimatenews.org/news/28032016/china-wind-energyprojects-suspends-clean-energy-climate-change.

Lucintel. 2012, November. Growth Opportunities in the Global Carbon Fiber Market: 2013-2018. Irving, TX.

Mai, Trieu, Wesley Cole, Eric Lantz, Cara Marcy, and Benjamin Sigrin. 2016. Impacts of Federal Tax Credit Extensions on Renewable Deployment and Power Sector Emissions. Golden, CO: National Renewable Energy Laboratory. NREL/TP-6A20-

65571. http://www.nrel.gov/docs/fy16osti/65571.pdf.

Manufacturing \& Technology News. 2010. "Zoltek Corp., Maker of Carbon Fibers, Circumvents U.S. Export Controls by Moving Offshore." Manufacturing \& Technology News

17(12). http://www.manufacturingnews.com/subscribers/users orig.cgi?mfgnews username= mbg\&flag=read article\&id title=1\&id article=4471\&id issue=294\&id sub=459\&id sl.

Manyika, James, Michael Chui, Mehdi Miremadi, Jacques Bughin, Katy George, Paul Willmott, and Martin Dewhurst. 2017. A Future That Works: Automation, Employment, and Productivity. McKinsey Global Institute.

http://www.mckinsey.com/ /media/McKinsey/Global\%20Themes/Digital\%20Disruption/Harnessin g\%20automation\%20for\%20a\%20future\%20that\%20works/MGI-A-future-that-works-Fullreport.ashx. 
Materials Today. 2014. "South Korean Government Invests in Carbon Fiber Hub." Materials Today. http://www.materialstoday.com/composite-industry/news/south-korean-governmentinvests-in-carbon-fiber/.

-- - 2016. "EC to Support Carbon Fiber Project." Materials

Today. http://www.materialstoday.com/carbon-fiber/news/ec-to-support-carbon-fiberproject/.

Matsui, J. 1990. Surface Properties of Carbon Fibre. Critical Reviews in Surface Chemistry 1(2).

Maxwell, Amanda. 2015. “Mexican Energy Ministry Commits to Better Fuel Economy Standards for Government Vehicles.

McGovern Michael. 2015. "Analysis: Mexico Aims to Triple Wind Capacity." Wind Power Monthly http://www.windpowermonthly.com/article/1329854/analysis-mexico-aims-triplewind-capacity.

McGuire, Jean. 2009. “Japanese Keiretsu: Past, Present, Future.” Asia Pacific Journal of Management 26(2):333-351.

McKinsey \& Company. 2012. Lightweight, Heavy Impact: How Carbon Fiber and other Lightweight Materials will Develop across Industries and Specifically in

Automotive. http://www.mckinsey.com/ /media/mckinsey/dotcom/client service/Automotive \%20and\%20Assembly/PDFs/Lightweight heavy impact.ashx.

Medders, Camilla. 2011. Oak Ridge National Lab and Industrial Technology Research Institute Join GRAPES Center. https://news.uark.edu/articles/17427/oak-ridge-national-lab-and-industrialtechnology-research-institute-join-grapes-center.

Ministere du Redressement Productif. 2013. Guide de L'Exportateur De Biens A Double Usage. http://www.dgcis.gouv.fr/files/files/directions services/biens-double-usage/guide.pdf

Ministry of Commerce. 2013. Renewable Energy Law of the People's Republic of China. http://english.mofcom.gov.cn/article/policyrelease/Businessregulations/201312/201312 $\underline{00432160 . s h t m l}$

Ministry of Economic Affairs. 2013. Policy for Promoting Renewable Energy \& Current Status in Taiwan. http://www.mofa.gov.tw/Upload/RelFile/2508/111035/2e9e6ebe-d594-4d46-822b1110f07f8482.pdf.

---. 2015. Renewable Energy Promotion Policies in

Taiwan. http://www.eclareon.com/sites/default/files/5 dr.ho taiwanembassy.pdf.

Morris, Craig. 2015. "German Government Announces New Rules for Solar." Energy

Transition. http://energytransition.de/2015/01/german-government-announces-new-rules-forsolarl.

Multi-state ZEV Task Force. (n.d.). About the ZEV Task Force. http://www.zevstates.us/about-us/. 
Musial, Walt, Donna Heimiller, Philipp Beiter, George Scott, and Caroline Draxl. 2016. 2016 Offshore Wind Energy Resource Assessment for the United States. Golden, CO: National Renewable Energy Laboratory. NREL/TP-5000-66599. http://www.nrel.gov/docs/fy16osti/66599.pdf.

Nevada Governor's Office of Economic Development. 2015. Business Facilities Names Tesla Deal of the Year. http://www.diversifynevada.com/news/news-articles/business-facilities-names-tesladeal-of-the-year.

NHTSA (National Highway Traffic Safety Administration). 2016. CAFE Fuel Economy Standards and Midterm Evaluation for Light-Duty Vehicles, MYs 2022-

2025. http://www.nhtsa.gov/Laws+\&+Regulations/CAFE+-+Fuel+Economy/ld-cafe-midtermevaluation-2022-25.

NIST (National Institute of Standards and Technology). 2016. Funded

Awards. http://nist.gov/amo/amtech/fundedawards.cfm.

Norton Rose Fulbright. 2013. European Renewable Energy Incentive Guide:

Germany. http://www.nortonrosefulbright.com/knowledge/publications/66180/europeanrenewable-energy-incentive-guide-germany.

Office of Missouri Governor Jay Nixon. 2012. Carbon Fiber Manufacturer in St. Peters to Significantly Expand Local Operations, Plans to Create 155 New Jobs, Gov. Nixon

Announces. https://governor.mo.gov/news/archive/carbon-fiber-manufacturer-st-peterssignificantly-expand-local-operations-plans-create.

OICA (International Organization of Motor Vehicle Manufacturers). n.d. 2015

Statistics. http://www.oica.net/category/production-statistics/2015-statistics/.

Organization for Economic Co-operation and Development. 2017. Level of GDP per captia and productivity. http://stats.oecd.org/Index.aspx?DataSetCode=PDB LV.

ORNL (Oakridge National Laboratory). 2016a. "Carbon Fiber Technology Facility." Innovations in Manufacturing. https://www.ornl.gov/sites/default/files/CFTF-factSheet.pdf.

-- - 2016b. ORNL seeking U.S. Manufacturers to License Low-Cost Carbon Fiber

Process. https://www.ornl.gov/news/ornl-seeking-us-manufacturers-license-low-cost-carbonfiber-process.

OSHA (Occupational Safety and Health Administration). n.d. "Section III: Chapter 1 Polymer Matrix Materials: Advanced Composites." OSHA Technical

Manual. https://www.osha.gov/dts/osta/otm/otm iii/otm iii 1.html\#7.

Papaioannou, Michael. 2006. Exchange Rate Risk Measurement and Management: Issues and Approaches for Firms. International Monetary

Fund. https://www.imf.org/external/pubs/ft/wp/2006/wp06255.pdf.

Pickrell Emily. 2015. "Mexico Passes Law Encouraging Renewables Investment." Bloomberg BNA. http://www.bna.com/mexico-passes-law-n57982065128/. 
Presidential Commission on Green Growth. n.d. Road to Our Future: GreenGrowth National Strategy and the Five-Year Plan

(2009 2013). http://www.greengrowthknowledge.org/sites/default/files/downloads/resource/ Road to Our Future GG Republic of Korea.pdf.

ProMexico. 2015. National Flight Plan Mexico's Aerospace Industry Road Map

2015. https://www.promexico.gob.mx/documentos/mapas-de-ruta/plan-nacional-vuelo.pdf.

PwC. 2015. Prosperity for the Masses by

2020. http://www.pwccn.com/webmedia/doc/635835257136032309 prosperity masses 2020 .pdf.

Red, Chris, and Peter Zimm. 2012. "2012 Global Market for Carbon Fiber Composites: Maintaining Competitiveness in the Evolving Materials Market." CompositesWorld Carbon Fiber 2012

Conference, La Jolla, CA, December 4-6.

Reinforcedplastics. 2014. Global Carbon Fibre Market Remains on Upward

Trend. http://www.materialstoday.com/download/79669/.

Respaut, Robin. 2015. "Reno has become a Tech Hub, and the Rest of the City is Struggling to Catch Up." Business Insider. http://www.businessinsider.com/r-can-reno-handle-the-challenges-of-itseconomic-successes-2015-2.

Reuters. 2007. "Zoltek Makes Strategic Acquisition in Mexico; Co to Invest \$100 Million." Reuters. http://www.reuters.com/article/idUSIN20071003161557ZOLT20071003.

Roane State Community College. n.d. "Composites Manufacturing." Mathematics and Sciences Division. https://www.roanestate.edu/?8201-Composites-Manufacturing.

Russell, Clyde. 2014. “China Walks Tightrope over Natural Gas Prices, Supply: Russell. Reuters. http://www.reuters.com/article/us-column-russell-china-gasidUSKBNOGL18R20140821.

Sandia National Laboratories. n.d. “Materials, Reliability, \& Standards. Energy \& Climate. http://energy.sandia.gov/energy/renewable-energy/wind-power/materials-reliabilitystandards/.

Schlossberg, Tatiana. 2016. "America's First Offshore Wind Farm Spins to Life." The New York Times. https://www.nytimes.com/2016/12/14/science/wind-power-block-island.html? $\quad \mathrm{r}=0$.

Sherman, Lilli Manolis. 2015. "Development of New Type of Carbon Fiber for Thermoplastics Gets Funding. Plastics Technology. http://www.ptonline.com/blog/post/development-of-new-type-ofcarbon-fiber-for-thermoplastics-gets-funding.

Sirkin, Harold L., Michael Zinser, and Justin R. Rose. 2014. The Shifting Economics of Global Manufacturing How Cost Competitiveness is Changing Worldwide. https://www.bcgperspectives.com/Images/The Shifting Economics of Global Ma nufacturing Aug 2014.pdf. 
Shanghai Advanced Research Institute. 2014. China's First Carbon Fiber Composite Materials Yacht Made a Successful Trial

Voyage. http://english.sari.cas.cn/re/rp/201404/t20140428 120200.html.

Sloan, Jeff. 2015a."For Carbon Fiber, the Future Certainly Looks Bright."

CompositesWorld. http://www.compositesworld.com/blog/post/for-carbon-fiber-the-futurecertainly-looks-bright

- - - 2015b. "Toray Extends Boeing Carbon Fiber Contract, Will Build New Carbon Fiber Plant." CompositesWorld. http://www.compositesworld.com/news/toray-extends-boeing-carbon-fibercontract-will-build-new-carbon-fiber-plant.

- - . 2015c. "SGL Group Wins Funds for Thermoplastics Composites Development." CompositesWorld. http://www.compositesworld.com/news/sgl-group-wins-funds-forthermoplastic-composites-development.

South Carolina Department of Commerce. 2014. "Toray Selects Spartanburg County for its Business Expansion in the U.S." http://sccommerce.com/news/press-releases/toray-selects-spartanburgcounty-its-business-expansion-us.

South Korea Ministry of Environment. n.d. Air Quality Standards and Air Pollution Level. http://eng.me.go.kr/eng/web/index.do?menuld=253.

Stephenson, Scott. 2012. "What is Carbon Fiber's Place in Wind Energy Systems?"

CompositesWorld. http://www.compositesworld.com/columns/what-is-carbon-fibers-place-inwind-energy-systems.

Taiwan Bureau of Foreign Trade. 2012. Regulations Governing Export and Import of Strategic Hightech

Commodities. http://www.trade.gov.tw/english/Pages/Detail.aspx?nodelD=298\&pid=417204\&d I DateRange=all\&txt SD=\&txt ED=\&txt Keyword=\&Pageid=0

The Conference Board. 2016a. International Comparisons of Hourly Compensation Costs in Manufacturing, 2015: Summary Tables. https://www.conferenceboard.org/ilcprogram/index.cfm?id=38269\#Table3.

-- - 2016b. International Comparisons of Hourly Compensation Costs in Manufacturing, 2015: China and India. https://www.conference-board.org/ilcprogram/index.cfm?id=38269\#Table4.

The Odessa Record. 2011. "Carbon Fiber plant opens in Moses Lake." The Odessa Record. http://www.odessarecord.com/story/2011/09/08/news/carbon-fiber-plant-opens-inmoses-lake/090820111850816721021.html.

The Roane Alliance. 2007. Toho Tenax America, Inc. Announces \$23 Million Investment in Rockwood Plant. http://www.roanealliance.org/Articles/toho tenax america inc announces 23 million investment in rockwood plant.aspx. 
Toray (Toray Industries Inc.). 2012. "Toray to Enhance Global Carbon Fiber Production Capacity 6,000 Tons Increase Annually at 4 Production Bases Around the World to Start Operations in 20142015." Press release. http://www.toray.com/news/crb/nr120309.html.

-- - 2014. Toray Completes Purchase of Zoltek

Shares. http://www.toray.com/news/manage/nr140303.html.

Tsai, Carlos. 2010. 2010 Carbon Fiber Valley in Taiwan: Global Financial Tsunami has Lead [sic] Taiwan's CFRP Industry

Upward. http://www.sports.org.tw/e/report/2010yearbook subject/01carbon.html.

Twomey, Brian. 2009. Understanding Japanese

Keiretsu. http://www.investopedia.com/articles/economics/09/japanese-

keiretsu.asp\#axzz1YrHbjsQP.

UNEP (United Nations Environmental Programme). 2015. The Chinese Automotive Fuel Economy Policy. http://www.unep.org/transport/gfei/autotool/case studies/apacific/china/ CHINA\%20CASE\%20STUDY.pdf.

U.S. Chamber of Commerce. 2016. The U.S. Chamber International IP Index "Infinite Possibilities." $4^{\text {th }}$ ed. http://www.theglobalipcenter.com/wp-content/themes/gipc/mapindex/assets/pdf/2016/GIPC IP Index 4th Edition.pdf.

U.S. Department of Commerce. 2015. U.S. Strategic Materials Assessment Carbon Fiber Composites. https://www.bis.doc.gov/index.php/forms-documents/doc download/1380carbon-fiber-composites.

U.S. Department of Justice. 2012. "Taiwanese National Pleads Guilty to Attempting to Illegally Export Aerospace-grade Carbon Fiber: Defendant Sought Thousands of Pounds of High-Tech Material." Press release. https://www.bis.doc.gov/index.php/component/content/article/98about-bis/newsroom/press-releases/press-releases-2012/478-taiwanese-national-pleadsguilty-to-attempting-to-illegally-export-aerospace-grade-carbon-fiber.

- - . 2016. "Chinese National Arrested for Illegally Attempting to Export High-Grade Carbon Fiber to China." https://www.justice.gov/opa/pr/chinese-national-arrested-illegally-attemptingexport-high-grade-carbon-fiber-china.

U.S. Department of State. 2015. About Export Control Reform (ECR). http://2016.export.gov/ecr/. U.S. Immigration and Customs Enforcement. 2013. Cyber-Sting Nets Chinese National in Attempt to Export Sensitive Technology. Press

release. http://www.ice.gov/news/releases/1305/130530brooklyn.htm

U.S. International Trade Commission. 2010. Small and Medium-Sized Enterprises: US and EU Export Activities, and Barriers and Opportunities Experienced by US Firms. Washington D.C:

U.S. International Trade Commission. https://www.usitc.gov/publications/332/pub4169.pdf. 
---. 2013. Renewable Energy and Related Services: Recent Developments. Washington D.C: U.S. International Trade Commission. https://www.usitc.gov/publications/332/pub4421.pdf.

Vanderbilt (Vanderbilt School of Engineering). 2015. "Simulating Success in Aerospace Manufacturing." March 31, 2015. http://engineering.vanderbilt.edu/news/2015/simulatingsuccess-in-aerospace-and-automotive-manufacturing/.

Warren C. David. 2011. Low Cost Carbon Fiber

Overview. http://energy.gov/sites/prod/files/2014/03/f11/Im002_warren_2011_o.pdf.

West Virginia Department of Commerce. n.d. Energy

Summits. http://www.wvcommerce.org/energy/summits/default.aspx.

Witten, Elmar, Thomas Kraus, and Michael Kühnel. 2015. Composites Market Report 2015 Market Developments, Trends, Outlook and

Challenges. http://www.eucia.eu/userfiles/files/Composites Market\%20Report 2015.pdf.

Witting, Peter. 2015. Global Expansion in Carbon Fiber Manufacturing: Strategic Considerations for Energy Utilization. Harper International. http://www.harperintl.com/resources/presentationsarchive-form/.

World Bank. 2016. Global Economic Monitor

(GEM). http://databank.worldbank.org/data/reports.aspx?source=global-economic-monitor(gem)\#.

Workforce Training \& Education Coordinating Board. 2016. Job Skills

Program. http://www.wtb.wa.gov/JobSkills.asp.

WTO (World Trade Organization). 2014a. "Organic Chemicals." Select

Tariffs. http://tariffdata.wto.org/ReportersAndProducts.aspx.

- - . 2014b. "Articles of Stone, Plaster, Cement, Asbestos, MICA or Similar Materials." Select

Tariffs. http://tariffdata.wto.org/ReportersAndProducts.aspx.

Xie, Bo, and Patrick Ma. 2011. "China: Transit and Shipment of Dual-use Items." White \& Case LLP. http://www.worldecr.com/wp-content/uploads/2012/07/China.pdf

Yang, Kap Seung. 2013. "Carbon in Korea." Carbon

60:568. http://www.sciencedirect.com/science/article/pii/S0008622313004065.

Yang, Jianxiang. 2015. "China Confirms Cut to Onshore Tariff." WindPower

Monthly. http://www.windpowermonthly.com/article/1328437/china-confirms-cut-onshoretariff.

Yin, Clifton. 2012. "Carbon Fiber: A Government Clean Tech Innovation Success Story." The Energy Collective. http://theenergycollective.com/cliftonyin/98391/carbon-fiber-government-cleantech-innovation-success-story 
Zhang, Bo, and Cong Cao. 2015. "Policy: Four Gaps in China's New Environmental Law." Nature. http://www.nature.com/news/policy-four-gaps-in-china-s-new-environmental-law1.16736.

Zhao, Bingtao, Yaxin Su, Shushen He, Mei Zhong, and Guomin Cui. 2016. "Evolution and comparative assessment of ambient air quality standards in China." Journal of Integrative Environmental Sciences. 13(2-4):85-

102. http://www.tandfonline.com/doi/full/10.1080/1943815X.2016.1150301.

Zoltek Corporation. n. d. What is Carbon Fiber? http://zoltek.com/carbonfiber/.

---. 2015. Zoltek de Mexico to Expand. http://zoltek.com/zoltek-de-mexico-to-expand/. 